\title{
Proposal of new genera and species of the subfamily Diosaccinae (Copepoda: Harpacticoida: Miraciidae)
}

\author{
Samuel GÓMEZ ${ }^{{ }_{1},{ }^{*}}$, Paulo Henrique Costa CORGOSINHO ${ }^{\oplus_{2}}$ \\ \& Karen I. RIVERA-SÁNCHEZ ${ }^{3}$ \\ ${ }^{1}$ Universidad Nacional Autónoma de México, Instituto de Ciencias del Mar y Limnología, \\ Unidad Académica Mazatlán, Mazatlán, Sinaloa, México. \\ ${ }^{2}$ Dep. Biologia Geral. Universidade Estadual de Montes Claros (UNIMONTES), \\ Montes Claros, MG, Brazil. \\ ${ }^{3}$ Posgrado en Ciencias del Mar y Limnología, Unidad Académica Mazatlán, \\ Mazatlán, Sinaloa, México. \\ *Corresponding author: samuelgomez@ola.icmyl.unam.mx \\ 2Email: pcorgo@gmail.com \\ ${ }^{3}$ Email: kitzel.rivera10@gmail.com \\ ${ }^{1}$ urn:lsid:zoobank.org:author:7BBFAB07-962F-4D10-9BE0-87B936993FBD \\ ${ }^{2}$ urn:lsid:zoobank.org:author:2B499408-5C00-4A01-8A8E-18FA969123CF \\ ${ }^{3}$ urn:lsid:zoobank.org:author:AB43CE7F-6C8A-45AF-B2D1-C3BD92644B18
}

\begin{abstract}
Representatives of several genera of the family Miraciidae (Copepoda: Harpacticoida) were found in sediment samples taken in the year 2019 from a coastal system in north-western Mexico. The subfamily Diosaccinae (Miraciidae) was by far the most diverse taxon followed by the subfamily Stenheliinae (Miraciidae). Here we report on a new miraciid species, Typhlamphiascus medici sp. nov., and provide a new amended diagnosis for Typhlamphiascus Lang, 1944 along with a key to its species. Additionally, Typhlamphiascus lamellifer lamellifer (Sars, 1911) and T. l. capensis Kunz, 1975 are considered as distinct species and the latter is given full species rank. Upon preliminary inspection, another diosaccin species was thought to be a derived form of Bulbamphiascus Lang, 1944. This promoted us to perform a more in-depth phylogenetic analysis. Our results showed that the new presumed derived form of Bulbamphiascus represents a new genus, Spinodiosaccus gen. nov. and that the genus Bulbamphiascus, which we propose a new amended diagnosis for, could be split into different genera. Also, the possible relationships amongst the different diosaccin clades found during our analyses are commented. Three new genera are proposed: Spinopedia gen. nov., Pallarica gen. nov. and Dinetia gen nov. We give a brief ecological analysis on the distribution of $T$. medici sp. nov. and S. primus gen. et sp. nov. in the Urías system.
\end{abstract}

Keywords. Taxonomy, meiofauna, key to species.

Gómez S., Corsosinho P.H.C. \& Rivera-Sánchez K.I. 2021. Proposal of new genera and species of the subfamily Diosaccinae (Copepoda: Harpacticoida: Miraciidae). European Journal of Taxonomy 759: 1-62.

https://doi.org/10.5852/ejt.2021.759.1433 


\section{Introduction}

With 53 genera and 479 species (WoRMS Editorial Board 2020), the family Miraciidae Dana, 1846 is one of the most diverse of Harpacticoida. The miraciid subfamilies Diosaccinae Sars, 1906a and Stenheliinae Brady, 1880 are the most species rich in the family. These two subfamilies were the most abundant and diverse harpacticoid taxa collected during a series of meiofauna samplings during the year 2019 along the Urías system, a polluted estuary in north-western Mexico (see also Gómez 2020a). A report of the subfamily Stenheliinae from the Urías system, with a record of Pseudostenhelia wellsi Coull \& Fleeger, 1977, and the description of Lonchoeidestenhelia prote Gómez, 2020 and Willenstenhelia reducta Gómez, 2020, were dealt with in Gómez (2020a). Besides the new taxa presented there, two species of Robertgurneya Apostolov \& Marinov, 1988 ( $R$. rostrata (Gurney, 1927) and $R$. mexicana Gómez, 2020; see Gómez 2020b), two species of Amphiascoides Nicholls, 1941 (A. cf. breviarticulatus Kunz, 1983 and A. atopus Lotufo \& Fleeger, 1995), one species of Sarsamphiascus Huys, 2009 (S. cf. minutus (Claus, 1863)) and one species of Haloschizopera Lang, 1944 (H. cf. ruthorum Por, 1967) (S. Gómez, pers. obs.) have been found in this system. Here we present the full description of a new species of the problematic genus Typhlamphiascus Lang, 1944, Typhlamphiascus medici sp. nov., and a new species of the so far monotypic new genus Spinodiosaccus gen. nov., S. primus gen. et sp. nov., collected during a sampling campaign carried out in January 2019.

The last diagnosis of the genus Typhlamphiascus is that by Lang (1948: 705). Here we propose a new diagnosis for the genus. The taxonomic complexity of Typhlamphiascus resides on the lack of apomorphies to objectively define the genus, but also on the failure to detect (syn)apomorphies for the known species (see Tables 1-2; Discussion section). Some potential (syn)apomorphies were detected and are presented below. The new species proposed herein, Typhlamphiascus medici sp. nov., belongs to Por's group II (Por 1963), and seems to be related to T. pectinifer Lang, 1965 and T. lutincola Soyer, 1963. These three species share the bifurcated distal inner seta of the male P5 exopod, but the Mexican species seems to be more closely related to T. pectinifer from Monterey Bay. Additionally, we propose a key to the species of Typhlamphiascus based on original descriptions and records.

If the loss of armature on the first to fourth swimming legs observed in Spinodiosaccus primus gen. et sp. nov. is considered as a derived trait, the species could be allocated to Bulbamphiascus Lang, 1944 (see Lang 1944; see Lang 1948 for a diagnosis of that genus). However, we opted to split the different lineages within Bulbamphiascus into new genera. So, in addition to the proposal of Spinodiosaccus gen. nov. for S. primus gen. et sp. nov., we propose Dinetia gen. nov., Pallarica gen. nov. and Spinopedia gen. nov. for B. minutus Dinet, 1971, B. cibimae Pallares, 1982 and B. spinulosus Mu \& Gee, 2000, respectively. Also, we offer a phylogenetic analysis based mostly on some character states displayed in the swimming legs revealing a close relationship between Spinodiosaccus gen. nov. and Bulbamphiascus.

Finally, we provide some ecological notes on $T$. medici sp. nov. and S. primus gen. et sp. nov. related to some environmental variables in the Urías system, north-western Mexico.

\section{Material and methods}

\section{Field work}

Sediment samples were taken from a series of sampling stations along the Urías system (a polluted estuary in southern Sinaloa State, north-western Mexico; see also Gómez 2020a: 43, fig. 1) on January 18,2019 , using an Eckman grab of $25 \times 25 \mathrm{~cm}$ (sampling surface $625 \mathrm{~cm}^{2}$ ). Triplicate sediment cores were taken at each station using acrylic corers of $5.6 \mathrm{~cm}$ ID (sampling surface $24.6 \mathrm{~cm}^{2}$ ) and $20 \mathrm{~cm}$ in length, from which the upper $3 \mathrm{~cm}$ layer was retrieved and fixed in pure ethanol. An additional sediment core was taken for the analysis of organic matter content and grain size. Environmental variables (dissolved oxygen ( $\mathrm{mg} \mathrm{l}^{-1}$ ), salinity (ups), and temperature $\left({ }^{\circ} \mathrm{C}\right)$ ) were recorded in situ with a YSI Professional Plus hand-held multiparameter meter. Depth was also recorded at each sampling station. 


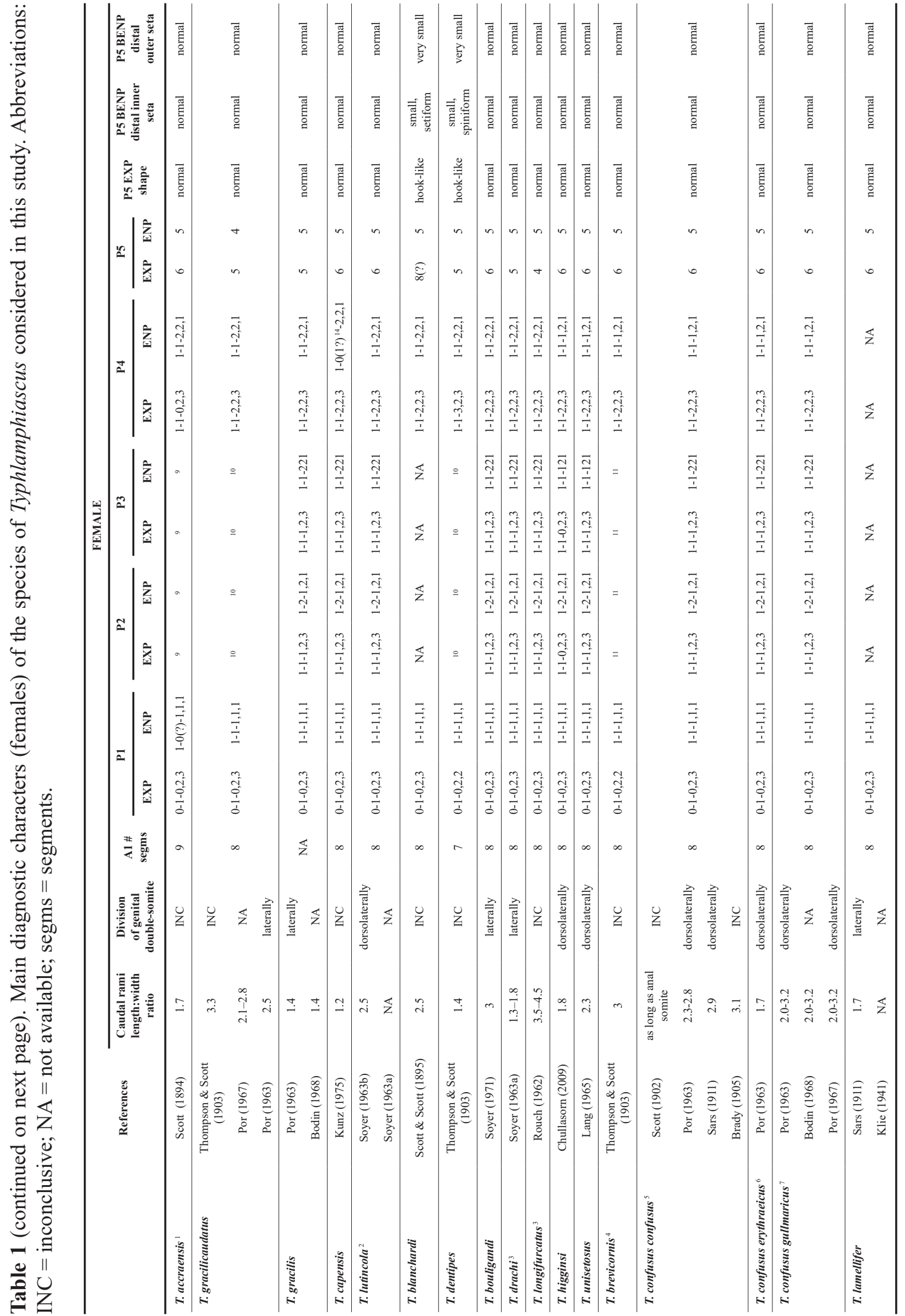


GÓMEZ S. et al., On new genera and species of Harpacticoida

Table 2. Main diagnostic characters (males) of the species of Typhlamphiascus considered in this study. Abbreviations: $\mathrm{INC}=$ inconclusive; $\mathrm{ME}=$ modified, elongate; $\mathrm{MU}=$ male unknown; $\mathrm{NA}=$ not available; $\mathrm{NM}=$ not modified; segms $=$ segments; $\mathrm{WO}=$ without.

\begin{tabular}{|c|c|c|c|c|c|c|c|}
\hline & \multirow[t]{3}{*}{ References } & \multicolumn{6}{|c|}{ MALE } \\
\hline & & \multirow{2}{*}{ A1 \# segms } & \multirow{2}{*}{$\begin{array}{l}\text { P1 basis } \\
\text { inner spine }\end{array}$} & \multirow{2}{*}{$\begin{array}{l}\text { P1 basis inner } \\
\text { accessory spines }\end{array}$} & \multicolumn{2}{|c|}{ P5 } & \multirow{2}{*}{$\begin{array}{l}\text { P5 EXP } \\
\text { inner seta }\end{array}$} \\
\hline & & & & & EXP & ENP & \\
\hline T. accraensis ${ }^{1}$ & Scott (1894) & $\mathrm{MU}$ & $\mathrm{MU}$ & $\mathrm{MU}$ & MU & MU & normal \\
\hline \multirow[t]{3}{*}{ T. gracilicaudatus } & Thompson \& Scott (1903) & & & & & & \\
\hline & Por (1967) & NA & NM & $3-5$ & 4 & 2 & normal \\
\hline & Por (1963) & & & & & & \\
\hline \multirow[t]{2}{*}{ T. gracilis } & Por (1963) & NA & NM & $7-8$ & 5 & 2 & normal \\
\hline & Bodin (1968) & $\mathrm{x}$ & $\mathrm{x}$ & $\mathrm{x}$ & $\mathrm{x}$ & $\mathrm{x}$ & $\mathrm{x}$ \\
\hline T. capensis & Kunz (1975) & MU & MU & MU & $\mathrm{MU}$ & $\mathrm{MU}$ & normal \\
\hline \multirow[t]{2}{*}{ T. lutincola ${ }^{2}$} & Soyer (1963b) & & & & & & \\
\hline & Soyer (1963a) & 9 & NM & 3 & 6 & 2 & bifurcated \\
\hline T. blanchardi & Scott \& Scott (1895) & MU & MU & MU & MU & MU & normal \\
\hline T. dentipes & Thompson \& Scott (1903) & MU & MU & MU & MU & MU & normal \\
\hline T. bouligandi & Soyer (1971) & 9 & ME & Wo & 4 & 2 & normal \\
\hline T. drachi $^{3}$ & Soyer (1963a) & 9 & ME & 3 & 5 & 2 & normal \\
\hline T. longifurcatus ${ }^{3}$ & Rouch (1962) & NA & ME & NA & 4 & 2 & normal \\
\hline T. higginsi & Chullasorn (2009) & 8 & NM & 3 & 6 & 2 & normal \\
\hline T. unisetosus & Lang (1965) & MU & MU & MU & $\mathrm{MU}$ & $\mathrm{MU}$ & normal \\
\hline T. brevicornis ${ }^{4}$ & Thompson \& Scott (1903) & MU & MU & MU & $\mathrm{MU}$ & $\mathrm{MU}$ & normal \\
\hline \multirow[t]{4}{*}{ T. confusus confusus ${ }^{5}$} & Scott (1902) & & & & & & \\
\hline & Por (1963) & NA & NM & $3-5$ & 6 & 2 & normal \\
\hline & Sars (1911) & NA & NIVI & $3=3$ & 0 & 2 & Hontial \\
\hline & Brady (1905) & & & & & & \\
\hline T. confusus erythraeicus ${ }^{6}$ & Por (1963) & NA & NM & 4 & NA & NA & normal \\
\hline \multirow[t]{3}{*}{ T. confusus gullmaricus ${ }^{7}$} & Por (1963) & & & & & & \\
\hline & Bodin (1968) & NA & NM & $5-7$ & NA & NA & normal \\
\hline & Por (1967) & & & & & & \\
\hline \multirow[t]{2}{*}{ T. lamellifer } & Sars (1911) & & & & & & \\
\hline & Klie (1941) & NA & NM & 2 & 6 & 2 & normal \\
\hline T. latifurca & Por (1968) & NA & NM & 3 & 5 & 2 & normal \\
\hline T. ovale & Wells \& Rao (1987) & 9 & NM & 8 & 6 & 2 & normal \\
\hline \multirow[t]{2}{*}{ T. pectinifer } & Lang (1965) & & & & & & \\
\hline & Pallares (1975) & 9 & NM & 3 & 6 & 2 & bifurcated \\
\hline T. tuerkayi & Ma \& Li (2017) & 9 & NM & 8 & 4 & 2 & normal \\
\hline T. typhloides ${ }^{3}$ & Sars (1911) & NA & NA & NA & NA & NA & normal \\
\hline \multirow[t]{4}{*}{ T. typhlops ${ }^{8}$} & Sars $(1906 b)^{11}$ & & & & & & \\
\hline & Klie (1941) & $\mathrm{INC}$ & NM & $4^{9}$ or $7-810$ & 6 & 2 & normal \\
\hline & Chislenko (1967) & & & & & & \\
\hline & Por (1963) & & & & & & \\
\hline T. medici sp. nov. & Present contribution & 10 & NM & 3 & 6 & 2 & normal \\
\hline
\end{tabular}

Incertae sedis in Wells (2007); identical with C. confusus (Por 1963).

2 Bodin (1964) questioned the necessity of creating T. lutincola. Incertae sedis in Wells (2007).

Incertae sedis in Wells (2007)

${ }^{4}$ The only difference between T. brevicornis and T. confusus are the bifid inner setae on the female P5 BENP in T. confusus, normal in T. brevicornis; the latter species might not be valid (Por 1963). Other differences between T. brevicornis and T. confusus are probably due to erroneous interpretations (Lang 1948).

5 Highly variable. Described in Brady (1905) as Stenhelia meeki. Por (1967) was reluctant to split T. confusus into several subspecies. See also Lang (1965).

${ }^{6}$ Por (1963) gave differences between T. c. confusus, T. c. erythraeicus and T. c. gullmaricus. Por (1967) was reluctant to split T. confusus into several subspecies.

${ }^{7}$ Por (1967) was reluctant to split T. confusus into several subspecies.

${ }^{8}$ Specimens in the Sars collection at the Zoological Museum in Oslo are actually T. confusus (Por 1963). Also, Sars' description of the male of T. typhlops (see Sars 1906b) is actually the male of T. confusus (Por 1963).Two samples of T. typhlops in Lang's collection at the Museum of Natural History in Stockholm possess an inner seta on P4ENP2 and were considered as representatives of that species by Por (1963).

After Sars (1906b).

${ }^{10}$ After Por (1963) and Chislenko (1967)

"The male of T. typhlops of Sars (1906b) is the male of T. confusus (Por 1963). 


\section{Laboratory analyses}

\section{Sample processing and taxonomy}

Each sample was sieved through 500 and $38 \mu \mathrm{m}$ sieves to separate macro- and meiofauna. Meiofauna was extracted through centrifugation with Ludox ${ }^{\circledR}$ HS-40 following Burgess (2001) and Rohal et al. (2016) and preserved in pure ethanol. Meiofauna was sorted at a magnification of $40 \times$ using an Olympus SZX12 stereo microscope equipped with a DF PLAPO $1 \times$ objective and WHS10 $\times$ eyepieces, and harpacticoid copepods were stored separately in $1 \mathrm{ml}$ vials with pure ethanol. Illustrations and figures were made from whole individuals and its dissected parts using a Leica DMLB microscope equipped with L PLAN $10 \times$ eyepieces, an N PLAN $100 \times$ oil immersion objective, and a drawing tube. The dissected parts were mounted on separate slides using lactophenol as mounting medium.

Huys \& Boxshall (1991) was followed for general terminology.

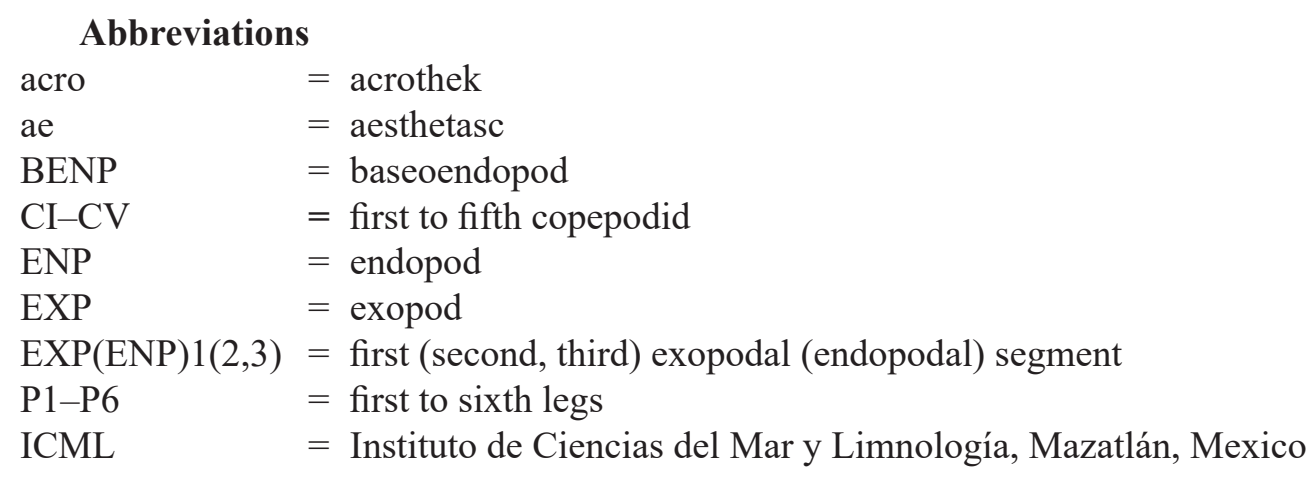

\section{Organic matter and grain size}

Organic matter and organic carbon content were determined through the Walkley-Black titration and colorimetric method, and the grain size was assessed with a Malvern Mastersizer Hydro 2000MU laser diffraction particle size analyser.

\section{Statistical analyses}

Spearman's correlation coefficient was calculated between the density of each species and the environmental variables using Minitab $^{\circledR}$ Statistical Software ver. 19.2020.1 (www.minitab.com). Differences in density of T. medici sp. nov. and S. primus gen. et sp. nov. between sampling stations were assessed through a non-parametric one-way analysis of variance. Principal coordinates analysis (PCoA) between the Euclidean distance dissimilarity matrix for the environmental variables and the Bray-Curtis similarity matrix combined with a CLUSTER analysis for biological samples was used to assess the effects of the environmental variables that had major effects on the distribution of T. medici sp. nov. and S. primus gen. et sp. nov. Non-parametric one-way analysis of variance and PCoA were performed using PRIMER ver. 7 and PERMANOVA+ (Clarke \& Gorley 2015).

\section{Phylogenetic analyses}

The position of the new genus within the Diosaccinae was assessed following Hennig (1966). The corresponding cladogram was generated using the program NONA (Goloboff 1999) for cladistic parsimony in interface with WINCLADA (Nixon 2002). This program uses a heuristic algorithm with unconstrained search and multiple TBR + TBR (searches for trees using the tree bisection-reconnection method of branch-swapping, then repeats this process the number of times as indicated in the number of replications box) as search strategy for the best topology, and a Fitch algorithm that supports character reversal (allows $0 \rightarrow \mathrm{n}$ and $\mathrm{n} \rightarrow 0$ character changes) as a 'similarity' algorithm, but characters are nonadditive; hence $0 \leftrightarrow 1 \leftrightarrow 2=2$ steps; $0 \leftrightarrow 2=1$ step. Character states are coded as binary $(0-1)$ 
GÓMEZ S. et al., On new genera and species of Harpacticoida

Table 3 (continued on next page). List of characters used for the phylogenetic analysis.

\begin{tabular}{|c|c|}
\hline Character & Description \\
\hline 1 & $\begin{array}{l}\text { Mxp: miraciid type, prehensile, but not heavily transformed into a grasping limb (0); transformed into a } \\
\text { grasping limb (1) }\end{array}$ \\
\hline 2 & $\begin{array}{l}\text { Male A1: haplocer, 11-segmented (0); haplocer, 10-segmented (1); haplocer, nine-segmented (2); haplocer, } \\
\text { eight-segmented ( } 3 \text { ) }\end{array}$ \\
\hline 3 & A2 EXP3, number of setae: 3 distal setae (0); one distal seta, one spine and a longer spiniform seta (1) \\
\hline 4 & $\begin{array}{l}\text { Male P1, dimorphic ornamentation of basis: without dimorphic ornamentation }(0) \text {; with chitinous } \\
\text { ornamentation proximal to inner spine (1) }\end{array}$ \\
\hline 5 & $\begin{array}{l}\text { P1 ENP: issuing from an attenuated roundish process of basis }(0) \text {; issuing from a long inner process, } \\
\text { reaching middle of EXP1 and from which issues the ENP (1) }\end{array}$ \\
\hline 6 & P1 EXP2, inner seta: present (0); absent (1) \\
\hline 7 & $\begin{array}{l}\text { P1 exopodal segments, relative length: subequal (0); P1 EXP2 longer than remaining exopodal segments } \\
\text { or as long as EXP1 and EXP3 combined (1); P1 EXP2 much longer than EXP1 and EXP3 combined (2) }\end{array}$ \\
\hline 8 & $\begin{array}{l}\text { P1 EXP3, outer armature: with three outer spines and two distal setae, distal outer element may be } \\
\text { transformed into a spiniform seta (0); with two outer spines and two distal setae (1); with two outer spines, } \\
\text { one distal spiniform seta, and one inner thin seta (2); only with distal elements (3) }\end{array}$ \\
\hline 9 & P1 EXP3, shape of proximal element: spiniform (0); transformed into a small seta (1) \\
\hline 10 & $\begin{array}{l}\text { P1 ENP, number of segments: three-segmented (0); two-segmented, with proximal seta of ENP2 indicating } \\
\text { place of original division between second and third original segments (1); two segmented without proximal } \\
\text { seta (2) }\end{array}$ \\
\hline 11 & $\begin{array}{l}\text { P1 ENP3, relative length: as long as ENP2 or ENP2 absent (0); elongate, at least } 1.5 \text { times as long as } \\
\text { ENP2 (1) }\end{array}$ \\
\hline 12 & P1 ENP1, relative length: shorter or slightly longer than EXP (0); ENP1 reaching far beyond EXP3 (1) \\
\hline 13 & $\begin{array}{l}\text { P1 distal endopodal segment, setae: with inner seta, distal (geniculate) seta and outer spiniform seta (0); } \\
\text { with inner seta (maybe lost or not illustrated in some descriptions), distal long spine and distal shorter } \\
\text { outer spine (1) }\end{array}$ \\
\hline 14 & P2 EXP1, inner seta: present (0); absent (1) \\
\hline 15 & P3 EXP1, inner seta: present (0); absent (1) \\
\hline 16 & P4 EXP1, inner seta: present (0); absent (1) \\
\hline 17 & P2 EXP2, inner seta: present (0); absent (1) \\
\hline 18 & P3 EXP2, inner seta: present (0); absent (1) \\
\hline 19 & P4 EXP2, inner seta: present (0); absent (1) \\
\hline 20 & P2 ENP1, inner seta: present (0); absent (1) \\
\hline 21 & P2 ENP2, number of inner setae: two (0); one (1) \\
\hline 22 & P3 ENP2, number of inner setae: two (0); one (1) \\
\hline 23 & P2 EXP3, inner seta(e): present (0); absent (1) \\
\hline 24 & P2 EXP3, short distal seta inserted on inner margin: absent (0); present (1) \\
\hline 25 & P3 EXP3, inner seta(e): present (0); absent (1) \\
\hline 26 & P3 EXP3, short distal seta inserted on inner margin: absent (0); present (1) \\
\hline 27 & P4 EXP3, inner seta(e): present (0); absent (1) \\
\hline 28 & P4 EXP3, short distal seta inserted on inner margin: absent (0); present (1) \\
\hline 29 & $\begin{array}{l}\text { Male P2 ENP1, spinular ornamentation: bare or weakly spinulose }(0) \text {; with a patch of spinules on the distal } \\
\text { outer margin (1) }\end{array}$ \\
\hline 30 & Male P2 ENP2, spinular ornamentation: bare or weakly spinulose (0); heavily spinulose (1) \\
\hline 31 & Male P3 EXP3, anterior dimorphic tube pore: absent (0); present (1) \\
\hline
\end{tabular}


Table 3 (continued). List of characters used for the phylogenetic analysis.

\begin{tabular}{cl}
\hline Character & \multicolumn{1}{c}{ Description } \\
\hline 32 & Female P5 BENP, number of setae: six (0); five (1); four (2); three (3) \\
33 & Female P5 EXP, number of setae: six (0); five (1) \\
34 & Male P5 EXP, number of setae/spines: six or seven (0); five (1); four (2); three (3) \\
35 & Male P5 EXP, number of setae/spines: seven (0); up to six (1) \\
36 & Male P5 EXP, medial and distal outer spines, relative length: about as long as proximal outer seta (0); \\
& shorter than proximal outer seta (1) \\
37 & Male P5 EXP, shape of outer distal element: seta or pinnate spine (0); bare spine (1) \\
39 & Male P5 EXP, medial outer spine: not transformed (0); transformed into short spine (1) \\
40 & Male P5 EXP, distal outer spine: not transformed (0); transformed into short spine (1) \\
41 & Female P5 EXP, distal outer spine: not transformed (0); transformed into short spine (1) \\
& Female P5 EXP, middle distal seta or third or fourth seta from outer to inner margin: not issuing from a \\
42 & setophore (0); issuing from a setophore (1) \\
& Female P5 EXP, middle inner seta or second from inner to outer margin: not issuing from a setophore, \\
43 & long, thin and smooth (0); issuing from a setophore (1) \\
& Male P5 EXP, middle distal seta or third (fourth in P. cibimae) from inner to outer margin: not issuing from \\
44 & a setophore, spine or thick seta (0); issuing from a setophore (1) \\
& Male P5 EXP, distal outer pedunculated pore: absent (0); present (1)
\end{tabular}

or multistate $(0-n)$. The state for each character can be seen in the character list (Table 3 , see the Discussion section). Also, the data matrix is given (Table 4, see the Discussion section). The characters are not differently weighted. The polarisation of characters was done a priori (zero $(0)$ represents the plesiomorphic condition, one (1) the apomorphic condition, and one (1) is plesiomorphic in comparison with two (2)) as in the ground pattern characters for Diosaccinae (Willen 2000). Additional decisions on character polarity were obtained by comparing the Diosaccinae ground pattern with the state of character present in the other Miraciidae and other Thalestridimorpha. The resulting cladogram is rooted. The term 'ground pattern' is used here in the sense of 'Grundmuster' (Ax 1984: 156) and refers to all plesiomorphies and autapomorphies present in each taxon ('Stammart' sensu Ax 1984). Unsupported nodes in the tree are hard collapsed. Characters are ACCTRAN (fast) optimized. We have obtained more than one (12) most parsimonious phylogenetic topology; hence, here we have applied strict consensus for the figure that we include within the body of the text. All possible phylogenetic trees are provided in Supplementary file 1 .

\section{Results}

\section{Taxonomy}

Type species

Subclass Copepoda Milne Edwards, 1840

Order Harpacticoida Sars, 1903

Family Miraciidae Dana, 1846

Subfamily Diosaccinae Sars, 1906

Typhlamphiascus Lang, 1944

Amphiascus typhlops Sars, 1906, by original designation. 
GÓMEZ S. et al., On new genera and species of Harpacticoida

\section{Other species and subspecies}

T. blanchardi (T. Scott \& A. Scott, 1895) (originally described in Stenhelia)

T. bouligandi Soyer, 1971

T. brevicornis (I.C. Thompson \& A. Scott, 1903) (originally described in Stenhelia)

T. capensis Kunz, 1975 comb. nov.

T. confusus (T. Scott, 1902) (originally described in Stenhelia)

T. confusus erythraeicus Por, 1963

T. confusus gullmaricus Por, 1963

T. dentipes (I.C. Thompson \& A. Scott, 1903) (originally described in Stenhelia)

T. gracilicaudatus (I.C. Thompson \& A. Scott, 1903) (originally described in Stenhelia)

T. gracilis Por, 1963

T. higginsi Chullasorn, 2009

T. lamellifer (Sars, 1911) (originally described in Amphiascus)

T. latifurca Por, 1968

T. medici sp. nov.

T. ovale Wells \& Rao, 1987

T. pectinifer Lang, 1965

T. tuerkayi Ma \& Li, 2017

T. unisetosus Lang, 1965

\section{Species incertae sedis}

Stenhelia hirsuta Thompson, 1893

T. accraensis (T. Scott, 1894) (described in Stenhelia)

T. drachi Soyer, 1963

T. longifurcatus Rouch, 1962

T. lutincola Soyer, 1963

T. typhloides (Sars, 1911) (described in Amphiascus)

\section{Species inquirendae}

T. typhlops (Sars, 1906) sensu Por (1963)

T. aff. confusus confusus (T. Scott, 1902) sensu Moore (1976)

T. confusus confusus (T. Scott, 1902) sensu Marinov \& Apostolov (1985)

Typhlamphiascus sp. in Vilela 1965

Typhlamphiascus sp.? in Bodin 1964

Typhlamphiascus sp.? in Bodin 1964

Typhlamphiascus sp. I (?confusus) in Marinov 1977

Typhlamphiascus sp. II in Marinov 1977

\section{Emended diagnosis}

Miraciidae: Diosaccinae. Body fusiform; length: width ratio of caudal rami from about 1.0 to about 3.0. Rostrum not fused to cephalothorax, triangular, elongate, as long as first and second antennulary segments combined, with pointed tip, with one subdistal sensilla on each side. Female genital and third urosomites distinct dorsally and/or laterally, completely fused ventrally forming genital double-somite; genital and third urosomites separated in males. Length: width ratio of caudal rami variable, from $1: 1$ to $3: 1$. Female antennule seven- to nine-segmented, with aesthetasc and seta fused basally on fourth segment, and with apical acrothek on last segment. Male antennule haplocer, eight-ten-segmented, with aesthetasc and seta fused basally on fifth segment, and with apical acrothek on last segment. Antennulary setae typically smooth, except for few slightly setulose setae on penultimate and last articles in females and males. Antenna with allobasis; exopod three-segmented, armature formula 1-0-1,3,0. Mandibular palp 


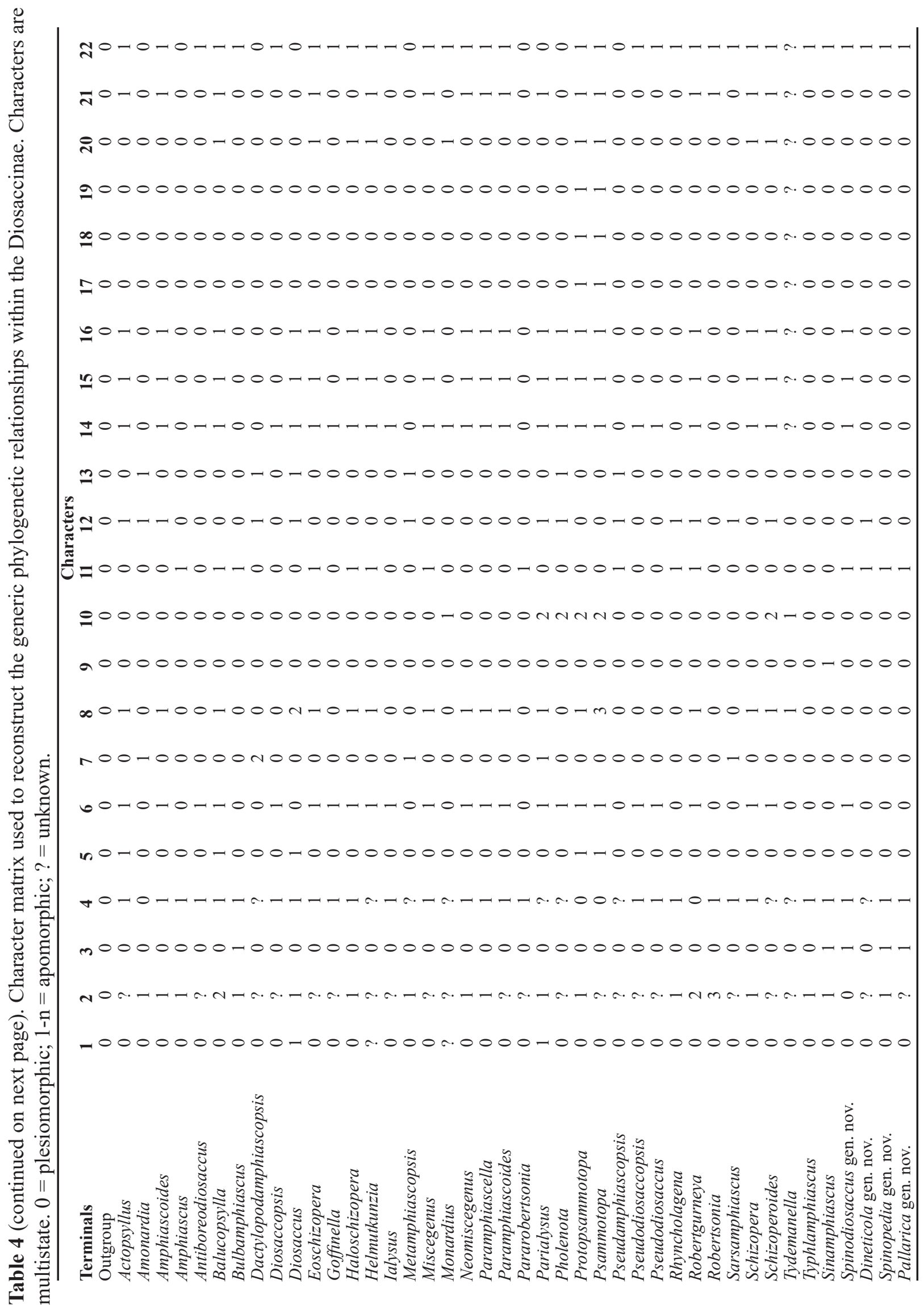


$\$ 00000000000000000000000000000000000000-10000$

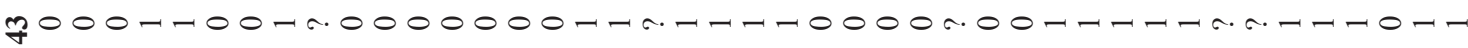
Y0000-00-0000000000-0-0-0000-00-1-100-1-1-100F000-100-10000000๙-1-1-10000-00 $80000000-0000000000000000000000000000000-0-0$ ले0000000-0000000000000000000000000000000-1000 m0000000-0000000000000000000000000000000-000 $n 0000000-0000000000000000000000000000000-n-1.0$ 10000000-0000000000000000000000000000000-0-1 ผ 党

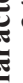
mo-0-00-000000-100-1-1-10000-100000000-10000000 लै m000-100-00000-000000-000000000-100000-100-n $100000000000000000000000000000000000000000-0$ $200000000000000000000000000000000000000000-0$ in $0000-00-00000000000000-000000000-1000.0-10-1$ స0000000000000000000000000-10000000-1-1.000000 त. $0000-00-0000000000-000-000000000-0000.0-10-1$ M0-0000-0000-00-0000000000-10000000-1-1.000000 I. N0-0-00-0000-0-100-0-1-1000-10000000-1-1.000000

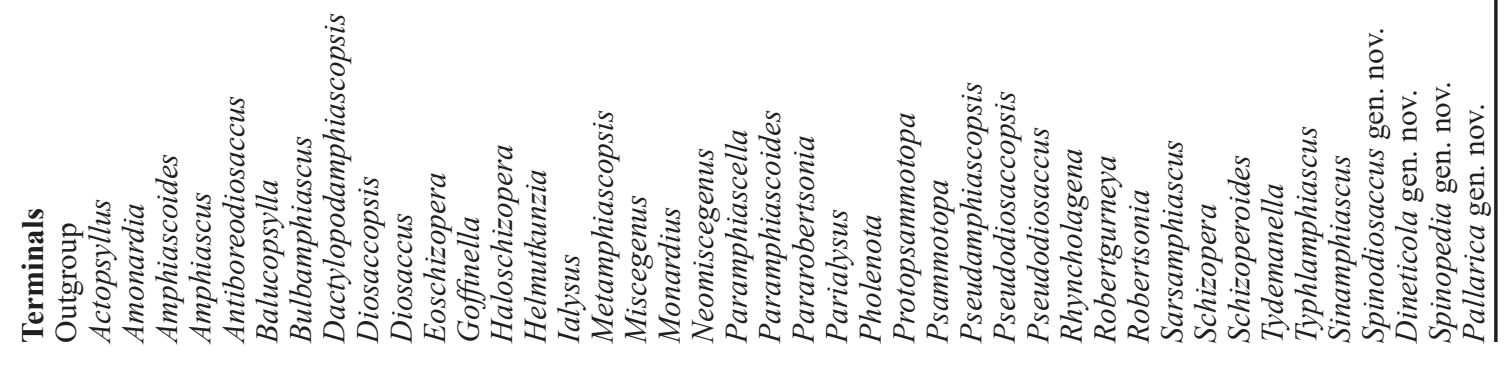


biramous; endopod one-segmented, larger than exopod; exopod two-segmented. Maxillule biramous; rami one-segmented. Maxilla with three endites; endopod two-segmented. Maxilliped subchelate; (syn)coxa with two to four, basis with two setae; endopod one-segmented, with claw and variable number of accompanying setae. P1-P4 with three-segmented rami. Male P1 basis sexually dimorphic, with normal or modified (elongate, blunt) inner spine, without or with variable number of inner accessory spines (two-eight). Male P2 sexually dimorphic, two-segmented; first segment with one inner seta, second segment with two inner setae, two subdistal elements (one of which thick and blunt) and two elements (one medial, one apical) issuing from elongate cylindrical extension fused to segment basally. P5 EXP typically longer than wide, with four to six setae in the female and male; P5 endopodal lobe with four to five setae in the female, with two setae in the male; two innermost elements of the female P5 endopodal lobe and armature of the male P5 endopodal lobe bifurcate distally.

Armature formula of P1-P5 as follows:

\begin{tabular}{|c|c|c|}
\hline & EXP & ENP/ENP lobe \\
\hline $\mathrm{P} 1$ & $0-1-0,2,3$ & $1-1-1,1,1$ \\
\hline $\mathrm{P} 2$ & $1-1-1(0), 2,3$ & ㅇ $1-2-1,2,1 /$ ठ dimorphic \\
\hline P3 & $1-1-1(0), 2,3$ & $1-1-2(1), 2,1$ \\
\hline P4 & $1-1-2(0,3), 2,3$ & $1-1(0)^{2}-2(1), 2,1$ \\
\hline $\mathrm{P} 5$ q / & q 4-6 $6^{1} /$ ô 4-6 & 우 4-5/ぷ 2 \\
\hline
\end{tabular}

${ }^{1}$ The report of eight setae on the female P5 EXP of T. blanchardi is most probably erroneous.

${ }^{2}$ Typhlamphiascus typhlops is known to lack inner armature on the P4 ENP2. The inner seta of P4 ENP2 of T. capensis comb. nov. might have become detached from the supporting segment as indicated by the interrupted cuticle (Kunz 1975).

Sexual dimorphism expressed in the male antennule (see above), P1 basis, P2 ENP (see above), P5 (see above), structure of P6, and in the separated genital and third urosomites.

Typhlamphiascus medici sp. nov.

urn:1sid:zoobank.org:act:67A13A9C-4D1E-4F86-82F2-CEE5407BCD26

Figs $1-10$

\section{Etymology}

The specific epithet from the Latin 'medicì', 'doctor', 'physician', is dedicated in honour and to the memory of all physicians and health personnel for their self-sacrifice during the fight against the COVID-19 pandemic. It is in the genitive singular, gender masculine.

\section{Material examined}

Holotype

MEXICO • $q$ (preserved in alcohol); Sinaloa State, Mazatlán, Urías coastal system, stn 2 (see also Gómez 2020a: 43, fig. 1); $23.1587^{\circ} \mathrm{N}, 106.3326^{\circ} \mathrm{W} ; 1.8 \mathrm{~m}$ depth; 18 Jan. 2019; S. Gómez leg.; organic carbon content $3.99 \%$, organic matter content $6.86 \%$, sand $80.42 \%$, clay $8.29 \%$, silt $11.28 \%$; ICMLEMUCOP-180119-40.

Allotype

MEXICO • ${ }^{\Uparrow}$ (preserved in alcohol); same collection data as for holotype; ICML-EMUCOP-180119-43. 


\section{Other paratypes}

MEXICO 3 ? $q$ (preserved in alcohol); same collection data as for holotype; ICML-EMUCOP-180119$103 \cdot 2$ 우, 2 ô $\widehat{o}$ (preserved in alcohol); same collection data as for holotype; ICML-EMUCOP-180119$46 \bullet 1$ \& (dissected); same collection data as for holotype; ICML-EMUCOP-180119-41 1 \& (dissected); same collection data as for holotype; ICML-EMUCOP-180119-42 • $1 \hat{\jmath}$ (dissected); same collection data as for holotype; ICML-EMUCOP-180119-44 1 $1 \widehat{\partial}$ (P1 and P2 dissected, rest intact and preserved in alcohol); same collection data as for holotype; ICML-EMUCOP-180119-45.

\section{Other material}

MEXICO • 8 CV, 4 CIV, 1 CII (preserved in alcohol); same collection data as for holotype; ICML-

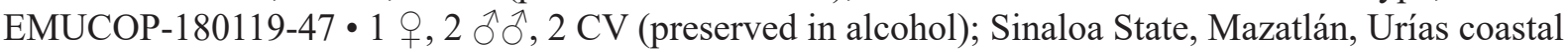
system, stn 4 (see also Gómez 2020a: 43, fig. 1); $23.1840^{\circ} \mathrm{N}, 106.3579^{\circ} \mathrm{W} ; 0.7 \mathrm{~m}$ depth; 18 Jan. 2019; S. Gómez leg.; organic carbon content $1.13 \%$, organic matter content $1.94 \%$, sand $82.44 \%$, clay $8.27 \%$, silt 9.29\%; ICML-EMUCOP-180119-48 - 1 CV, 1 CIV, 1 CI (preserved in alcohol); Sinaloa State, Mazatlán, Urías coastal system, stn 5 (see also Gómez 2020a: 43, fig. 1); $23.2056^{\circ} \mathrm{N}, 106.3715^{\circ} \mathrm{W}$; 0.6 m depth; 18 Jan. 2019; S. Gómez leg.; organic carbon content $0.99 \%$, organic matter content $1.71 \%$, sand $78.61 \%$, clay $6.72 \%$, silt $14.67 \%$; ICML-EMUCOP-180119-49 $11 \hat{\mathrm{O}}, 1 \mathrm{CIII}$ (preserved in alcohol); same collection data as for preceding; ICML-EMUCOP-180119-50 - 1 q, 2 CIV, 1 CII (preserved in alcohol); same collection data as for preceding; ICML-EMUCOP-180119-51 - $1 \mathrm{CV}$, 1 CIII, 2 CII (preserved in alcohol); Sinaloa State, Mazatlán, Urías coastal system, stn 6 (see also Gómez 2020a: 43, fig. 1); $23.2123^{\circ} \mathrm{N}, 106.3780^{\circ} \mathrm{W} ; 1.4$ m depth; 18 Jan. 2019; S. Gómez leg.; organic carbon content $1.65 \%$, organic matter content $2.84 \%$, sand $61.44 \%$, clay $14.57 \%$, silt $23.99 \%$; ICMLEMUCOP-180119-52 1 ô, $1 \mathrm{CV}, 1 \mathrm{CIV}$ (preserved in alcohol); same collection data as for preceding; ICML-EMUCOP-180119-53 • $1 \widehat{\jmath}$ (preserved in alcohol); same collection data as for preceding; ICMLEMUCOP-180119-54) • 1 q, 1 CIV (preserved in alcohol); Sinaloa State, Mazatlán, Urías coastal system, stn 10 (see also Gómez 2020a: 43, fig. 1); $23.1815^{\circ} \mathrm{N}, 106.4214^{\circ} \mathrm{W} ; 6.0 \mathrm{~m}$ depth; 18 Jan. 2019; S. Gómez leg.; organic carbon content $1.2 \%$, organic matter content $2.07 \%$, sand $69.12 \%$, clay $7.91 \%$, silt 22.97\%; ICML-EMUCOP-180119-55 - 3 CIV (preserved in alcohol); same collection data as for preceding; ICML-EMUCOP-180119-56.

\section{Description}

\section{Female}

GENERAL. Total body length measured from tip of rostrum to posterior margin of caudal rami ranging from 705 to $850 \mu \mathrm{m}$ (mean $762 \mu \mathrm{m} ; \mathrm{n}=5$; total body length of holotype $850 \mu \mathrm{m}$ ); habitus fusiform, widest at posterior end of cephalothorax in dorsal view, tapering posteriad (Fig. 1A).

Prosome (Figs 1A-B, 2A). Consisting of cephalothorax with fused first pedigerous somite and second to fourth free pedigerous somites; prosomites without expansions nor spinular ornamentation; posterior hyaline frill of cephalothorax, second and third pedigerous somites broad, with posterior margins finely serrated, striated, of fourth pedigerous somite visibly narrower, finely serrated, without striations.

Urosome (Figs 1A-D, 2A). Consisting of fifth pedigerous somite (first urosomite), genital doublesomite (genital - second urosomite - and third urosomites fused), two free urosomites, anal somite and caudal rami; urosomites without expansions. First urosomite narrower than preceding somites in dorsal view (Fig. 1A), without spinular ornamentation, with posterior sensilla as depicted, with one lateral pore on each side (Fig. 1C), posterior frill as in preceding somite dorsally and laterally (Fig. 1A, C). Genital double-somite (Figs 1A, C, 2A) rectangular, slightly longer than wide, with sensilla and minute surface spinules dorsolaterally as shown; anterior and posterior halves (second - genital - urosomite and third urosomite, respectively) distinct dorsally and laterally (Fig. 1A, C), completely fused ventrally (Fig. 2A); dorsolateral posterior margin of anterior half serrated and with two large spinules on each side 
(Fig. 1A, C); posterior half of genital double-somite with dorsal (Fig. 1A) and lateral (Figs 1C, 2A) large posterior spinules, posterior hyaline frill deeply incised and striated, the latter continuous dorsolaterally (Fig. 1A, C) and interrupted ventrally (Fig. 2A); P6 at anterior third of genital somite (anterior half of genital double-somite) and with genital field as shown (Fig. 2A). Fourth urosomite largely as in posterior half of genital double-somite, but with additional paired lateroventral pores and posterior medial transverse spinular row (Figs 1A, C, 2A). Fifth urosomite without sensilla, with one lateral row of small spinules (Fig. 1C) and with paired lateroventral pores (Figs 1C, 2A), with short medial row of large spinules ventrally (Fig. 2A), with continuous deeply incised posterior hyaline frill, the latter with medial part slightly crescentic dorsally (Fig. 1A). Anal somite slightly wider than long in dorsal view (Fig. 1A-B), without anal operculum, cleft medially dorsally (Fig. 1A-B) and ventrally (Fig. 2A), with two posterior sensilla dorsally (Fig. 1A-D), with lateral and ventral pores as shown (Figs 1C-D, 2A),
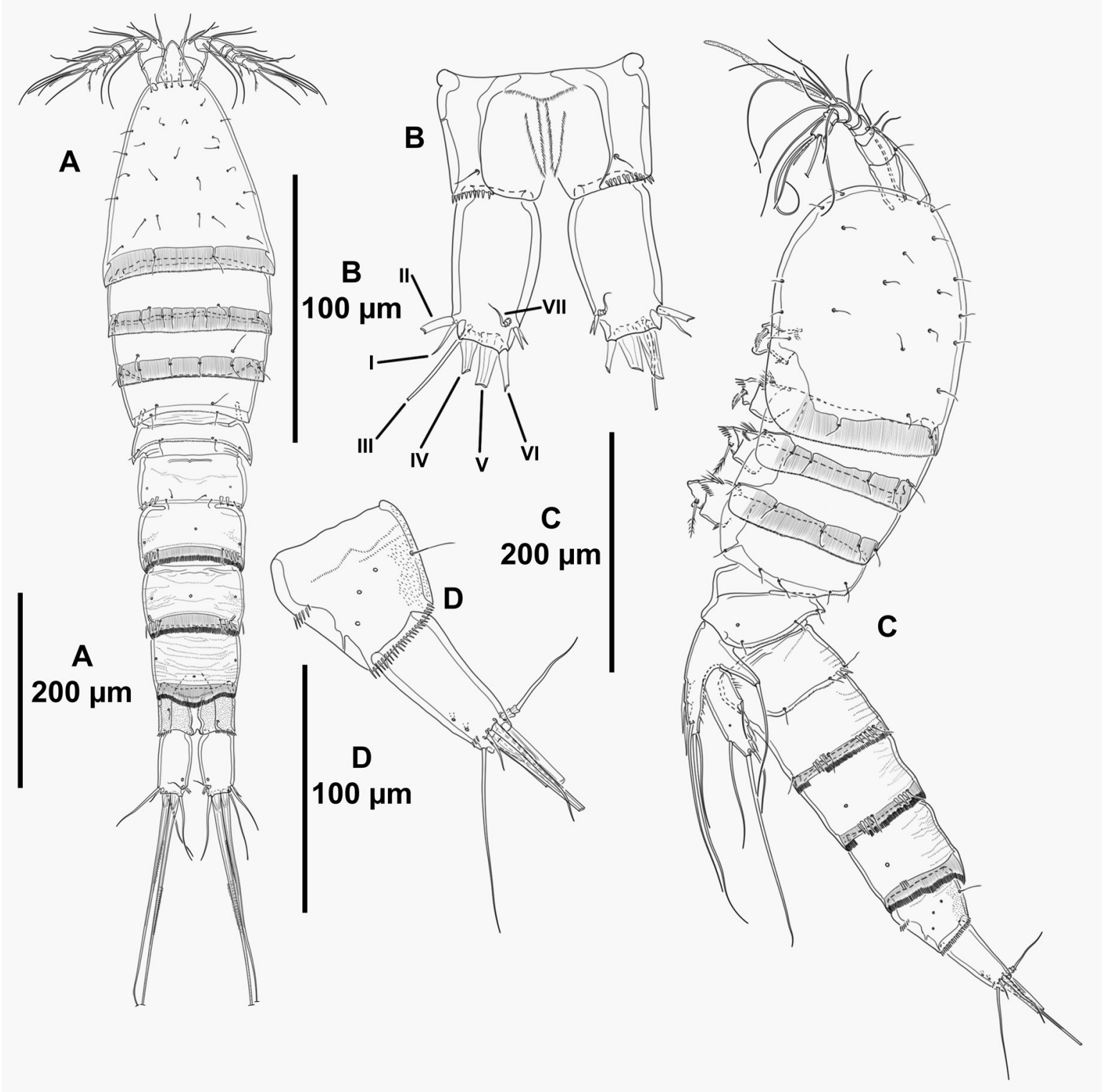

Fig. 1. Typhlamphiascus medici sp. nov., holotype, $q$ (ICML-EMUCOP-180119-40). A. Habitus, dorsal view. B. Anal somite and caudal rami, dorsal view. C. Habitus, lateral view. D. Anal somite and left caudal ramus, lateral view. 
and with small spinules close to joint with caudal rami. Caudal rami well-developed (Figs 1A-D, 2A), about 1.7 times as long as wide and with straight outer and slightly convex inner margin (Fig. 1A-B), with pores as shown; with seven setae (Fig. 1B) as follows: setae I and II situated subdistally on outer margin, the former very small and ventral to the latter; seta III displaced ventrally close to outer margin; setae IV and V normal, with fracture plane, the former shorter; seta VI arising at inner distal corner; dorsal seta VII issuing subdistally, close to inner margin, triarticulated.

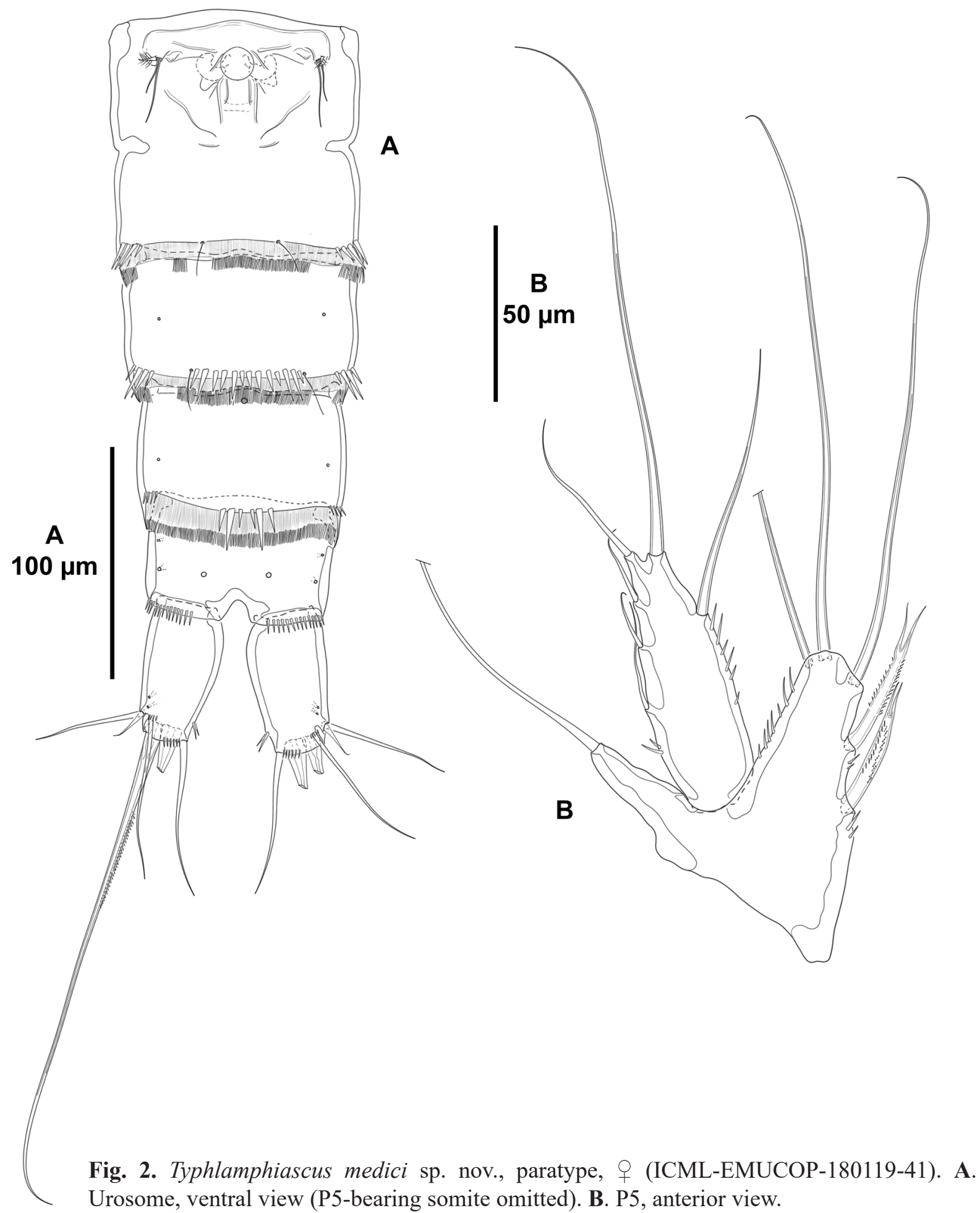




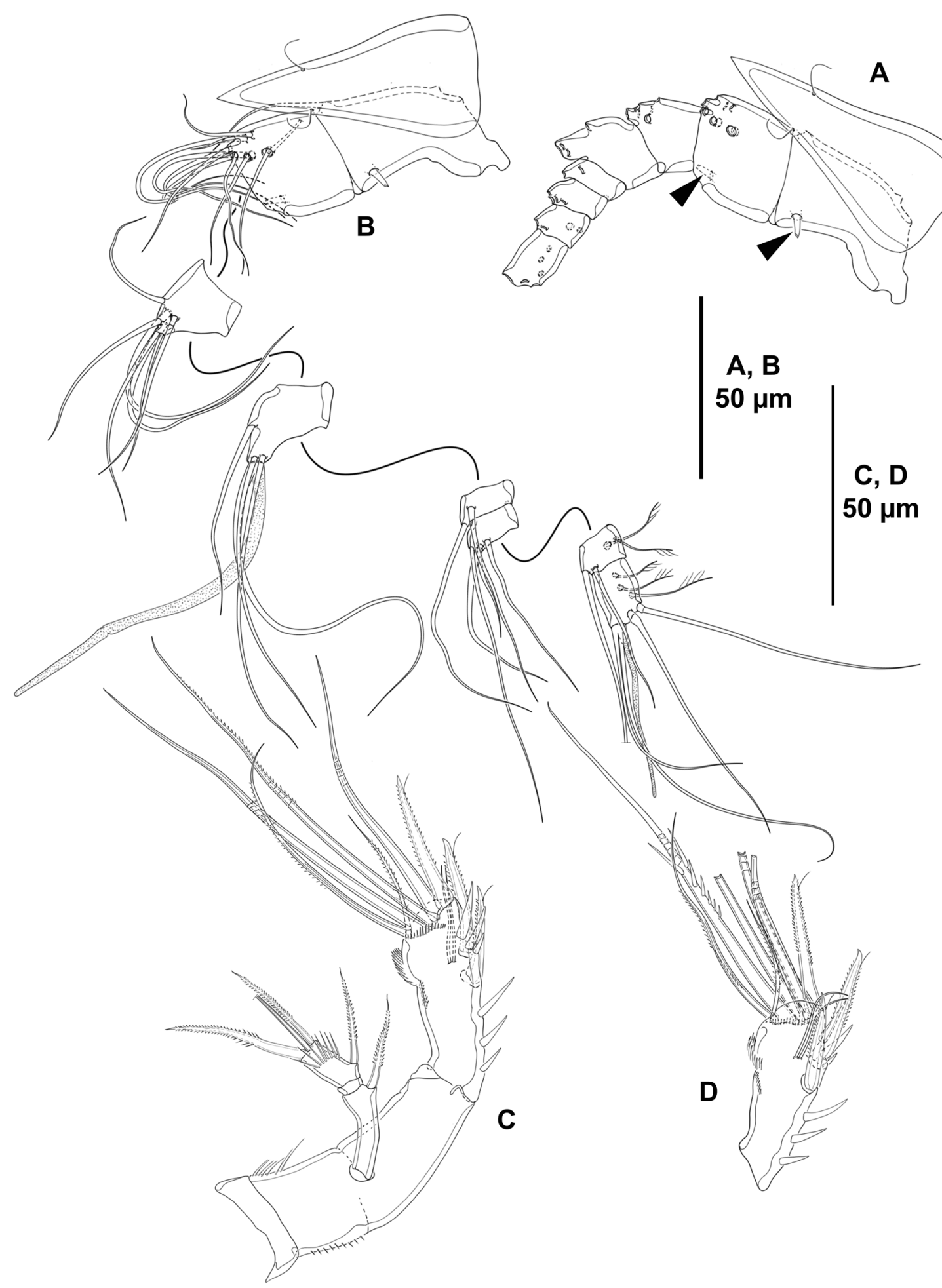

Fig. 3. Typhlamphiascus medici sp. nov., paratype, $q$ (ICML-EMUCOP-180119-41). A. Rostrum and antennule (armature omitted for simplicity; arrows indicate tube pores on first and second segments). B. Rostrum and antennule showing armature. C. Antenna with aberrant outermost geniculate seta (without spinular ornamentation), and with only two free geniculate setae. D. Free endopodal segment of another antenna. 
Rostrum (Figs 1A, C, 3A-B). Not fused to cephalothorax, triangular, pointed, with one sensilla arising at distal third on each side, reaching distal margin of second antennulary segment.

AnTENNUle (Fig. 3A-B). Eight-segmented; all segments smooth; first and second segments with tube pore (arrowed in Fig. 3A); all setae smooth except for two and three biarticulated setulose setae on seventh and eight segments, respectively; outer subdistal seta of eighth segment biarticulated basally, neighbouring seta swollen basally. Armature formula: 1(1); 2(11); 3(7); 4(3+(1+ae)), 5(2); 6(4); 7(4); $8(5+$ acro $)$. Acrothek consisting of two setae and one aesthetasc fused basally.

ANTENNA (Fig. 3C-D). With small unornamented coxa. Allobasis with remains of former division between basis and first endopodal segment, slightly longer than free endopodal segment, with outer slender spinules proximally, without abexopodal seta. Exopod three-segmented; first segment longer than second and third segments combined, second segment smallest; first and second segments unornamented, the former with one, the latter without seta; third segment with subapical row of spinules, armed with three setae, of which one bare, the other two bipinnate. Free endopodal segment with proximal and subdistal inner strong spinules as shown, and with two outer frills; armed with two lateral inner flagellate spines and two slender setae (the latter set close to each other), one inner apical flagellate spine, three single geniculate setae, one slender bipinnate short seta and one strongly spinulose geniculate outer seta fused basally to slender pinnate element.

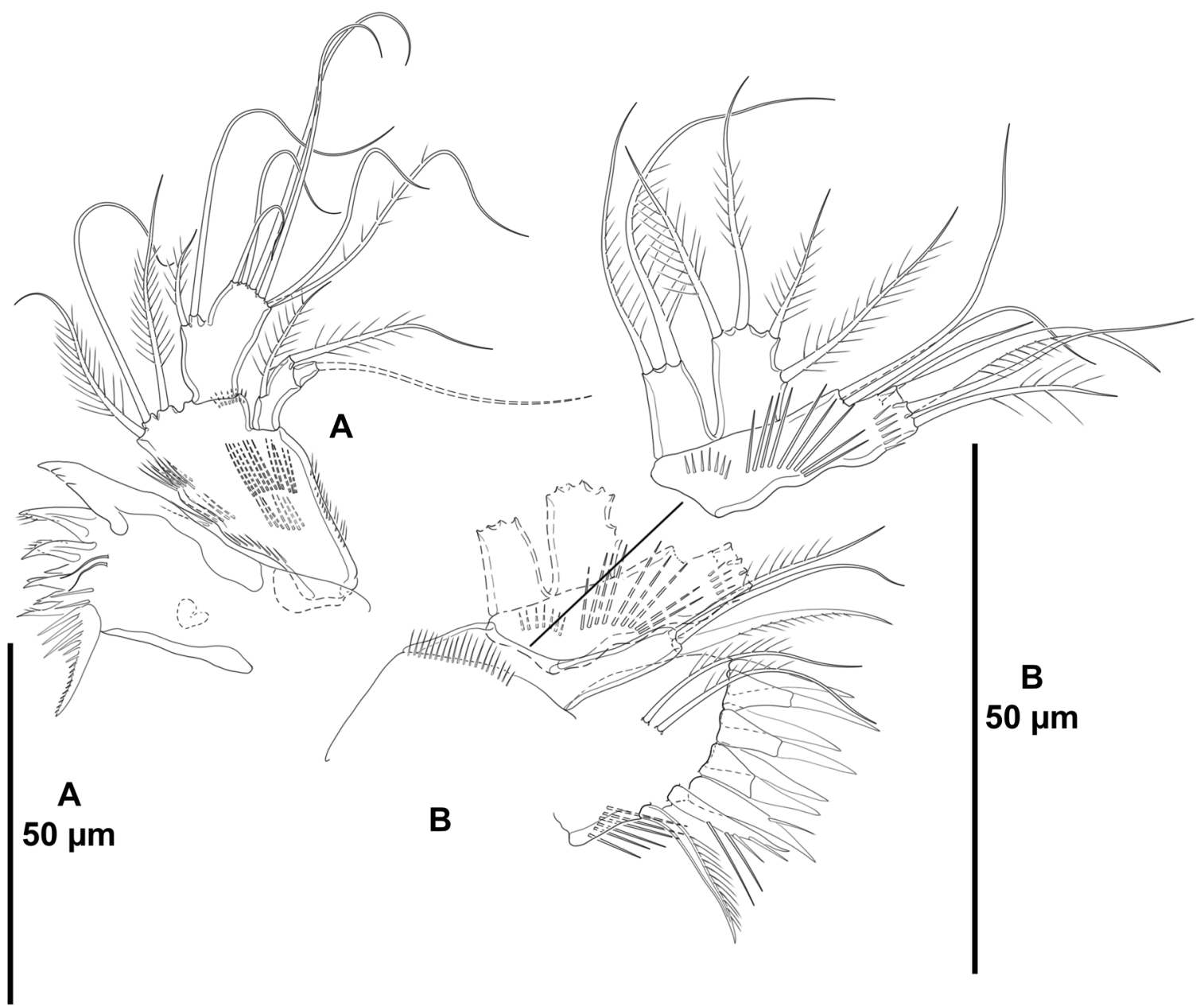

Fig. 4. Typhlamphiascus medici sp. nov., paratype, + (ICML-EMUCOP-180119-41). A. Mandible. B. Maxillule. 
MANDIBLE (Fig. 4A). With well-developed gnathobasis bearing strong multi- and bicuspidate teeth as shown, subdistally with two small slender setae and two spinules medially, and with one strongly spinulose element. Basis massive, with spinules as depicted, with three inner setae. Exopod twosegmented; first segment longer than second, the former with one lateral and one distal seta, the latter with one apical element. Endopod one-segmented, visibly larger that exopod; with two lateral and six distal setae.

MAXILlule (Fig. 4B). With arthrite ornamented with some slender spinules and armed with two surface setae, seven distal spines as shown, one spinulose element and one recurved stiff pinnate seta. Coxal endite with three setae. Basis with spinular row as depicted and armed with two lateral, one subdistal and three distal elements, one of which visibly stronger. Rami one-segmented, exopod with two, endopod with four elements - two distal, one inner subdistal and one inner medial seta.

Maxilla (Fig. 5A). With large syncoxa ornamented with small outer spinules; with three endites; proximal endite smallest, with three setae; middle and distal endites nearly subequal in length, the former with two, the latter with three setae. Basis drawn out into strong claw with minute pinnae, additionally

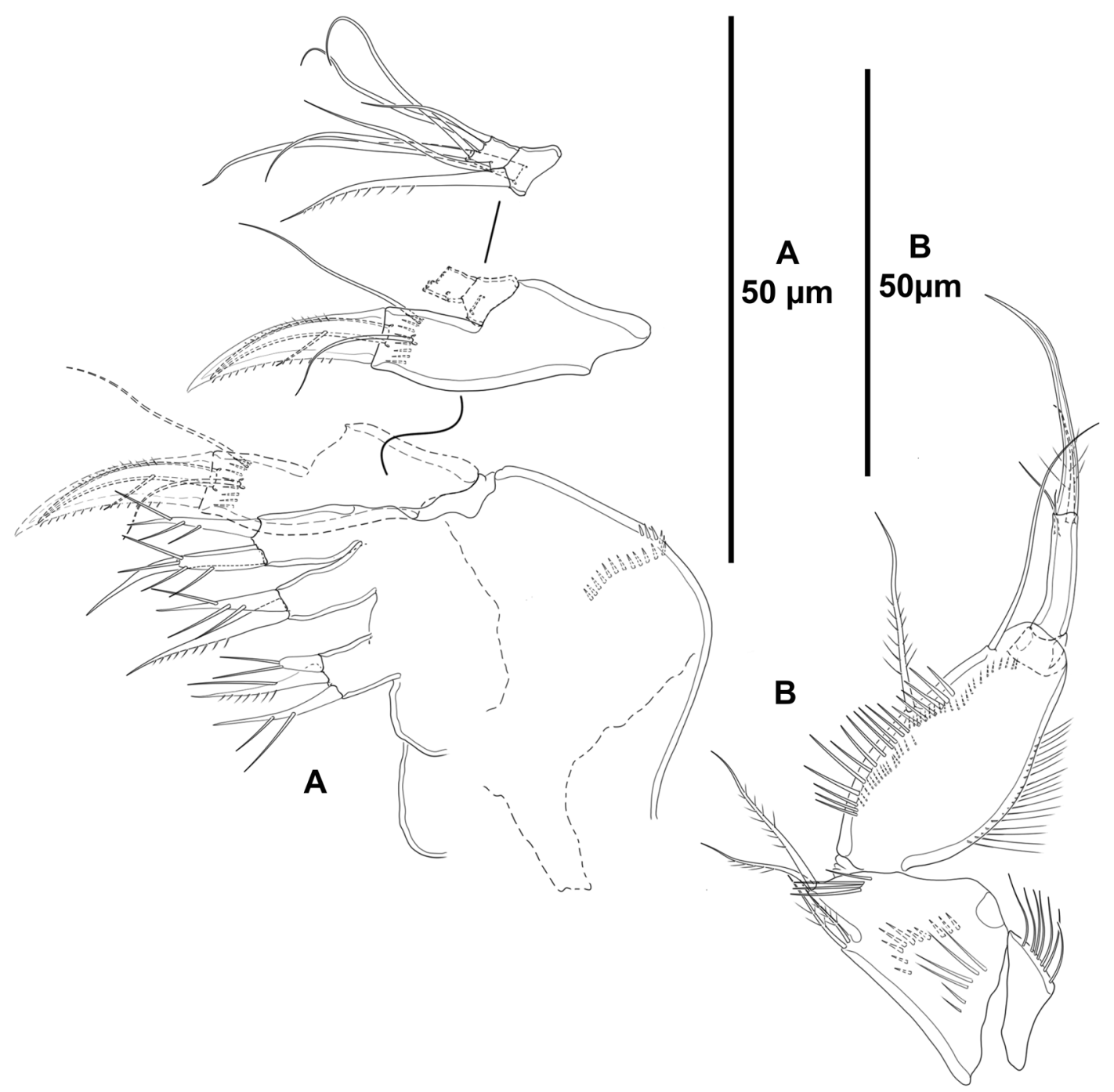

Fig. 5. Typhlamphiascus medici sp. nov., paratype, + (ICML-EMUCOP-180119-41). A. Maxilla. B. Maxilliped. 


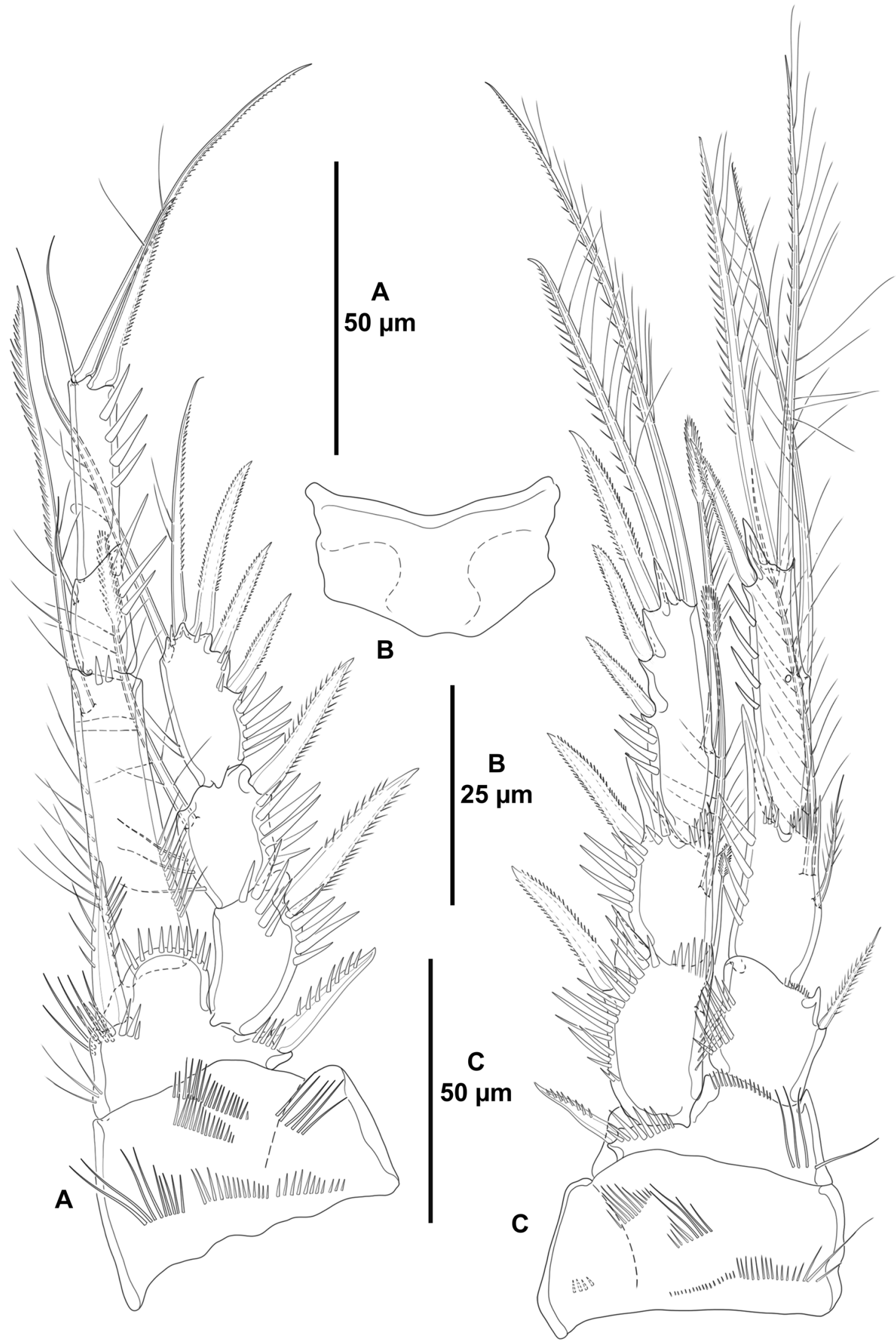

Fig. 6. Typhlamphiascus medici sp. nov., paratype, $q$ (ICML-EMUCOP-180119-41). A. P1, anterior view. B. Intercoxal sclerite of P1, anterior view. C. P2, anterior view. 
with strong spine bearing one long spinule and two slender setae - one anterior, one posterior. Endopod two-segmented; first segment with two, second segment with one lateral and four distal setae.

MAXILLIPED (Fig. 5B). Subchelate. Praecoxa small, trapezoidal, ornamented with slender outer spinules. Coxa trapezoidal, with proximal, medial and subdistal spinules as shown; with two inner small setae

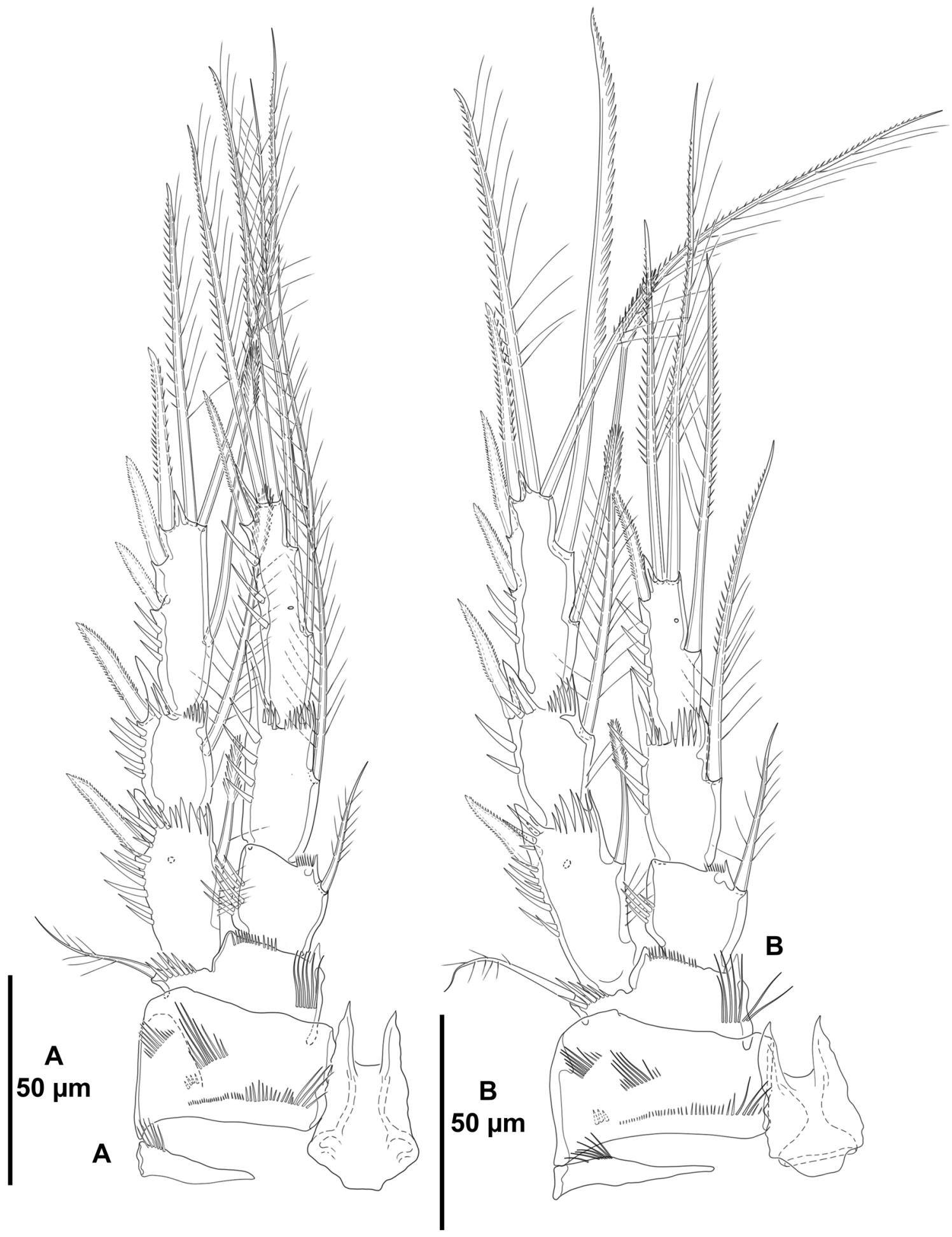

Fig. 7. Typhlamphiascus medici sp. nov., paratype, $q$ (ICML-EMUCOP-180119-41). A. P3, anterior view. B. P4, anterior view. 
issuing at distal fourth and two long apical setae. Basis longer than coxa, oval, with outer slender longitudinal spinules, and one posterior and one anterior row of spinules as depicted, with one medial inner and one subdistal inner seta. Endopod one-segmented, elongate, with three setae - one lateral, one subdistal and one small distal - and apical claw.

P1 (Fig. 6A-B). With broad unornamented intercoxal sclerite (Fig. 6B). Coxa massive, with several spinular rows as shown. Basis with inner and outer spinulose spines; with slender long inner spinules proximally and close to insertion of inner spine, and with shorter but stronger spinules at base of inner and outer seta, and distally on medial distal rounded protrusion. Exopod three-segmented, arising at a lower level than that of the endopod and reaching slightly beyond ENP1; ENP:EXP length ratio 1.5; exopodal segments subequal in length, with strong outer spinules as shown; first segment without, second segment with one inner seta with comb tip; third segment with five elements. Endopod three-segmented, arising from pedestal; ENP1 about four times as long as wide, as long as second and third segments combined, with outer and inner longitudinal rows of slender spinules, with one inner stiff, long, strongly pectinate seta; second and third segments ornamented with strong outer spinules as shown, the former shorter, nearly as long as wide and half as long as the latter, with one inner, slender, short seta; third segment elongate with one inner distal slender seta, one apical long element and one outer distal spine.

P2 (Fig. 6B). Narrow intercoxal sclerite (not shown) with acute distal projection on each side, largely as in P3. Praecoxa (not shown) as in P3. Coxa with three anterior rows of spinules - one proximal and two medial transverse - and with posterior small spinules close to proximal outer margin. Basis with long slender spinules proximally close to inner margin, with small spinules between rami, and with comparatively larger spinules at base of exopod and at base of outer pinnate spine. Rami threesegmented, endopod and exopod subequal in absolute length. Exopod three-segmented, arising at a lower level than that of the endopod, not reaching tip of ENP; exopodal segments with strong outer spinules as shown; EXP1 and EXP2 with outer distal acute projection, on EXP1 shorter, both segments with coarse inner distal hyaline frill and inner seta with comb tip, on EXP1 visibly shorter; EXP3 with six elements - three outer spines, two apical elements and one inner seta with comb tip. Endopod three-segmented, arising from pedestal; endopodal segments with strong outer spinules as shown; ENP1 shortest, as long as wide, with small distal spinules close to small inner projection, without outer distal projection nor inner hyaline frill, with one short inner seta; ENP2 elongate, 1.7 times as long as wide and 0.6 times as long as ENP3, with strong outer spinules and with small spinules at base of outer distal acute projection, with coarse inner distal frill, with two inner setae of which proximal one short; ENP3 longest, elongate, 4.8 times as long as wide, with medial outer pore, with four elements (one inner and two apical setae, and one outer spine), with acute projection between outer spine and inner apical seta.

P3 (Fig. 7A). Narrow intercoxal sclerite with acute distal projection on each side. Praecoxa small, with transverse distal row of slender spinules close to outer margin. Coxa and basis as in P2 except for outer setiform element of basis on P3. Rami three-segmented, endopod and exopod subequal in absolute length. Exopod largely as in P2 except for additional posterior pore on P3 EXP1. Endopod largely as in P2 except for one inner seta only on P3 ENP2 and two inner setae on P3 ENP3.

P4 (Fig. 7B). With intercoxal sclerite, praecoxa, coxa and basis as in P3. Exopod longer than endopod; EXP:ENP length ratio 1.3; largely as in P3 except for two inner setae on P4 EXP3 of which distalmost one visibly thicker and strongly pectinate. Endopod reaching slightly beyond middle of EXP3; largely as in P3 except for stiffer inner seta on P4 ENP2, and one inner seta only on P4 ENP3. 
Armature formula of P1-P4 as follows:

\begin{tabular}{lcc} 
& EXP & ENP \\
\cline { 2 - 3 } P1 & $0-1-0,2,3$ & $1-1-1,1,1$ \\
P2 & $1-1-1,2,3$ & $1-2-1,2,1$ \\
P3 & $1-1-1,2,3$ & $1-1-2,2,1$ \\
P4 & $1-1-2,2,3$ & $1-1-1,2,1$ \\
\hline
\end{tabular}

P5 (Fig. 2B). With outer seta of BENP arising from long setophore. Endopodal lobe triangular, reaching middle of exopod; with small spinules along outer margin and at base of inner setae; with five elements - one outer subdistal, one apical and one inner subdistal normal seta, and two inner bifurcate elements. Exopod elongate, 2.8 times as long as wide; with spinules along inner margin and with few proximal outer spinules; with six elements - three outer slender, short setae, two apical elements, of which outermost one shorter, and one inner seta.

P6 (Fig. 2A). With three setae - one short bipinnate element, and one medial and one inner bare seta of which medial one shorter.

\section{Male}

GENERAL. Total body length measured from tip of rostrum to posterior margin of caudal rami ranging from 675 to $900 \mu \mathrm{m}$ (mean $731 \mu \mathrm{m} ; \mathrm{n}=5$; total body length of allotype $680 \mu \mathrm{m}$ ).

Prosome (Fig. 8A). As in female.

Urosome (Fig. 8A-B). As in female except for second - P6-bearing somite - and third urosomites separated, and for continuous spinular rows and hyaline frill of third and fourth urosomites ventrally.

SEXUAL DIMORPHISM. Expressed in the ventral somatic ornamentation, antennule, basis of P1, P2 ENP, P5 and P6.

Antennule (Fig. 9A-B). Ten-segmented, haplocer. All segments smooth; first and second segments with tube pore. All setae smooth except for two and three biarticulated setulose setae on ninth and tenth segments, respectively; outer subdistal seta of tenth segment biarticulated basally, neighbouring seta swollen basally. Armature formula: $1(1) ; 2(11) ; 3(5) ; 4(3) ; 5(7+(1+\mathrm{ae})) ; 6(1) ; 7(1+2$ spines $) ; 8(1+2$ spines); 9(4); 10(5+acro). Acrothek consisting of two setae and one aesthetasc fused basally.

ANTenNa, MANDible, MAXiLlule, MAXilla AND MAXILliped (not shown). As in female.

P1. As in female except for basis without slender inner, long spinules, and with three inner accessory spines and a proximal inner, nose-like outgrowth in the male (Fig. 9C).

P2 EXP (not shown). As in female. Endopod (Fig. 10A) sexually dimorphic, two-segmented; ENP1 0.7 times length of ENP2, with sinuous inner margin, with proximal and medial outer slender spinules, with one short inner seta; ENP2 oval, with longitudinal row of outer slender, long spinules, with two short inner setae arising from pedestal, subdistally with one posterior strong, blunt element, and with one anterior stiff, bare seta with subapical rounded expansion and pointed tip, with one lateral and one apical seta arising from elongate cylindrical extension fused to segment basally.

P3 AND P4 (not shown). As in female. 
P5 (Fig. 10B). With outer seta of baseoendopod arising from long setophore. Endopodal lobe reaching middle of exopod, with inner and outer spinules as shown, with two distal bifurcate setae of which outermost one slightly shorter. Exopod rectangular, 2.5 times as long as wide, with longitudinal row of inner spinules and medial pore, with few proximal outer spinules, with six setae - three outer elements

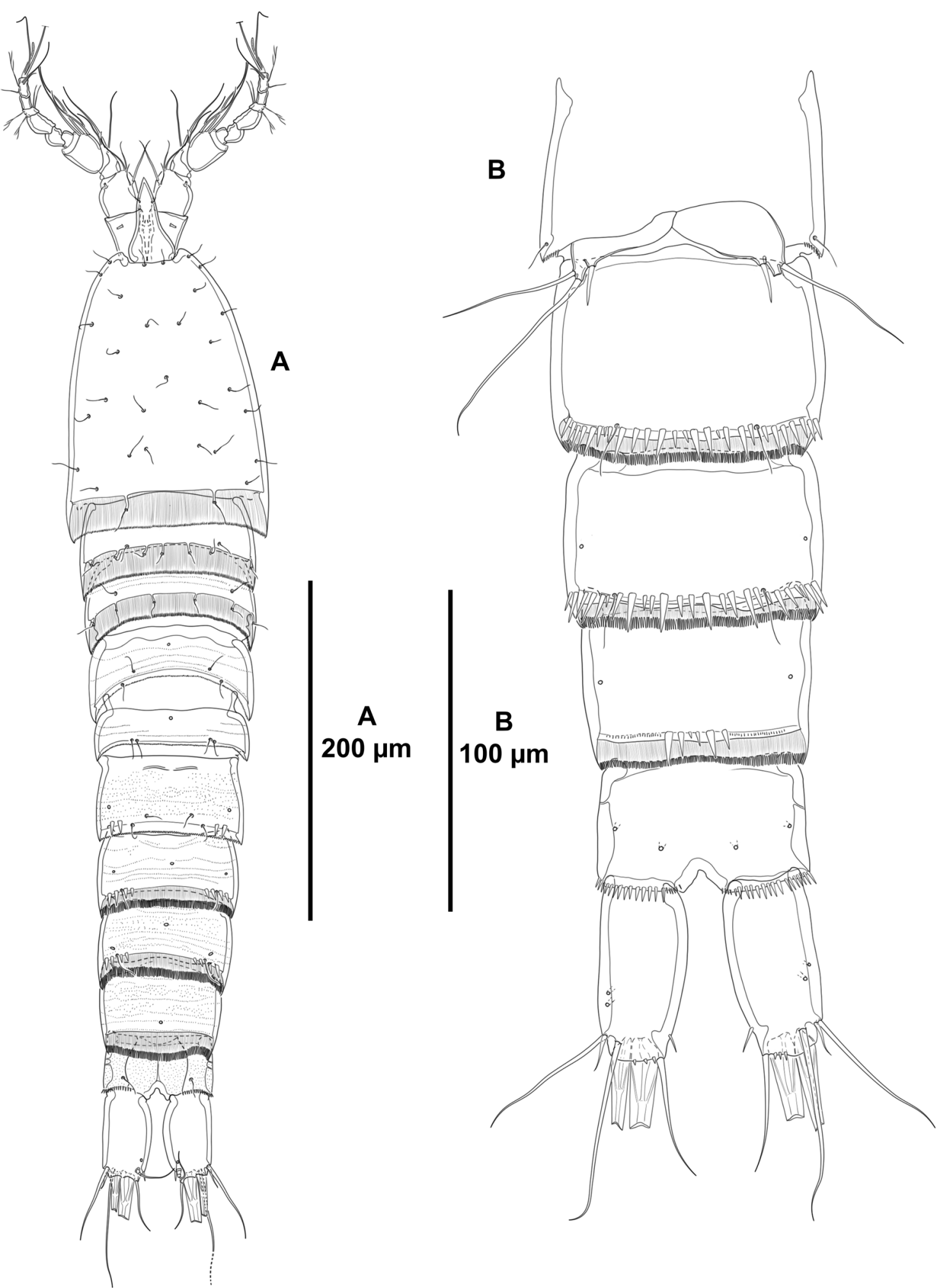

Fig. 8. Typhlamphiascus medici sp. nov. A. Allotype, ô (ICML-EMUCOP-180119-43); habitus, dorsal view. B. Paratype, ô (ICML-EMUCOP-180119-44); urosome, ventral view (P5-bearing somite omitted). 
of which proximalmost visibly longer, one subdistal outer seta arising from setophore and two distal setae of which innermost one $1 / 3$ length of outermost and with bifurcate tip.

P6 (Fig. 8B). Asymmetrical, each leg with three setae of which innermost one shortest and spiniform, medial and outermost ones slender, medial one longest.

\section{Variability}

The left dorsal sensilla of the anal somite of the holotype is situated more proximally than the right sensilla. One female possesses five instead of six setae on one mandibular endopod and two instead of three maxillary endites on one maxilla.

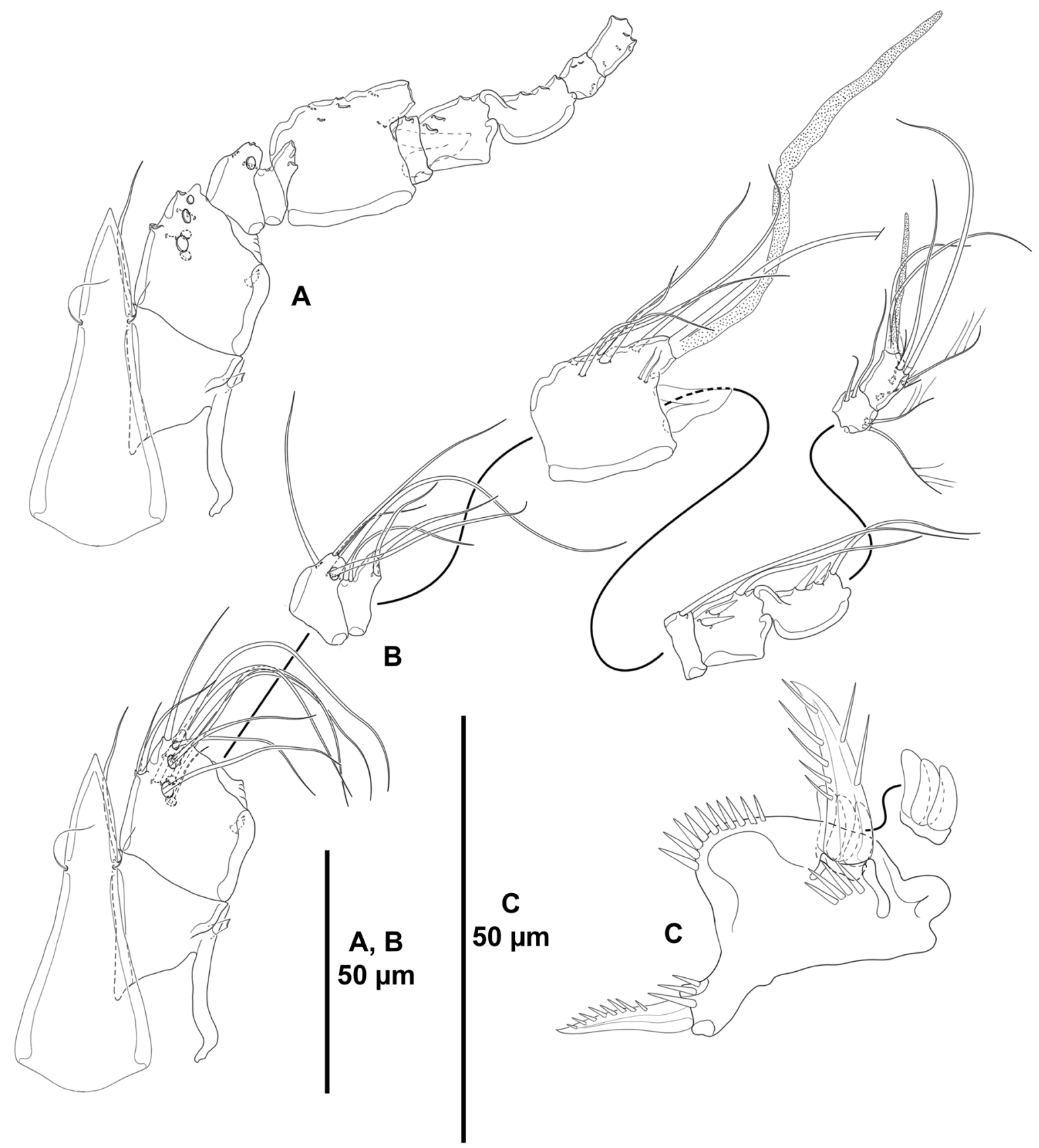

Fig. 9. Typhlamphiascus medici sp. nov., paratype, $\widehat{\partial}$ (ICML-EMUCOP-180119-44). A. Rostrum and antennule (armature omitted for simplicity). B. Rostrum and antennule showing armature. C. P1 basis, anterior view. 


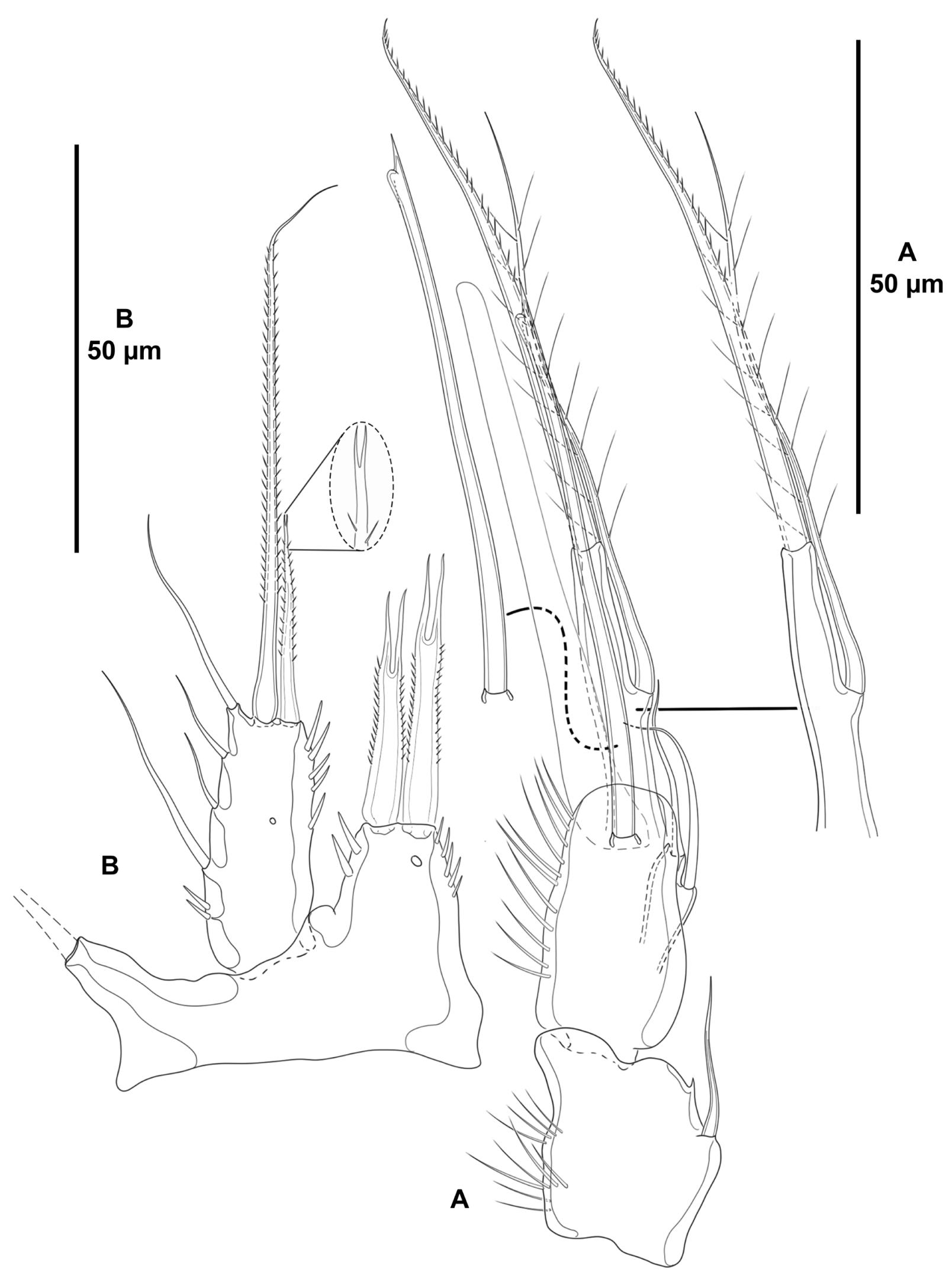

Fig. 10. Typhlamphiascus medici sp. nov., paratype, $\widehat{\jmath}$ (ICML-EMUCOP-180119-44). A. P2 ENP. B. P5, anterior view. 


\section{Spinodiosaccus gen. nov. urn:1sid:zoobank.org:act:B8A6B755-8375-48B0-BC31-EBCCB4B9F9DE}

\section{Type and only species}

Spinodiosaccus primus gen. et sp. nov., by monotypy.

Diagnosis (based on Spinodiosaccus primus gen. et sp. nov.)

Miraciidae: Diosaccinae. Body fusiform. Rostrum not fused to cephalothorax, elongate, almost as long as the first, second and third antennulary segments combined, with one subdistal sensilla on each side issuing at the third quarter of its length. Pro- and urosomites without extensions; with a flexible unsclerotized cuticle between prosome and urosome, the latter seemingly more evident in the male. Female genital double-somite (genital - second urosomite - and third urosomites fused) completely fused ventrally, with a dorsolateral cuticular rib marking former division between somites. Anal somite trapezoidal, without anal operculum. Caudal rami short, 1.6 times as wide as long in dorsal view, unornamented, with slender tube pore ventrally; with seven setae. Female antennule eight-segmented, with aesthetasc and seta fused basally on fourth segment and with apical acrothek on last segment. Male antennule haplocer, 11-segmented, with aesthetasc and seta fused basally on fifth segment and with apical acrothek on last segment. Antennulary setae typically smooth. Antenna with allobasis; exopod three-segmented, armature formula 1-1-1,3,0. Mandibular palp biramous; endopod one-segmented, exopod two-segmented. Maxillule biramous; rami one-segmented. Maxilla with three endites; ENP one-segmented. Maxilliped subchelate; (syn)coxa with four, basis with two setae; ENP one-segmented, with claw and three accompanying setae. P1-P4 with three-segmented rami. P1-P2 EXP shorter than endopod, P3 EXP and ENP of approximately the same length, P4 ENP shorter than EXP. Male P1 basis sexually dimorphic, with inner unipinnate spine and inner modified accessory spine. Male P2 sexually dimorphic, two-segmented; first segment with one inner seta; second segment with two inner, one inner subdistal almost straight element, and two setae (one medial, one apical) issuing from elongate cylindrical extension fused to segment basally, and one strong outer subdistal spine, the latter strongly tapering distally. P2-P4 EXP1 without, EXP2 with inner seta; P2-P4 ENP1 with inner seta; P2 ENP2 with two, P3-P4 ENP2 with one inner seta, inner distal seta of EXP3 visibly shorter than other elements of same segment. Both P5 EXP separated in the female, baseoendopods fused medially in the male; rami of P5 distinct in both sexes; P5 EXP with six setae in both sexes, whip-like in the female, two medial outer elements transformed into short spines in the male; P5 endopodal lobe with five setae in the female, with two setae in the male.

Armature formula of P1-P5 as follows:

\begin{tabular}{|c|c|c|}
\hline & EXP & ENP/ENP lobe \\
\hline P1 & $0-0-0,2,3$ & $1-1-1,1,1$ \\
\hline $\mathrm{P} 2$ & $0-1-2,2,3$ & ㅇ 1-2-1,2,1 / ठ̂ dimorphic \\
\hline P3 & $0-1-2,2,3$ & $1-1-2,2,1$ \\
\hline P4 & $0-1-3,2,3$ & $1-1-1,2,1$ \\
\hline $\mathrm{P} 5 q / \widehat{O}$ & q $6 /$ ภै 6 & q $5 /$ ठ 2 \\
\hline
\end{tabular}

Sexual dimorphism expressed in the male antennule, P1 basis, P2 ENP, P5, P6, and in the genital and third urosomite separated in males.

\section{Etymology}

The prefix 'spino' from the Latin 'spīna', 'spine', refers to the two medial elements of the male P5 EXP modified into strong short spines. Gender masculine. 
GÓMEZ S. et al., On new genera and species of Harpacticoida

\section{Apomorphies of Spinodiosaccus gen. nov.}

This new genus can easily be recognised by i) the male A1 with 11 segments resulting from the reexpression of the plesiomorphic condition, ii) the absence of an inner seta on the P1 EXP2 and iii) the absence of inner armature on P2-P4 EXP1.

Spinodiosaccus primus gen. et sp. nov.

urn:1sid:zoobank.org:act:4B5EB240-AC9A-4F68-A79F-BADEF42F6880

Figs $11-18$

\section{Etymology}

The specific epithet comes from the Latin 'prīmus', 'first', and refers to the first - and type - species described for Spinodiosaccus gen. nov. It is in the nominative singular, gender masculine.

\section{Material examined}

Holotype

MEXICO - $q$ (preserved in alcohol); Sinaloa State, Mazatlán, Urías coastal system, stn 5 (see also Gómez 2020a: 43, fig. 1); $23.2056^{\circ} \mathrm{N}, 106.3715^{\circ} \mathrm{W}$; 0.6 m depth; 18 Jan. 2019; S Gómez leg.; organic carbon content $0.99 \%$, organic matter content $1.71 \%$, sand $78.61 \%$, clay $6.72 \%$, silt $14.67 \%$ ); ICMLEMUCOP-180119-57.

\footnotetext{
Allotype

MEXICO • $\widehat{\jmath}$ (preserved in alcohol); same collection data as for holotype; ICML-EMUCOP-180119-58.

Paratypes

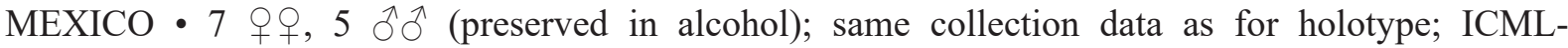
EMUCOP-180119-59 - 1 क (preserved in alcohol); same collection data as for holotype; ICML-

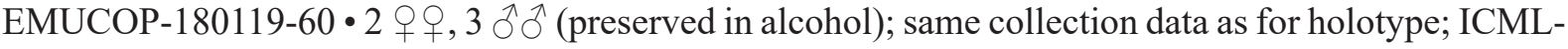
EMUCOP-180119-61 • 1 q (dissected); same collection data as for holotype; ICML-EMUCOP-180119-

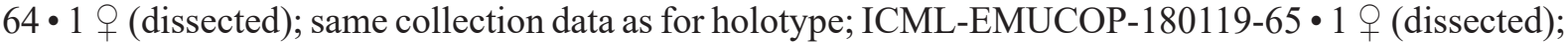
same collection data as for holotype; ICML-EMUCOP-180119-66 • 1 त (dissected); same collection data as for holotype; ICML-EMUCOP-180119-67 - $1 \hat{\jmath}$ (dissected); same collection data as for holotype; ICML-EMUCOP-180119-68 • 1 ठ (dissected); same collection data as for holotype; ICMLEMUCOP-180119-69・1 (preserved in alcohol); Sinaloa State, Mazatlán, Urías coastal system, stn 6 (see also Gómez 2020a: 43, fig. 1); $23.2123^{\circ}$ N, 106.3780 W; 1.4 m depth; 18 Jan. 2019; S. Gómez leg.; organic carbon content $1.65 \%$, organic matter content $2.84 \%$, sand $61.44 \%$, clay $14.57 \%$, silt $23.99 \%$; ICML-EMUCOP-180119-63.
}

\section{Other material}

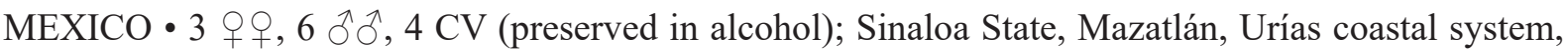
stn 2 (see also Gómez 2020a: 43, fig. 1); $23.1587^{\circ}$ N, $106.3326^{\circ} \mathrm{W} ; 1.8 \mathrm{~m}$ depth; 18 Jan. 2019; S. Gómez leg.; organic carbon content $3.99 \%$, organic matter content $6.86 \%$, sand $80.42 \%$, clay $8.29 \%$, silt 11.28\%; ICML-EMUCOP-180119-70 • 1 +, 1 đ (preserved in alcohol); Sinaloa State, Mazatlán, Urías coastal system, stn 4 (see also Gómez 2020a: 43, fig. 1); $23.1840^{\circ} \mathrm{N}, 106.3579^{\circ} \mathrm{W} ; 0.7 \mathrm{~m}$ depth; 18 Jan. 2019; S. Gómez leg.; organic carbon content 1.13\%, organic matter content 1.94\%, sand 82.44\%, clay 8.27\%, silt 9.29\%; ICML-EMUCOP-180119-71 • 1 क (preserved in alcohol); same collection data as for preceding; ICML-EMUCOP-180119-72 - $2 \mathrm{CV}$ (preserved in alcohol); same collection data as for preceding; ICML-EMUCOP-180119-73 - $1 \mathrm{CV}$ (preserved in alcohol); same collection data as for holotype; ICML-EMUCOP-180119-62 • 1 CV, 1 CIII (preserved in alcohol); Sinaloa State, Mazatlán, Urías coastal system, stn 6 (see also Gómez 2020a: 43, fig. 1); $23.2123^{\circ} \mathrm{N}, 106.3780^{\circ} \mathrm{W} ; 1.4 \mathrm{~m}$ depth; 
18 Jan. 2019; S. Gómez leg.; organic carbon content $1.65 \%$, organic matter content $2.84 \%$, sand $61.44 \%$, clay $14.57 \%$, silt $23.99 \%$; ICML-EMUCOP-180119-74 • 2 ऊ̂े (preserved in alcohol); same collection

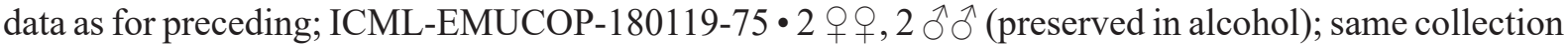
data as for preceding; ICML-EMUCOP-180119-76 • 1 ㅇ, 1 § (preserved in alcohol); Sinaloa State, Mazatlán, Urías coastal system, stn 9 (see also Gómez 2020a: 43, fig. 1); 23.1904 N, $106.4121^{\circ} \mathrm{W}$; 5.4 m depth; 18 Jan. 2019; S. Gómez leg.; organic carbon content $1.41 \%$, organic matter content $2.43 \%$, sand $64.81 \%$, clay $8.09 \%$, silt 27.11\%; ICML-EMUCOP-180119-77 • 4 $\widehat{\jmath}, 1 \mathrm{CV}$ (preserved in

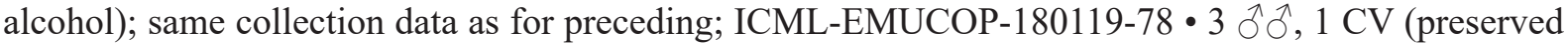
in alcohol); same collection data as for preceding; ICML-EMUCOP-180119-79 1 ○ (preserved in alcohol); Sinaloa State, Mazatlán, Urías coastal system, stn 10 (see also Gómez 2020a: 43, fig. 1); $23.1815^{\circ} \mathrm{N}, 106.4214^{\circ} \mathrm{W} ; 6.0 \mathrm{~m}$ depth; $18 \mathrm{Jan} .2019$; S. Gómez leg.; organic carbon content 1.2\%, organic matter content $2.07 \%$, m sand $69.12 \%$, clay $7.91 \%$, silt $22.97 \%$; ICML-EMUCOP-180119-80 • $1 \widehat{\partial}$ (preserved in alcohol); same collection data as for preceding; ICML-EMUCOP-180119-81.

\section{Description}

\section{Female}

GENERAL. Total body length measured from tip of rostrum to posterior margin of caudal rami ranging from 510 to $695 \mu \mathrm{m}$ (mean $605.4 \mu \mathrm{m} ; \mathrm{n}=13$; total body length of holotype $695 \mu \mathrm{m}$ ); habitus fusiform, widest at posterior end of cephalothorax in dorsal view, tapering posteriad (Fig. 11A).

Prosome (Fig. 11A, C). Consisting of cephalothorax, with fused first pedigerous somite, and second to fourth free pedigerous somites; prosomites without expansions nor spinular ornamentation; posterior hyaline frill of cephalothorax, second and third pedigerous somites broad, of P4-bearing somite visibly narrower, with posterior margins plain; posterior frill of second and third pedigerous somites with transverse row of minute spinules.

Urosome (Figs 11A-D, 12A). Consisting of fifth pedigerous somite (first urosomite), genital doublesomite (genital - second urosomite - and third urosomites fused), two free urosomites, anal somite and caudal rami; urosomites without expansions. First urosomite narrower than preceding somites in dorsal view (Fig. 11A), without spinular ornamentation, with posterior sensilla as depicted, with one lateral pore on each side (Fig. 11C), posterior frill as in preceding somite dorsally and laterally (Fig. 11A, C). Genital double-somite (Figs 11A, C, 12A) rectangular, slightly longer than wide, with sensilla as shown, without spinular ornamentation; original division between anterior and posterior halves (second - genital - urosomite and third urosomite, respectively) marked by inner cuticular rib dorsally and laterally (Fig. $11 \mathrm{~A}, \mathrm{C}$ ), completely fused ventrally (Fig. 12A); posterior half of genital double-somite with two dorsal pores and one lateroventral pore on each side, with posterior hyaline frill finely serrated and striated; P6 at anterior third of genital somite (anterior half of genital double-somite) and with genital field as shown (Fig. 12A). Fourth urosomite largely as in posterior half of genital double-somite, but with additional medial pore ventrally and posterior ventrolateral transverse spinular row on frill (Figs 11A, C, 12A). Fifth urosomite without sensilla or spinules, with two dorsal and two ventral pores, posterior hyaline frill as in preceding somites (Figs 1A, C, 12A). Anal somite wider than long in dorsal view (Fig. 11A-B), without anal operculum, cleft medially dorsally (Fig. 11A-B) and ventrally (Fig. 12A), with two posterior sensilla dorsally, two dorsolateral pores (Fig. 11A-C) and two ventral pores (Fig. 12A), dorsally without spinules, with one ventrolateral and one short ventral spinular row on each side close to joint with caudal rami as shown (Fig. 12A). Caudal rami short, twice as wide as long in dorsal view (Fig. 11A-B), unornamented, with slender tube pore ventrally; with seven setae (Figs 1B, D, 2A) as follows: setae I and II situated almost medially on outer margin, the former very small and ventral to the latter; seta III displaced ventrally close to outer margin; setae IV and V normal, with fracture plane, the former shorter; seta VI arising at inner distal corner; dorsal seta VII issuing subdistally, close to inner margin, triarticulated. 
Rostrum (Fig. 13A). Not fused to cephalothorax, elongate, triangular, with blunt tip, with one sensillum arising at distal third on each side, without pore, reaching distal margin of second antennulary segment.

ANTENNULE (Fig. 13B-C). Eight-segmented; all segments smooth, except for one proximal and one subdistal short spinular row on first segment; all setae smooth; with two and four biarticulated setae on penultimate and last segments, respectively. Armature formula: $1(1) ; 2(10) ; 3(6) ; 4(3+(1+\mathrm{ae})) ; 5(2)$; $6(4) ; 7(4) ; 8(5+$ acro $)$. Acrothek consisting of two setae and one aesthetasc fused basally.

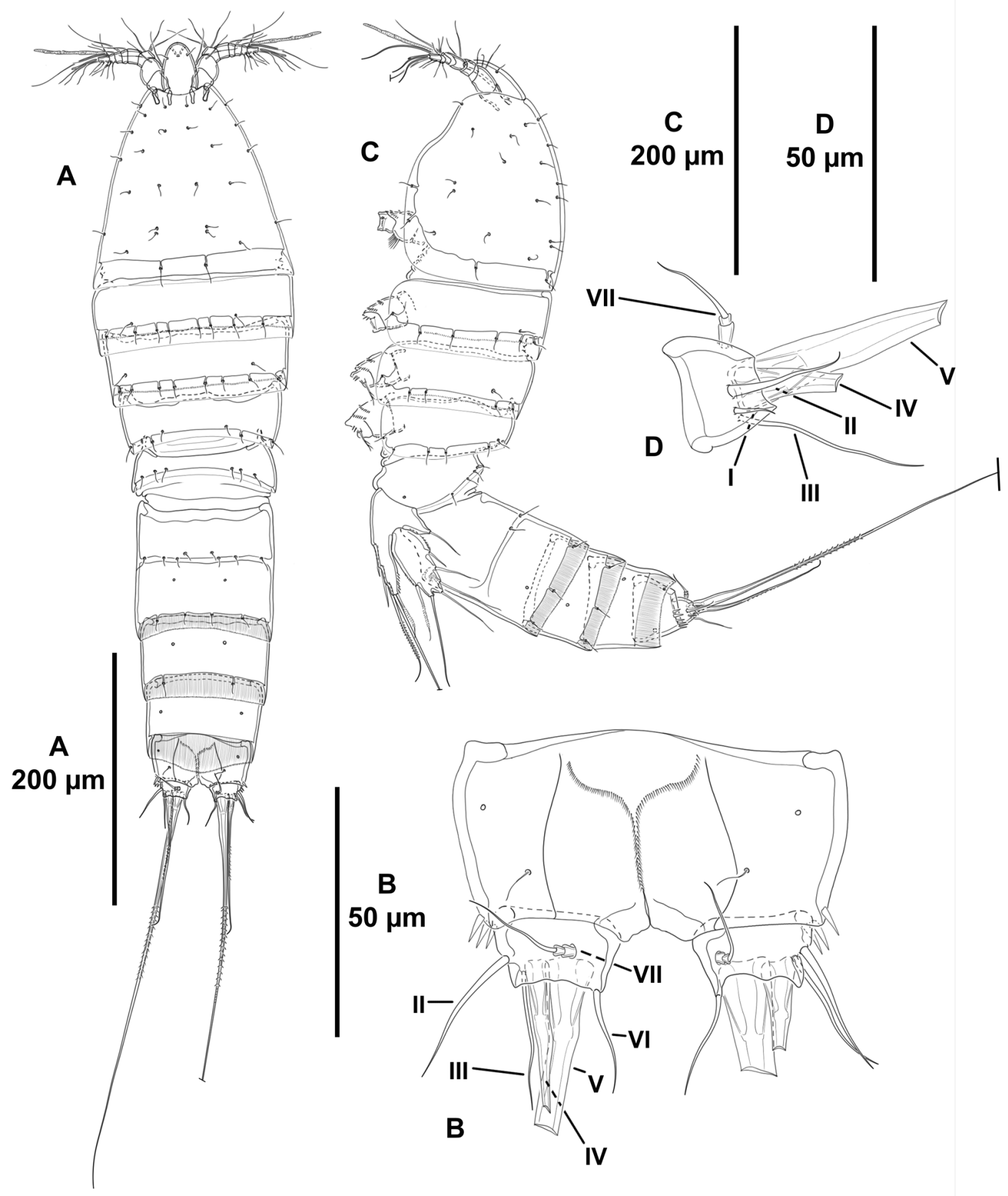

Fig. 11. Spinodiosaccus primus gen. et sp. nov., holotype, + (ICML-EMUCOP-180119-57). A. Habitus, dorsal view. B. Anal somite and caudal rami, dorsal view. C. Habitus, lateral view. D. Left caudal ramus, lateral view. 
ANTENNA (Fig. 13D). With small coxa ornamented with outer spinules. Allobasis with remains of former division between basis and first endopodal segment, as long as free endopodal segment, with outer spinules proximally, with one abexopodal seta. Exopod three-segmented; first and third ones subequal in length, second segment smallest; first and second segments unornamented, with one seta each; third segment unornamented, with four elements - one proximal bipinnate, one small subdistal and two distal spine-like elements. Free endopodal segment with proximal and subdistal inner strong spinules, and

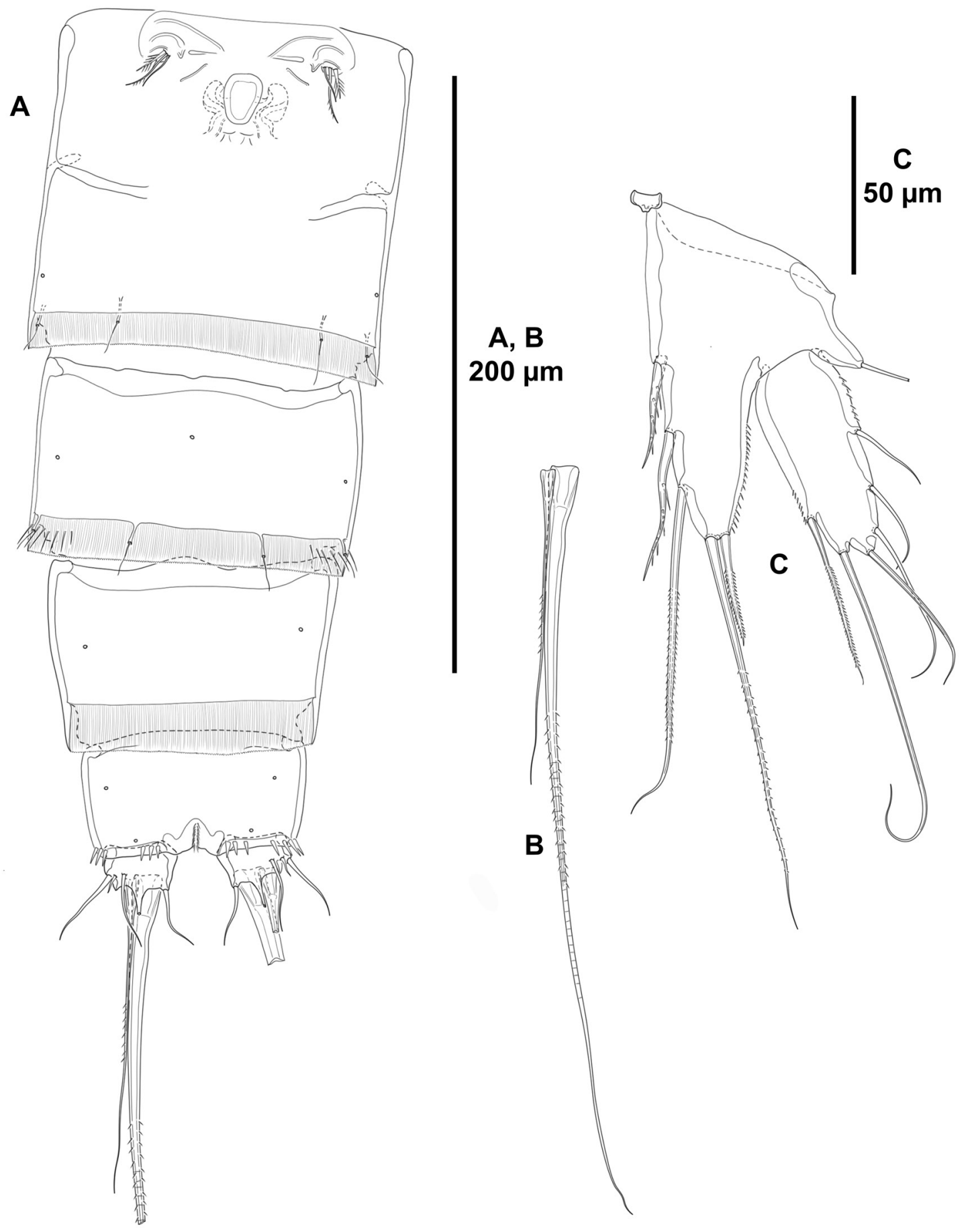

Fig. 12. Spinodiosaccus primus gen. et sp. nov., paratype, + (ICML-EMUCOP-180119-64). A. Urosome, ventral view (P5-bearing somite omitted). B. Caudal setae IV and V, ventral view. C. P5, anterior view. 


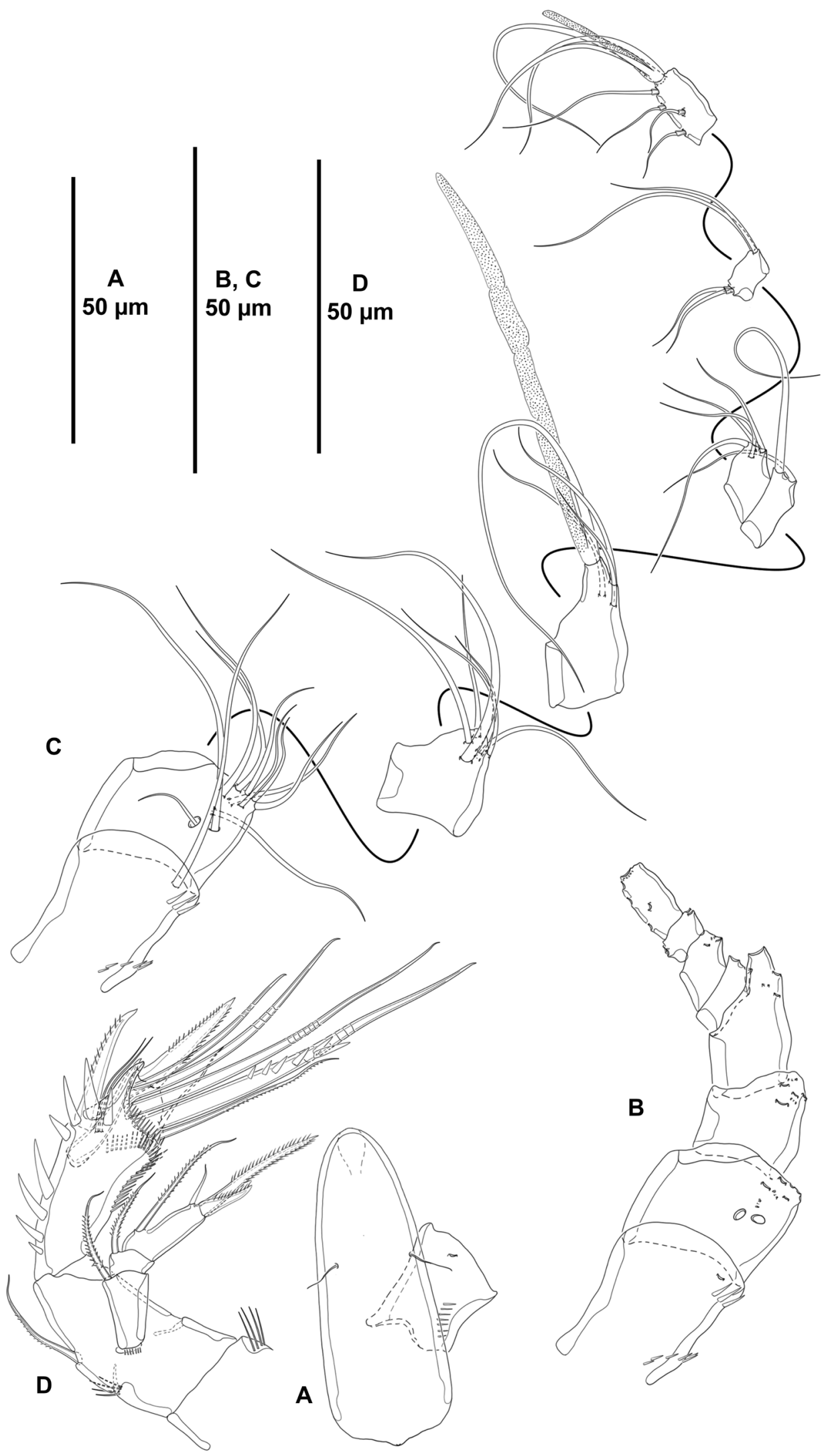

Fig. 13. Spinodiosaccus primus gen. et sp. nov., paratype, q (ICML-EMUCOP-180119-64). A. Rostrum, dorsal view. B. Antennule (armature omitted for simplicity). C. Antennule showing armature. D. Antenna. 
with row of outer small spinules as shown; armed with two lateral inner spines and two slender setae, the latter set close to each other, one inner apical spine, three single geniculate setae, one slender seta, and one strongly spinulose geniculate outer seta fused basally to slender pinnate element.

MANDiBLE (Fig. 14A). With well-developed gnathobasis bearing strong multi- and bicuspidate teeth as shown, with two long spinules and one pinnate seta. Basis massive, with strong spinules, with three inner setae. Exopod two-segmented; first segment longer than second, the former with one lateral and one distal seta, the latter with three apical elements. Endopod one-segmented, visibly larger than exopod; with two lateral and six distal setae, of which three fused basally.

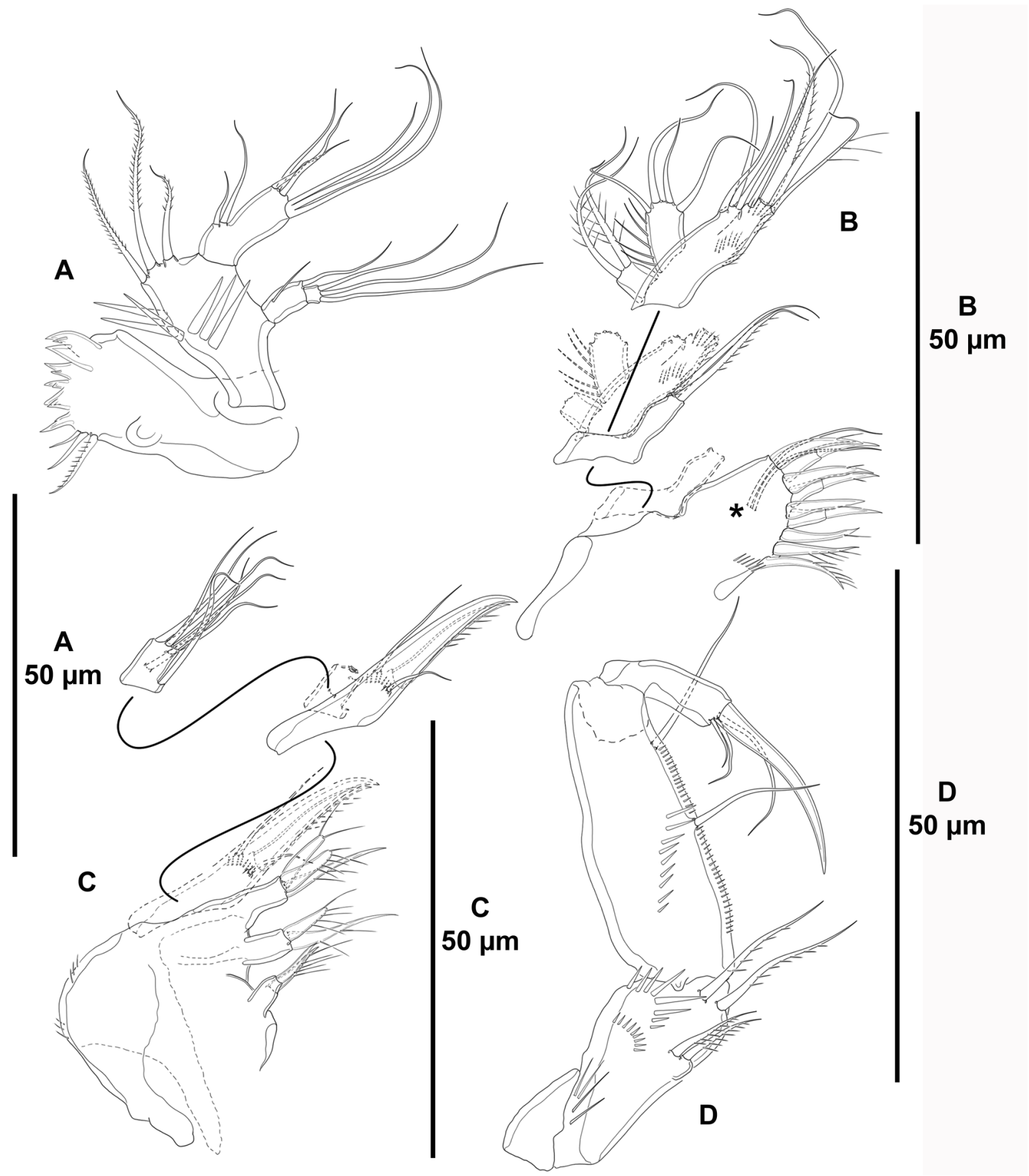

Fig. 14. Spinodiosaccus primus gen. et sp. nov., paratype, q (ICML-EMUCOP-180119-64). A. Mandible. B. Maxillule (asterisk indicates two surface setae). C. Maxilla. D. Maxilliped. 
MaXiLlule (Fig. 14B). With arthrite ornamented with some slender spinules and armed with two surface setae (the latter indicated with an asterisk on figure), seven distal spines as shown, one spinulose element and one recurved, stiff pinnate seta. Coxal endite with two setae. Basis with spinular rows as depicted and armed with three lateral, one subdistal and three distal elements, one of which visibly stronger. Rami one-segmented, exopod unornamented and with two setae, endopod with longitudinal spinular row and with four elements - one inner subdistal, two distal and two outer subdistal setae.
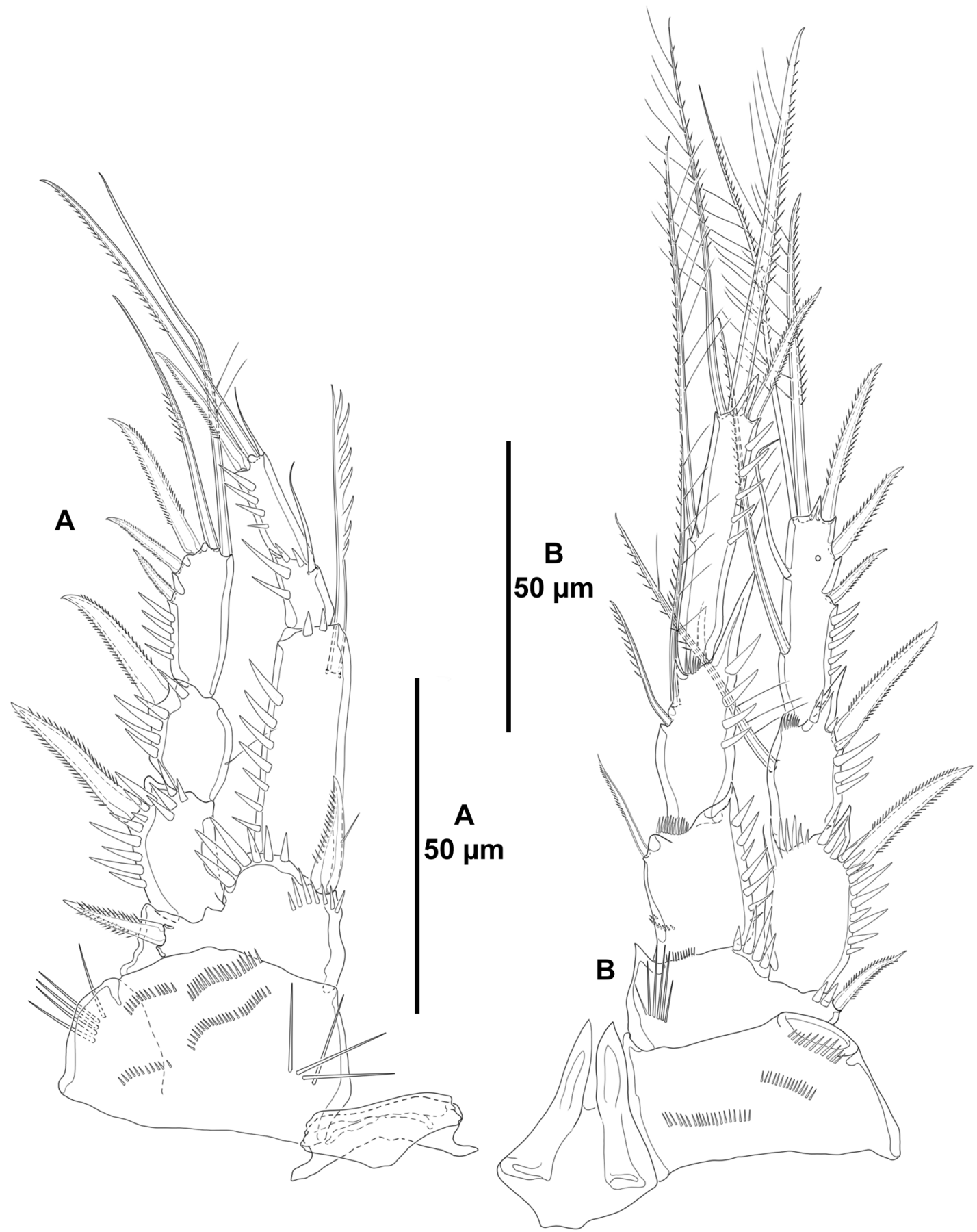

Fig. 15. Spinodiosaccus primus gen. et sp. nov., paratype, $q$ (ICML-EMUCOP-180119-65). A. P1, anterior view. B. P2, anterior view. 
Maxilla (Fig. 14C). With large syncoxa ornamented with small outer spinules; with three endites; proximal endite smallest, with two setae; middle endite longer than proximal endite, with two setae; distal endite longest, with three setae. Basis drawn out into strong claw, additionally with pinnate spine, and two slender setae - one anterior, one posterior. Endopod one-segmented, with one proximal, one medial, one subdistal and four apical setae.

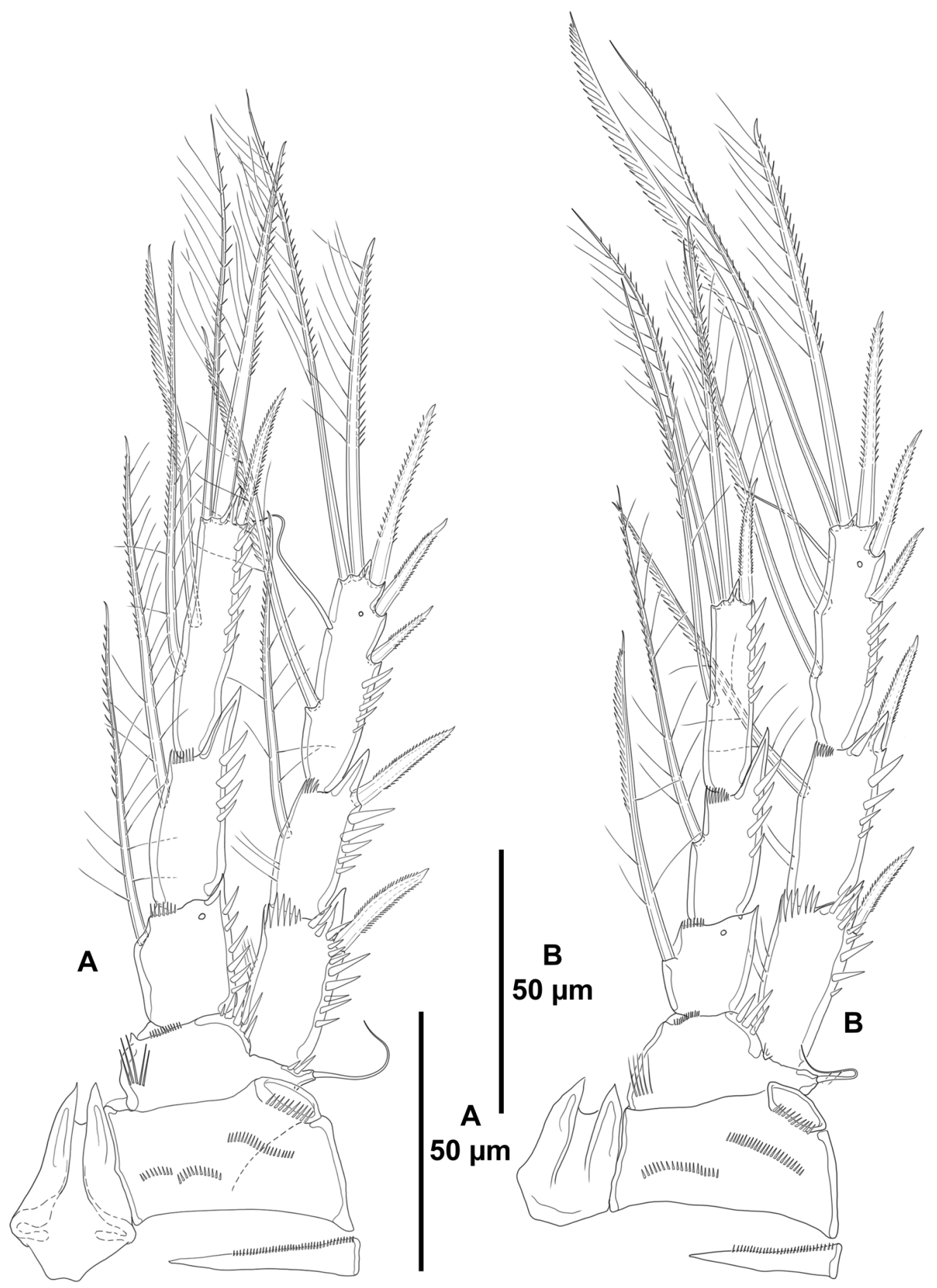

Fig. 16. Spinodiosaccus primus gen. et sp. nov., paratype, $q$ (ICML-EMUCOP-180119-65). A. P3, anterior view. B. P4, anterior view. 
MaxilliPed (Fig. 14D). Subchelate. Praecoxa small. Coxa elongate, with proximal, medial and subdistal spinules as shown; with two inner small setae issuing at middle of segment and two long apical setae. Basis longer than coxa, elongate, with medial row of small spinules and with longitudinal row of minute outer spinules, with one medial inner and one subdistal inner seta. Endopod one-segmented, elongate, with apical claw and three setae of different lengths.

P1 (Fig. 15A). With unornamented intercoxal sclerite. Coxa massive, with several spinular rows as shown. Basis with inner and outer spinulose spines; with strong spinules at top of crescentic medial extension, and with smaller spinules at base of inner spine. Exopod three-segmented, arising at a lower level than that of endopod and reaching tip of ENP2; ENP: EXP length ratio 1.2; exopodal segments with strong outer spinules as shown; second segment shortest, third segment longest; first and second segments without inner armature, outer spine of first segment longer than that of second segment; third segment with five elements of which outer proximal and medial spines shorter than those of preceding segments. Endopod three-segmented, arising from pedestal; ENP1 about 2.8 times as long as wide, 1.4 times as long as second and third segments combined, with outer longitudinal row of strong spinules, with one inner stiff, long, strongly pectinate seta; second and third segments with strong outer spinules as shown, the former shorter, slightly longer than wide, with one inner seta; third segment elongate, 1.5 times as long as preceding segment, with one inner distal slender seta, one apical long element and one outer distal spine.

P2 (Fig. 15B). With narrow intercoxal sclerite unornamented, with acute distal projection on each side. Coxa with three anterior rows of spinules. Basis with small inner acute outgrowth, with long slender inner spinules, with minute spinules at base of endopod, and with strong spinules between rami and at base of outer spine. Rami three-segmented, endopod longer than exopod. Exopod three-segmented, arising at a lower level than that of the endopod, reaching slightly above the middle of ENP3; exopodal segments with strong outer spinules as shown; EXP1 and EXP2 with outer distal acute projection, of EXP1 shorter, inner distal frill of first segment coarse, of second segment small, first segment without, second segment with inner seta; EXP3 with subdistal outer pore and seven elements - three outer spines, two apical elements and two inner setae of which distalmost one visibly shorter. Endopod three-segmented, arising from pedestal; endopodal segments with strong outer spinules as shown; ENP1 shortest, slightly longer than wide, with posterior small spinules proximally, with small inner distal spinules and with outer short acute projection, with one short inner seta; ENP2 elongate, twice as long as wide and 0.6 times as long as ENP3, with small inner distal spinules, with long outer distal acute projection, with two inner setae of which proximal shorter; ENP3 longest, elongate, six times as long as wide, with four elements (one inner and two apical setae, and one outer spine), with acute projection between outer spine and inner apical seta.

P3 (Fig. 16A). With triangular praecoxa ornamented with transverse row of minute spinules. Intercoxal sclerite and coxa as in P2. Basis largely as in P2, but with smaller inner distal outgrowth and setiform outer element. Rami three-segmented, endopod slightly longer than exopod. Exopod largely as in P2. Endopod largely as in P2 except for lack of posterior spinules and with outer subdistal pore on ENP1, for inner seta of P3 ENP1 comparatively longer, for one long seta only on P3 ENP2, and for two inner setae on P3 ENP3.

P4 (Fig. 16B). With intercoxal sclerite, praecoxa, and coxa as in P3. Basis as in P3 except for lack of inner distal outgrowth. Exopod longer than endopod; EXP:ENP length ratio 1.3; largely as in P3 except for three inner setae on P4 EXP3 of which medial one visibly thicker and strongly pectinate. Endopod reaching slightly beyond middle of EXP3; largely as in P3 except for one inner seta only on P4 ENP3. 
Armature formula of P1-P4 as follows:

\begin{tabular}{ccc} 
& EXP & ENP \\
\cline { 2 - 3 } P1 & $0-0-0,2,3$ & $1-1-1,1,1$ \\
P2 & $0-1-2,2,3$ & $1-2-1,2,1$ \\
P3 & $0-1-2,2,3$ & $1-1-2,2,1$ \\
P4 & $0-1-3,2,3$ & $1-1-1,2,1$ \\
\hline
\end{tabular}

P5 (Fig. 12C). With outer seta of baseoendopod arising from setophore. Endopodal lobe triangular, reaching distal third of exopod; with small spinules along outer margin; with five elements - one outer and one inner apical and one inner subdistal long setae, and two inner spiniform elements. Exopod elongate, 2.2 times as long as wide; with spinules at base of innermost seta and on outer margin proximally; with six elements - three outer slender setae, two apical elements of which outermost one shorter and one inner seta.

P6 (Fig. 12A). With three setae - one short bipinnate element, and one medial and one inner slender seta.

\section{Male}

GENERAL. Total body length measured from tip of rostrum to posterior margin of caudal rami ranging from 380 to $510 \mu \mathrm{m}$ (mean $455 \mu \mathrm{m} ; \mathrm{n}=8$; total body length of allotype $510 \mu \mathrm{m}$ ).

Prosome (Fig. 17A). As in female.

Urosome (Fig. 17A-B). As in female except for second - P6-bearing somite - and third urosomites separated, for medial row of eight ventral spinules on third urosomite, and for lack of spinules on hyaline frill of fourth urosomite.

SEXUAL DIMORPHISM. Expressed in ventral somatic ornamentation (see above), antennule, and basis of P1, P2 ENP, P5 and P6.

ANTENNULE (Fig. 18A-B). 11-segmented, haplocer. All segments smooth, except for proximal and subdistal spinular rows on first segment. All setae smooth except for two and four biarticulated setae on tenth and eleventh segments, respectively. Armature formula: 1(1); 2(11);3(6); 4(1); 5(5+(1+ae)); $6(2) ; 7(2+2$ spines); 8(0); 9(1); 10(4); 11(5+acro). Acrothek consisting of two setae and one aesthetasc fused basally.

Antenna, mandible, maXillule, maXilla AND maXiLliped (not shown). As in female.

P1. As in female except for basis without slender inner long spinules, without spinules at base of inner spine and with inner modified accessory spine (Fig. 18C).

P2 EXP (not shown). As in female. Endopod (Fig. 18D) sexually dimorphic, two-segmented; ENP1 as long as ENP2 (excluding distal cylindrical extension of ENP2), with longitudinal row of outer spinules, with outer distal acute outgrowth, with one inner short seta; proximal part of ENP2 rectangular, distal extension cylindrical, 2.4 times as long as wide excluding distal cylindrical extension, with longitudinal row of outer spinules, with two inner setae arising from pedestal of which proximal (seta I on Fig. 18D) visibly shorter, subdistally with one strong inner and almost straight element (element III on Fig. 18D), with one lateral and one apical seta (setae IV and V on Fig. 18D) arising from distal elongate cylindrical 
extension fused to segment basally and with strong outer subdistal element strongly tapering distally (element VI on Fig. 18D).

P3 AND P4 (not shown). As in female.

P5 (Fig. 18E). With outer seta of baseoendopod arising from setophore. Endopodal lobe reaching middle of exopod, with outer spinules as shown, with two distal modified setae as shown of which outermost

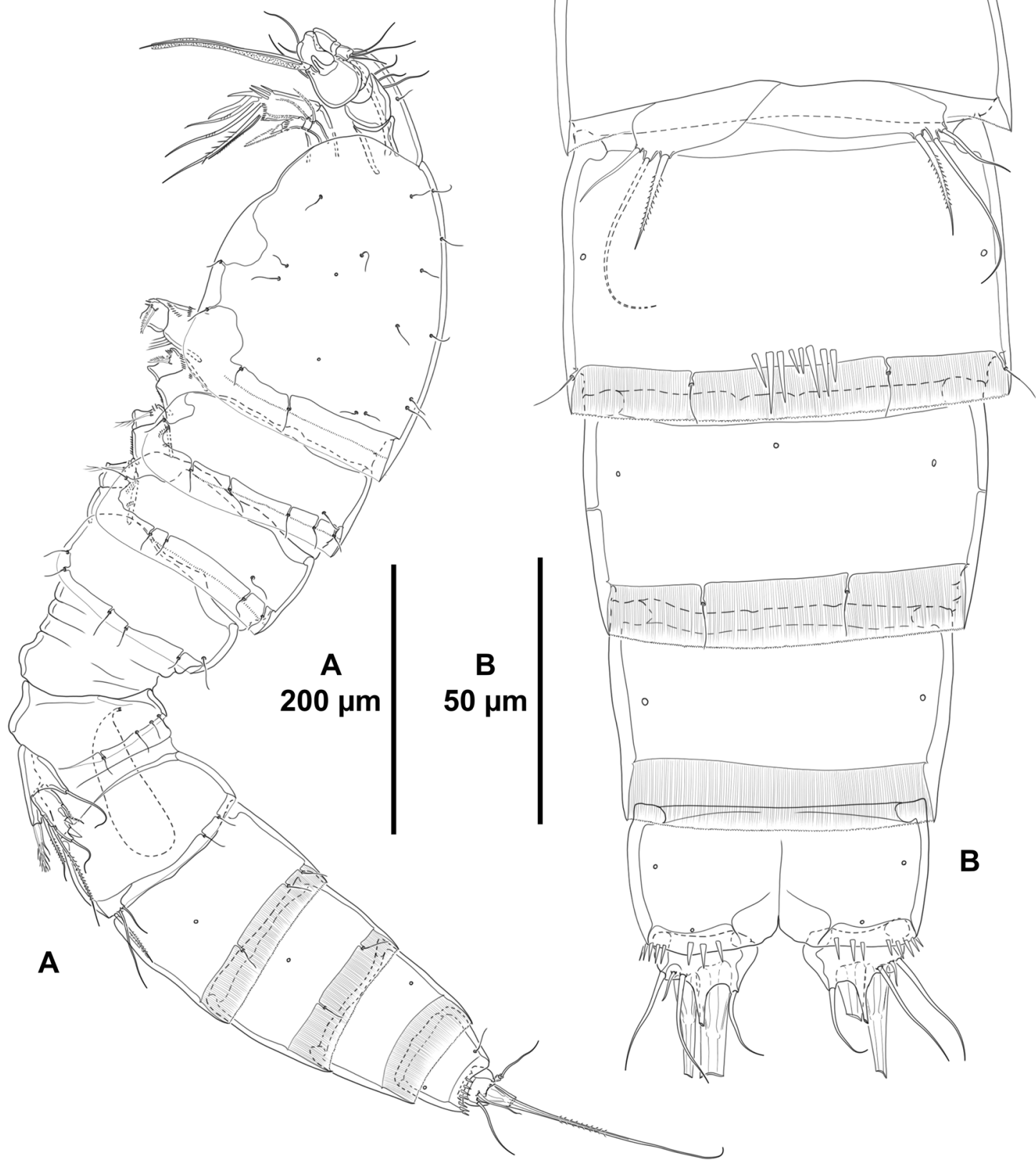

Fig. 17. Spinodiosaccus primus gen. et sp. nov. A. Allotype, $\widehat{\partial}$ (ICML-EMUCOP-180119-58); habitus, lateral view. B. Paratype, ô (ICML-EMUCOP-180119-67); urosome, ventral view (P5-bearing somite omitted). 
one shorter. Exopod triangular, 1.6 times as long as wide, with inner subdistal pore, with six setae - one proximal bipinnate seta, one medial and one subdistal short strong spines of which medial one shorter, one distal seta arising from setophore and two inner setae of which proximal one shorter.

P6 (Fig. 17B). Asymmetrical, only one leg functional, each leg with three setae of which innermost one bipinnate, medial longest and bare, outermost shortest and bare.

\section{Variability}

Both caudal setae I spiniform in one female. One male possesses only one outer spine on P5 EXP.

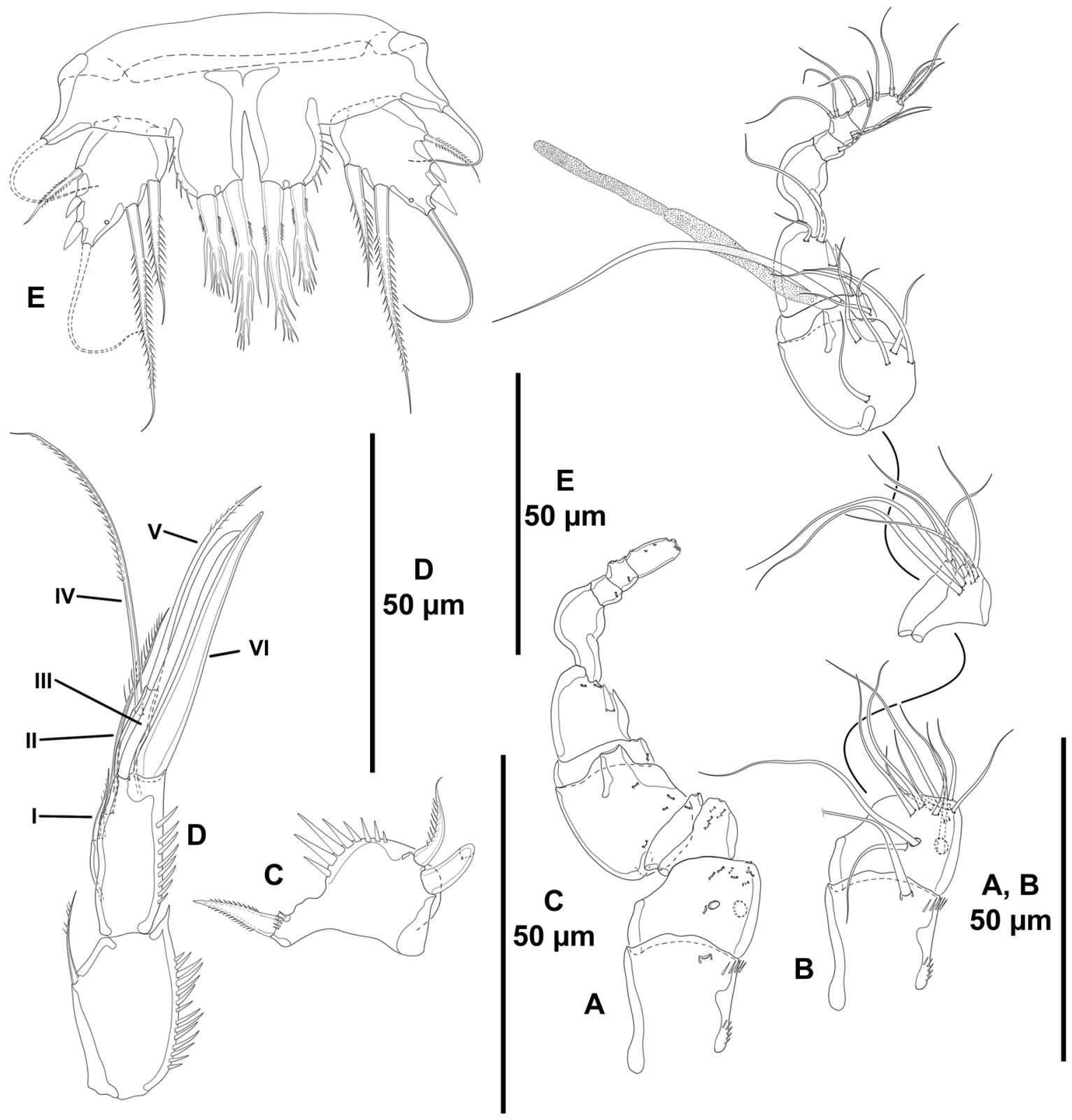

Fig. 18. Spinodiosaccus primus gen. et sp. nov. A-B, E. Paratype, §̊ (ICML-EMUCOP-180119-68). C-D. Paratype, ô (ICML-EMUCOP-180119-69). A. Antennule (armature omitted for simplicity). B. Antennule showing armature. C. Basis of P1, anterior view. D. P2 ENP. E. P5, anterior view. 
GÓMEZ S. et al., On new genera and species of Harpacticoida

Bulbamphiascus Lang, 1944

\section{Type species}

Canthocamptus imus Brady, 1872, by original designation.

\section{Other species}

Bulbamphiascus denticulatus (Thompson, 1893), B. incus Gee, 2005, B. plumosus Mu \& Gee, 2000 and B. scilloniensis Gee, 2005.

\section{Species incertae sedis}

Bulbamphiascus chappuisi Rouch, 1962.

\section{Amended diagnosis}

Miraciidae: Diosaccinae. Body fusiform. Rostrum not fused to cephalothorax, triangular, elongate, with rounded apical margin, almost as long as first, second and third antennulary segments combined, with one subdistal sensilla on each side at third quarter of its length. Pro- and urosomites without extensions; with a flexible unsclerotized cuticle between prosome and urosome. First urosomite (P5-bearing somite) narrower than preceding somites in dorsal view. Female genital double-somite (genital-second urosomite - and third urosomites fused) completely fused ventrally, with a dorsolateral cuticular rib marking former division between somites. Anal somite trapezoidal, without anal operculum. Caudal rami 1.6 times as wide as long in dorsal view, with seven setae. Female antennule eight-segmented, with aesthetasc and seta fused basally on fourth segment and with apical acrothek on last segment. Male antennule haplocer, 10 -segmented, with aesthetasc and seta fused basally on fifth segment, and with apical acrothek on last segment. Antennulary setae typically smooth. Antenna with allobasis and abexopodal seta; exopod threesegmented, armature formula 1-1-1,3,0. Mandibular palp biramous; endopod one-segmented, exopod two-segmented. Maxillule biramous; rami one-segmented. Maxilla with three endites, proximal and middle endites with two, distal endite with three elements; ENP one-segmented. Maxilliped subchelate; (syn)coxa with four, basis with two setae, ENP one-segmented with claw and three accompanying setae. P1-P4 with three-segmented rami. Male P1 basis sexually dimorphic, with inner unipinnate spine and inner modified accessory spine. P1 EXP shorter than ENP, reaching tip of ENP2; EXP2 with inner seta; ENP1 with inner seta; ENP3 longer than the ENP2, with one inner seta, a distal long and geniculate seta, and an outer spine. P2-P4 EXP and ENP of approximately the same length; P2-P4 EXP1 with inner seta; inner distal seta of EXP3 visibly shorter than other elements of same segment; P2 ENP2 with two setae, proximal shorter. Male P2 ENP sexually dimorphic, two-segmented; first segment with one inner seta; second segment with two inner setae, one inner subdistal sigmoid element, one subdistal and one distal seta arising from cylindrical extension fused basally to segment, and one strong distal outer element strongly tapering distally. P5 EXP with six setae in female and male; one or two medial outer elements transformed into short spines. P5 endopodal lobe with five setae in female, with two setae in male; armature of male P5 endopodal lobe strongly bipinnate.

Armature formula of P1-P5 as follows:

\begin{tabular}{|c|c|c|}
\hline & EXP & ENP/ENP lobe \\
\hline $\mathrm{P} 1$ & $0-1-0,2,3$ & $1-1-1,1,1$ \\
\hline $\mathrm{P} 2$ & $1-1-2,2,3$ & q 1-2-1,2,1/ $\widehat{\jmath}$ dimorphic \\
\hline P3 & $1-1-2,2,3$ & $1-1-2,2,1$ \\
\hline P4 & $1-1-3,2,3$ & $1-1-1,2,1$ \\
\hline $\mathrm{P} 5$ P / ठ & q $6 /$ ô 6 & $q 5 / \widehat{o} 2$ \\
\hline
\end{tabular}


Sexual dimorphism expressed in male antennule, P2 ENP, P5, P6, and in genital and third urosomites being separated.

\section{Apomorphies for Bulbamphiascus}

We did not detect any apomorphy for Bulbamphiascus. However, Bulbamphiascus is part of a larger monophyletic group composed of Spinodiosaccus gen. nov., Spinopedia gen. nov. and Pallarica gen. nov. (Fig. 19). The subdistal outer element of the male P2 ENP2 with almost parallel margins, viz slightly tapering distally, is considered here as part of the ground pattern of this monophyletic group and is regarded as a potential synapomorphy for this clade. The modification of this spine into a strong tapering element is regarded here as secondary and is a synapomorphy for Bulbamphiascus and Spinodiosaccus gen. nov. The combination of an outer subdistal tapering spine and a sigmoid inner subdistal element on the male P2 ENP2 is unique to Bulbamphiascus (the outer subdistal spine on the male P2 ENP2 of

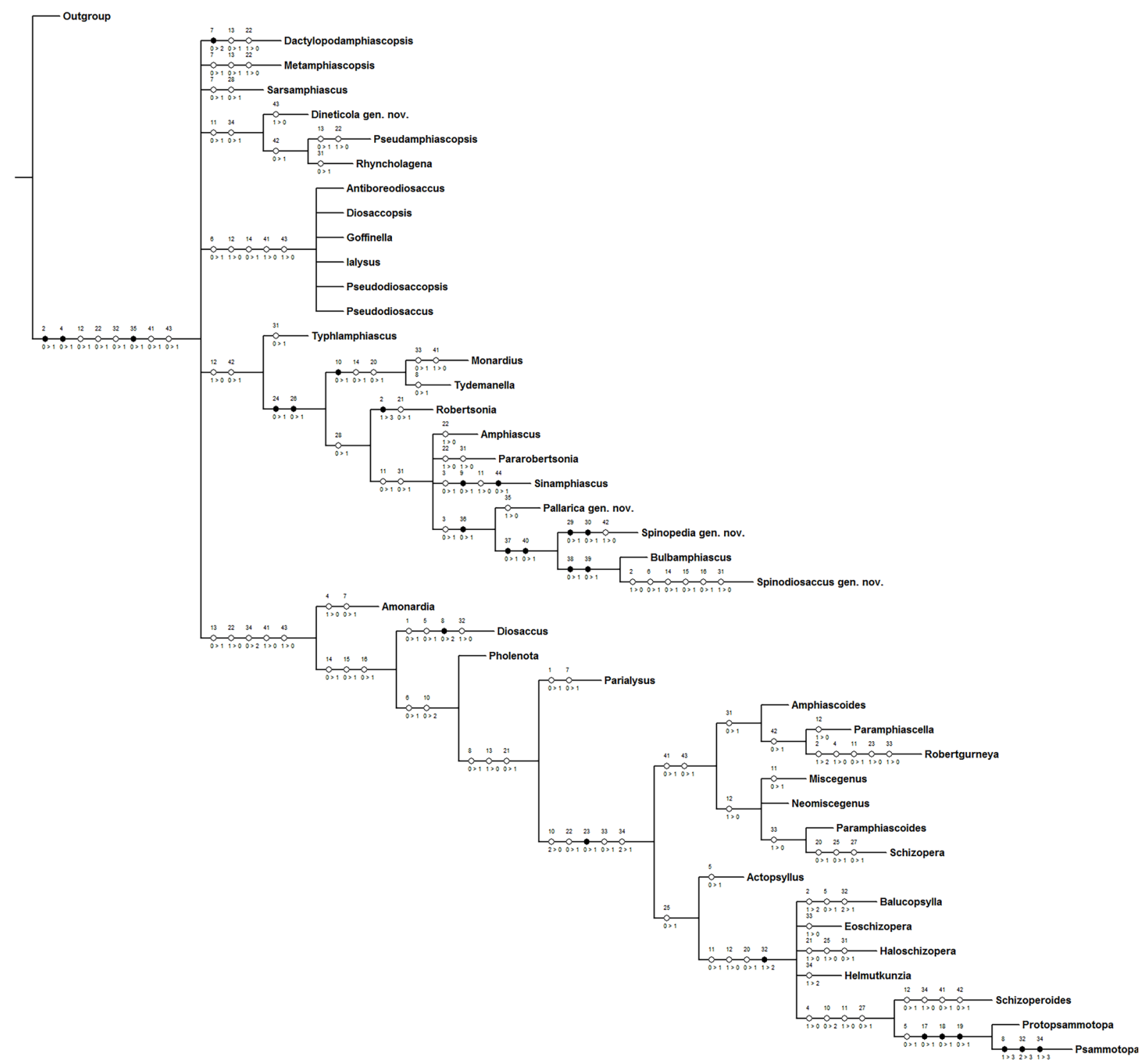

Fig. 19. Strict consensus cladogram of the generic relationships within the Diosaccinae. 
GÓMEZ S. et al., On new genera and species of Harpacticoida

Spinodiosaccus gen. nov. also tapers distally, but the inner subdistal element on the same segment of this species is rather straight).

Bulbamphiascus chappuisi is here relegated to incertae sedis due to the shape of the rostrum and furca, and to the morphology of the male P2 ENP, the illustrations of which (see Rouch 1962: 247, figs 29-33) are too schematic, preventing any further comparison.

Spinopedia gen. nov.

urn:Isid:zoobank.org:act:F6DD1CA7-26EE-476D-AC00-2C4401B63014

Bulbamphiascus Lang, 1944: 19, pro parte.

\section{Type and only species}

Bulbamphiascus spinulosus $\mathrm{Mu} \&$ Gee, 2000 (= Spinopedia spinulosa (Mu \& Gee, 2000) comb. nov.), by monotypy.

\section{Diagnosis}

Miraciidae: Diosaccinae. Body fusiform; body surface seemingly covered with minute denticles. Rostrum not fused to cephalothorax, triangular, elongate, with round apical margin, almost as long as first and second antennulary segments combined, with one subdistal sensilla on each side at third quarter of its length. Pro- and urosomites without extensions; with a flexible unsclerotized cuticle between prosome and urosome. First urosomite (P5-bearing somite) narrower than preceding somites in dorsal view. Genital double-somite (genital - second urosomite - and third urosomites fused) completely fused ventrally, with a dorsolateral cuticular rib marking original division between genital and third urosomites. Telson trapezoidal, without anal operculum. Caudal rami short, about 1.5 times as wide as long in dorsal view, with seven setae. Female antennule eight-segmented, with aesthetasc and seta fused basally on fourth segment and with apical acrothek on last segment. Male antennule haplocer, 10-segmented, with aesthetasc and seta fused basally on fifth segment and with apical acrothek on last segment. Setae of first and second antennulary segments typically bipinnate, smooth in remaining segments. Antenna with allobasis and abexopodal seta; exopod three-segmented, armature formula 1-1-1,3,0. Mandibular palp biramous; endopod one-segmented, larger than exopod, the latter two-segmented. Maxillule biramous; rami one-segmented. Maxilla with three endites, proximal and middle endites with two, distal endite with three elements; ENP one-segmented. Maxilliped subchelate; (syn)coxa with four, basis with two setae; ENP one-segmented, with claw and three accompanying setae. P1-P4 with three-segmented rami. Male P1 basis sexually dimorphic, with inner unipinnate spine and inner modified accessory spine. P1 EXP shorter than ENP, reaching tip of ENP2; P1 ENP1 with strong bipinnate inner seta; P1 ENP3 2.5 times as long as ENP2, with one small inner seta, a distal long geniculate seta and one outer spine; P1 EXP2 with inner seta; P2-P4 EXP and ENP of approximately the same length. P2-P4 EXP1 with inner seta; inner distal seta of P2-P4 EXP3 visibly smaller than other inner setae on same segment. P2 ENP2 with two setae, proximalmost shorter. P2-P4 basis with inner chitinous projection. Male P2 ENP sexually dimorphic, two-segmented; first segment with one inner seta; second segment completely covered by spinules and setules of different lengths, with two inner setae subequal in length, two elements (one medial, one apical) issuing from elongate cylindrical extension fused to segment basally, and with one inner subdistal sigmoid blunt element and one outer subdistal blunt spine with almost parallel margins, viz slightly tapering distally, of which the former is shorter. P5 EXP longer than wide, comparatively shorter in male, with six setae in both sexes; two medial outer elements modified into stiff short spines in male; distal outer spine foliaceous in female. P5 endopodal lobe with five setae in female, with two setae in male; armature of male P5 endopodal lobe strongly bipinnate. 
Armature formula of P1-P5 as follows:

\begin{tabular}{|c|c|c|}
\hline & EXP & ENP/ENP lobe \\
\hline $\mathrm{P} 1$ & $0-1-0,2,3$ & $1-1-1,1,1$ \\
\hline $\mathrm{P} 2$ & $1-1-2,2,3$ & ㅇ 1-2-1,2,1/ §ิ dimorphic \\
\hline $\mathrm{P} 3$ & $1-1-2,2,3$ & $1-1-2,2,1$ \\
\hline P4 & $1-1-3,2,3$ & $1-1-1,2,1$ \\
\hline P5 $+/$ ठ & $q 6 / \hat{\sigma} 6$ & $q 5 / \hat{0} 2$ \\
\hline
\end{tabular}

Sexual dimorphism expressed in male antennule, P2 ENP, P5, P6, and in separated genital and third urosomites.

\section{Etymology}

The prefix 'spino' from the Latin 'spīna', 'spine', and the sufix 'pedia' from the Latin 'pēs', 'pedis', 'foot', refers to the presence of a spinular patch on the male P2 ENP1, and to the presence of several spinules and setules covering the male P2 ENP2. Gender feminine.

\section{Apomorphies for Spinopedia gen. nov.}

Two apomorphies for Spinopedia have been detected: i) presence of an inner subdistal spinular patch on the male P2 ENP1 and ii) male P2 ENP2 completely covered with spinules and setules of different lengths. In addition, the subdistal inner seta of the female P5 EXP arises directly from the ramus (i.e., the seta does not arise from a setophore) (character 42 in Table 3 ; see also Fig. 19). The lack of a setophore for the subdistal inner seta of the female P5 EXP is regarded here as autapomorphic for the genus and is a result of reversal. The presence of a setophore for the inner subdistal seta of the female P5 EXP is autapomorphic for a larger group of genera to which Spinopedia gen. nov. belongs (Fig. 19) and seems to have evolved convergently in more than one evolutionary lineage within the Diosaccinae (Fig. 19).

Pallarica gen. nov.

urn:1sid:zoobank.org:act:78F45B32-1B47-41BB-99E0-E7F8327E3333

Bulbamphiascus Lang, 1944: 19, pro parte.

\section{Type and only species}

Bulbamphiascus cibimae Pallares, 1982 (= Pallaricia cibimae (Pallares, 1982) comb. nov.), by monotypy.

\section{Diagnosis}

Miraciidae: Diosaccinae. Body fusiform. Rostrum not fused to cephalothorax, triangular, elongate, with round apical margin, almost as long as first, second and third antennulary segments combined, with one subdistal sensilla at third quarter of its length, on each side. Pro- and urosomites without expansions. Genital double-somite (genital - second urosomite - and third urosomites fused) completely fused ventrally, with a dorsolateral cuticular rib marking original division between somites. Caudal rami about 1.5 times as wide as long in dorsal view; with seven setae. Female antennule eight-segmented, with aesthetasc and seta fused basally on fourth segment, and with apical acrothek on last segment. Antennulary setae typically smooth. Antenna with allobasis and abexopodal seta; exopod threesegmented, armature formula 1-1-1,3,0. Mandibular palp biramous; endopod one-segmented, larger than exopod, the latter two-segmented. Maxillule biramous; rami one-segmented. Maxilla with three endites, proximal and middle endites with two, distal endite with three elements; ENP two-segmented. 
GÓMEZ S. et al., On new genera and species of Harpacticoida

Maxilliped subchelate; (syn)coxa with three, basis with two setae; ENP one-segmented, with claw and three accompanying setae. P1-P4 with three-segmented rami. Male P1 basis sexually dimorphic, with inner unipinnate spine and inner modified accessory spine. P1 EXP shorter than ENP, reaching tip of ENP2; P1 ENP1 with strong bipinnate inner seta; ENP3 2.5 times as long as ENP2, with one small inner seta, a long distal geniculate seta, and an outer spine; EXP2 with inner seta. P2-P4 EXP and ENP of approximately same lengths; P2-P4 EXP1 with inner seta; inner distal seta of P2-P4 EXP3 visibly shorter than other inner setae on same segment. P2 ENP2 with two setae, proximalmost small. Male P2 ENP sexually dimorphic, two-segmented; first segment with one inner seta; second segment with two inner setae, two elements (one medial, one apical) issuing from elongate cylindrical extension fused to segment basally, and inner subdistal element almost straight and outer subdistal element slightly thicker and longer than the former and with almost parallel margins (i.e., slightly tapering distally). P5 EXP longer than wide in female, comparatively shorter in male, with six setae in female and seven setae in male; two medial outer elements stiff short spine-like in male, slender and smooth in female. P5 endopodal lobe with five setae in female, with two setae in male; armature of male P5 endopodal lobe strongly bipinnate.

Armature formula of $\mathrm{P} 1-\mathrm{P} 5$ as follows:

\begin{tabular}{|c|c|c|}
\hline & & \\
\hline & EXP & ENP \\
\hline $\mathrm{P} 1$ & $0-1-0,2,3$ & $1-1-1,1,1$ \\
\hline $\mathrm{P} 2$ & $1-1-2,2,3$ & ㅇ 1-2-1,2,1/ Љ dimorphic \\
\hline P3 & $1-1-2,2,3$ & $1-1-2,2,1$ \\
\hline P4 & $1-1-3,2,3$ & $1-1-1,2,1$ \\
\hline P5 $q / \hat{O}$ & $q 6 / \widehat{0} 6$ & + $5 / \widehat{o} 2$ \\
\hline
\end{tabular}

Sexual dimorphism expressed in male antennule, P2 ENP, P5, P6, and in separated genital and third urosomites.

\section{Etymology}

This genus is dedicated to Rosa E. Pallares for her contribution to the taxonomy of harpacticoid copepods from Argentina. Gender feminine.

\section{Apomorphies for Pallarica gen. nov.}

This genus is unique by the possession of seven setae on the male P5 EXP, which is regarded here as apomorphic for the genus. The presence of an additional seta is regarded here as a character reversal.

Dinetia gen. nov. urn:1sid:zoobank.org:act:570211A6-5E4D-42CA-A26D-61E2F0E6BC6A

Syn. Bulbamphiascus Lang, 1944: 19, pro parte.

\section{Type and only species}

Bulbamphiascus minutus Dinet, 1971 (= Dinetia minuta (Dinet, 1971) comb. nov), by monotypy.

\section{Diagnosis}

Miraciidae: Diosaccinae. Body fusiform. Width: length ratio of caudal rami 0.8-1.2. Rostrum not fused to cephalothorax, elongate, with rounded tip. Female antennule eight-segmented, with aesthetasc 
and seta fused basally on fourth segment. Antennulary setae typically smooth. Antenna with allobasis and abexopodal seta; EXP three-segmented, armature formula 1-1-1,3,0. Mandibular palp extremely reduced. Maxillule biramous; rami one-segmented. Maxilla with three endites. Maxilliped subchelate; (syn)coxa with two, basis with two setae; ENP one-segmented, with claw and two accompanying setae. P1-P4 with three-segmented rami. P1 EXP shorter than ENP1, reaching its distal third; P1 ENP1 with strong bipinnate inner seta; ENP3 about twice as long as ENP2, with one small inner seta, a long distal geniculate seta and an outer spine; P1 EXP2 with inner seta, EXP3 with three outer spines, proximal one shortest, and two geniculate distal setae. P2-P4 EXP1 with inner seta; P2-P4 EXP3 with reduced inner armature. P2 ENP1 with inner setae; ENP2 with two setae of approximately same length. Female P5 EXP longer than wide, with six setae - three outer, two distal and one inner element. P5 endopodal lobe with five setae.

Armature formula of P1-P5 as follows:

\begin{tabular}{|c|c|c|}
\hline & EXP & ENP \\
\hline $\mathrm{P} 1$ & $0-1-0,2,3$ & $1-0(1 ?)-1,1,1$ \\
\hline $\mathrm{P} 2$ & $1-1-1,2,3$ & $1-2-1.2 .1$ \\
\hline P3 & $1-1-1,2,3$ & $1-1-2,2,1$ \\
\hline P4 & $1-1-2,2,3$ & $1-1-2,2,1$ \\
\hline P5 $q / \widehat{O}$ & o $6 / \hat{0} 6$ & $q 5 / \hat{O} 2$ \\
\hline
\end{tabular}

Male unknown.

\section{Etymology}

This genus is dedicated to Alain Dinet for his contribution to the taxonomy of harpacticoid copepods from France. Gender feminine.

\section{Apomorphies for Dinetia gen. nov.}

The exclusion of Bulbamphiascus minutus from that genus and from any other genus presented here, and its reallocation into Dinetia gen. nov., is supported by, for example, the lack of the short inner distal seta on P2-P4 EXP3. Bulbamphiascus minutus probably bears a sister-group relationship with Pseudamphiascopsis Lang, 1944 and Rhyncholagena Lang, 1944, with which it forms a monophyletic group (see Fig. 19). These three genera share the longer P1 ENP1 relative to the P1 EXP. Given that B. minutus could not be included in Bulbamphiascus or into any other diosaccin genus, and pending the discovery of the male of this species, we propose a new genus, Dinetia gen. nov., for B. minutus. The assessment and significance of character 43 for D. minuta comb. nov. (see Table 3 ) is still pending until the male is described.

\section{Phylogenetic statistics and resolution}

Our partial phylogenetic analysis resulted in 12 most parsimonious topologies with 126 steps, CI of 42, and RI of 77 (see Supplementary File 1). The strict consensus topology (nine branches collapsed) returned the following clades of unclear phylogenetic affinities between each other: a) a small clade composed by Dinetia gen. nov., Pseudamphiascopsis and Ryncholagena; b) a clade formed by Antiboreodiosaccus Lang, 1944, Diosaccopsis Brian, 1925, Goffinella Wilson, 1932, Ialysus Brian, 1927, Pseudodiosaccopsis Lang, 1944 and Pseudodiosaccus T. Scott, 1906; c) a clade formed by Typhlamphiascus Lang, 1944, Monardius Huys, 2009, Tydemanella A. Scott, 1909, Robertsonia Brady, 1880, Amphiascus Sars, 1905, Pararobertsonia Lang, 1944, Sinamphiascus Mu \& Gee, 2000, Pallarica 
gen. nov., Spinopedia gen. nov., Bulbamphiascus and Spinodiosaccus gen. nov.; d) a clade composed of Amonardia Lang, 1944, Diosaccus Boeck, 1872, Pholenota Vervoort, 1964, Parialysus Nicholls, 1941, Amphiascoides Nicholls, 1941b, Paramphiascella Lang, 1944, Robertgurneya Apostolov \& Marinov, 1988, Miscegenus Wells, Hicks \& Coull, 1982, Neomiscegenus Karanovic \& Ranga Reddy, 2004, Paramphiascoides Wells, 1967, Schizopera Sars, 1905, Actopsyllus Wells, 1967, Balucopsylla Rao, 1972, Eoschizopera Wells \& Rao, 1976, Haloschizopera Lang, 1944, Helmutkunzia Wells \& Rao, 1976, Schizoperoides Por, 1968, Protopsammotopa Geddes, 1968 and Psammotopa Pennak, 1942. The phylogenetic position of the genera Dactylopodamphiascopsis Lang, 1944, Metamphiascopsis Lang, 1944 and Sarsamphiascus Huys, 2009 remains uncertain. It is important to highlight the high level of character convergence within the Diosaccinae.

Clades a-d above are present in the 12 most parsimonious topologies (see Supplementary File 1), but their relationships are not consistent. The positions of the clade Dinetia gen. nov.-Rhyncholagena and the genera Sarsamphiascus, Metamphiascopsis and Dactylopodamphiscopsis are unclear, sometimes forming a clade with Typhlamphiascus-Spinodiosaccus gen. nov. (6 times), sometimes forming a clade with Amonardia-Psammotopa (6 times). The same happens to the clade AntiboreodiosaccusPseudodiosaccus which appears either as the sister group of the remaining Diosaccinae or as the sister group of a clade including Dinetia gen. nov.-Rhyncholagena, Sarsamphiascus, Metamphiascopsis, Dactylopodamphiscopsis and Typhlamphiascus-Spinodiosaccus gen. nov.

\section{Key to the species of Typhlamphiascus Lang, 1944}

1. P4 ENP3 with two inner setae (five setae in all). Female: P5 EXP with tip normal or hook-like. Male: P1 basis with inner seta normal or modified, elongate .........2 [Por's group I (Pors 1963)]

- P4 ENP3 with one inner seta (four setae in all). Female: P5 EXP with tip normal. Male: P1 basis with inner seta normal, not modified 11 [Por's group II (Pors 1963)]

2. Female P5 EXP with tip hook-like; endopodal lobe with apical outer seta very small ............3

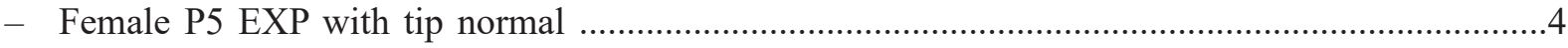

3. Female: antennule seven-segmented; P5 EXP and endopodal lobe with five setae each, endopodal lobe with apical inner element spiniform; P4 EXP3 with three inner setae (male unknown) …………………………………….... dentipes (I.C. Thompson \& A. Scott, 1903)

- Female: antennule eight-segmented; P5 EXP and endopodal lobe with five setae each, endopodal lobe with apical inner element setiform; P4 EXP3 with two inner setae (male unknown) T. blanchardi (T. Scott \& A. Scott, 1895) ${ }^{1}$

4. Female: antennule eight-segmented; P5 EXP with five, endopodal lobe with four setae. Male: P1 basis with inner spine not modified, with three to five inner accessory spines; P5 EXP with four, endopodal lobe with two bifurcate setae .....T. gracilicaudatus (I.C. Thompson \& A. Scott, 1903) ${ }^{6}$

- These characters not combined .5

5. Female: antennule eight-segmented; P5 EXP with four, endopodal lobe with five setae. Male: P1 basis with inner element modified, elongate; P5 EXP with four, endopodal lobe with two bifurcate setae T. longifurcatus Rouch, 1962

- These characters not combined .6

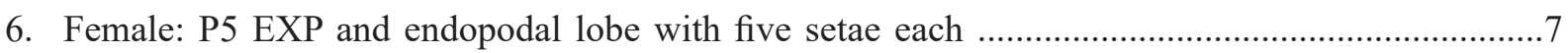

- Female: P5 EXP with six setae, endopodal lobe with five setae ................................................... 
7. Female: caudal rami 1.4-1.5 times as long as wide, shorter than anal somite; P5 second exopodal seta from outer to inner margin 1.5 times as long as third element; third seta 1.7 times as long as first seta and longer than exopod; innermost (fifth) seta 1.2 times as long as fourth seta. Male: P1 basis with inner spine normal, with seven to eight inner accessory spines; P5 EXP with five seate, endopodal lobe with two setae; P5 second exopodal seta from outer to inner margin shorter than first seta ............................................................................... gracilis Por, $1963^{7}$

- Female: caudal rami twice as long as wide, as long as anal somite; P5 second exopodal seta from outer to inner margin 4.5 times as long as third element; third seta as long as first seta and shorter than exopod; innermost (fifth) seta 2.3 times as long as fourth seta. Male: P1 basis with inner spine modified, elongate, with three inner accessory spines; P5 EXP with five setae, endopodal lobe with two setae; P5 second exopodal seta from outer to inner margin longer than first seta ....

T. drachi Soyer, 1963

8. P4 EXP3 without inner armature, formula 0,2,3. Female: antennule nine-segmented (male unknown).

- P4 EXP3 with two inner setae, formula 2,2,3. Female: antennule eight-segmented

9. Caudal rami 1.2 times as long as wide, shorter than anal somite ...T. capensis Kunz, 1975 comb. nov.

- Caudal rami twice as long as wide, as long as anal somite

10. Caudal rami as long as anal somite, rather cylindrical, with inner margin slightly concave. Female: second antennulary segment about 1.5 times as wide as long; P5 EXP with three outer setae subequal in length; outermost seta of P5 endopodal lobe long, reaching well beyond tip of exopod. Male: P1 basis with three inner accessory spines, inner seta normal, not modified; P5 EXP with six setae, endopodal lobe with two bifurcate setae; P5 innermost exopodal seta bifurcate .........T. lutincola Soyer, 1963

- Caudal rami 1.5 times as long as anal somite, elongate, elliptic. Female: second antennulary segment three times as long as wide; P5 EXP with outer proximal seta very long, medial and subdistal outer setae small and subequal in length. Male: second antennulary segment three times as long as wide; P1 basis without inner accessory spines, inner seta modified, elongate; P5 EXP with four setae, endopodal lobe with two bifurcate setae; P5 innermost exopodal seta normal ...T. bouligandi Soyer, 1971

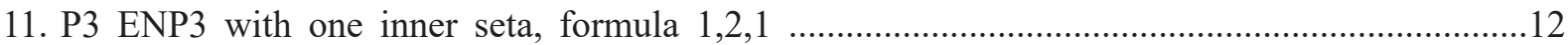

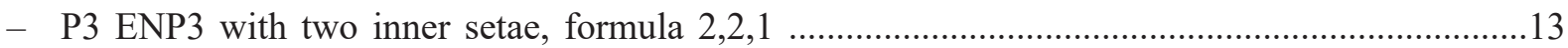

12. P2-P3 EXP3 without inner armature, formula 0,2,3; caudal rami nearly twice as long as wide (length: width ratio 1.8). Male: P1 basis with three inner accessory spines; P5 EXP with six normal (not bifurcated) setae, endopodal lobe with two bifurcate setae ......T. higginsi Chullasorn, 2009

- P2-P3 EXP3 with one inner seta, formula 1,2,3; caudal rami slightly more than two times as long as broad (length: width ratio 2.3) (male unknown) T. unisetosus Lang, 1965

13. Caudal rami slightly more than three times as long as wide (length: width ratio 3.2). Female: P5 EXP with six setae, endopodal lobe with four setae. Male: P1 basis with eight inner accessory spines; P5 EXP with four normal setae, endopodal lobe with two bifurcated elements

T. tuerkayi Ma \& Li, 2017

- Female: P5 EXP with six, endopodal lobe with five setae ......................................................14

14. P4 ENP2 without inner seta; caudal rami from 1.7 to 2.2 times as long as wide. Male: P1 basis with four ${ }^{3}$ or from seven to eight ${ }^{4}$ inner accessory spines; P5 EXP with six normal setae, endopodal lobe with two bifurcated elements T. typhlops (Sars, 1906) ${ }^{2,8}$

- P4 ENP2 with inner seta 
GÓMEZ S. et al., On new genera and species of Harpacticoida

15. P1 EXP3 with four elements; caudal rami three times as long as wide (male unknown)

T. brevicornis (I.C. Thompson \& A. Scott, 1903)

- P1 EXP3 with five elements

16. Caudal rami less than 1.5 times as long as wide

- Caudal rami more than 1.5 times as long as wide

17. Caudal rami about as long as wide. Female: P5 EXP elongate. Male: P1 basis with three inner accessory spines; P5 EXP with five setae

T. latifurca Por, 1968

- Caudal rami length: width ratio from 1.3 to 1.5. Female: P5 EXP oval. Male: P1 basis with eight inner accessory spines; P5 EXP with six setae T. ovale Wells \& Rao, 1987

18. Caudal seta V characteristically deformed proximally, with inner blunt outgrowth

T. typhloides (Sars, 1911)

- Caudal seta V normal

19. Length:width ratio of caudal rami variable, from about 1.7 to 3.1 times as long as wide, with concave inner margins, with lenticular, biconvex thickening of external chitinous walls, with one spinule on inner distal margin. Female: ventral surface of posterior half of genital double-somite without medial spinules, with two posterior transverse sets of three to five spinules, each close to outer margin; ventral surface of fourth urosomite with one medial spinular row of 21 to 30 spinules and one posterior transverse row of 15 to 24 spinules; ventral surface of fifth urosomite with two medial sets of three to ten spinules on each side or with a medial continuous row of about 24 spinules, and with short posterior row of four to six medial spinules or with three sets of spinules of which medial one with ten spinules and marginal sets with three to four spinules; ventral surface of anal somite without spinular ornamentation. Male: ventral surface of third urosomite with two medial transverse sets of four spinules each or with medial continuous spinular row of eight to ten transverse spinules, posterior margin with transverse row of 14 to 26 spinules; ventral surface of fourth urosomite with two medial sets of four to eight transverse spinules or with short medial row of four transverse spinules, and with posterior transverse row of 16 to 24 spinules; ventral surface of fifth urosomite without medial spinules or with two medial sets of four transverse spinules, posterior margin with transverse row of four to 12 spinules; P1 basis with three to five inner accessory spines; P5 EXP with six setae, endopodal lobe with two bifurcate setae .

T. confusus confusus (T. Scott, 1902) ${ }^{5,7}$

- Caudal rami from about 1.7 to 3.2 times as long as wide; ventral spinular pattern of female and male and number of inner accessory spines on male P1 basis different

20. Caudal rami shorter than anal somite

- Caudal rami longer than anal somite

21. Rostrum with concave lateral margin proximally; length: width ratio of caudal rami 1.7. Female: P5 EXP with three outer setae subequal in length, fourth seta from outer to inner margin longer than preceding elements and of about same length as innermost seta. Male: P1 basis with four inner accessory spines .........T. confusus erythraeicus Por, 1963

- Rostrum with convex lateral margin proximally; length: width ratio of caudal rami 1.7. Female: P5 EXP with outer proximal seta shorter than two neighbouring elements, fourth seta from outer to inner margin shorter than two preceding elements and shorter than innermost seta. Male: P1 basis with two inner accessory spines T. lamellifer (Sars, 1911) ${ }^{8}$ 
22. Length: width ratio of caudal rami from 2.0 to 3.2. Female: three outer setae and innermost seta of P5 EXP long, subequal in length. Male: P1 basis with five to seven inner accessory spines .................................................. confusus gullmaricus Por, 1963

- Length:width of caudal rami from 1.7 to 2.2. Female: proximal seta of P5 EXP longer than two following elements, all three outer setae noticeably shorter than innermost element. Male: P1 basis with three inner accessory spines; innermost seta of P5 EXP bifurcate .........23

23. Caudal rami with subdistal inner set of long spinules forming a comb. Female: both halves of genital double-somite without dorsolateral spinular ornamentation; setae of P6 subequal in length; with five midventral spinules on fourth urosomite. Male: genital, third and fourth urosomites without dorsolateral spinular ornamentation

T. pectinifer Lang, 1965

- Caudal rami with few subdistal inner short spinules; inner setae of P6 noticeably longer than outer ones. Female: both halves of genital double-somite with a few posterior spinules dorsolaterally; with 13 midventral spinules on fourth urosomite. Male: genital, third and fourth urosomites with few a dorsolateral spinules

T. medici sp. nov.

${ }^{1}$ The female P5 EXP was described with eight setae (Scott \& Scott 1895: pl. 15 (9)), but this is most probably erroneous.

${ }^{2}$ Two samples of T. typhlops in Lang's collection at the Museum of Natural History in Stockholm possess an inner seta on P4ENP2 and were considered as representatives of T. typhlops by Por (1963).

${ }^{3}$ After Sars (1906b).

${ }^{4}$ After Por (1963) and Chislenko (1967).

${ }^{5}$ This species is highly variable. It is highly advisable to check the available descriptions.

${ }^{6}$ See also Por (1967).

${ }^{7}$ See also Bodin (1968).

${ }^{8}$ See also Klie (1941).

\section{Discussion}

\section{Typhlamphiascus medici sp. nov.}

The highly complex taxonomy of Typhlamphiascus results from poor and incomplete original descriptions, in which the somatic spinular ornamentation was omitted and one or several appendages were not appropriately described, arguing that they resemble those of other congeners or species of somewhat related genera (for example, see Scott (1894) for T. accraensis; Thompson \& Scott (1903) for T. gracilicaudatus; Por (1968) for T. latifurca; Scott (1902) and Sars (1911) for T. confusus confusus; Por (1963) for T. c. erythraeicus). This complexity is fuelled also by the high variability of some species (see Por (1963) and Lang (1965) for a discussion of T. c. confusus, T. c. erythraeicus and T. c. gullmaricus), but also by observational misinterpretations. This has led to a failure to detect potential (aut)apomorphies for the objective definition of the genus and its species.

In the last revision of Typhlamphiascus, Por (1963) proposed to subdivide the genus into two species groups based on the inner armature complement - total number of setae/spines - on P4 ENP3. Por (1963) defined his group I by the presence of two inner setae (five elements in all) on the P4 ENP3 and his group II by the presence of one seta only (four elements in all) on the same segment. This criterion has been followed since and has proved to be useful for identification purposes. Por also suggested that this group might be characterized by the female genital somite and third urosomite being separated only laterally, but fused dorsally and ventrally. We could not find enough evidence for this, but the female genital and the third urosomites seem to be divided laterally only in T. gracilis (see Por 1963: 198; T. gracilicaudatus, see Por 1963: 199; T. bouligandi, see Soyer 1971: 275, fig. 6a; T. drachi, see Soyer 1963a: 821, fig. 1a). The condition of T. accraensis, T. blanchardi, T. capensis, T. dentipes and 
T. longifurcatus remains uncertain, and the genital and third urosomites are divided dorsolaterally in T. lutincola (see Soyer 1963b: 235, fig. 1a). As for group II, the genital and third urosomites are divided dorsolaterally in most species, but this condition is inconclusive for T. brevicornis, and they seem to be divided laterally in T. lamellifer, T. typhloides and T. typhlops. The genital and third urosomites of T. latifurca were described as separated dorsally and ventrally (see Por 1968: 40-41, pl. 3 fig. 13). This needs to be confirmed.

Also, we observed that the female P5 EXP in Por's group I can be either normal or with the tip deformed into a hook-like process, and the inner spine of the P1 basis of the males can be either a normal, unmodified spine or it can be modified into an elongate, unornamented element with blunt tip, and that the P5 EXP of the females in Por's group II is always normal and the inner spine of the P1 basis of the males is always non-modified. Also, in group I there seems to be a tendency towards the reduction of the apical setae on the female P5 endopodal lobe. This reduction is more pronounced in T. dentipes and T. blanchardi. A similar, though less pronounced tendency is observable also in T. ovale of group II.

Por's group I is currently composed of T. blanchardi, T. dentipes, T. gracilis, T. gracilicaudatus, and - probably - T. typhloides (Por 1963). Sars (1911: 391) noted that T. typhloides differs very little from T. confusus, and it most probably belongs to Por's group II. Group I also includes T. lutincola, T. drachi (Lang 1965), T. accraensis, T. l. capensis (Ma \& Li 2017) and also T. longifurcatus. Ma \& Li (2017) erroneously allocated T. longifurcatus to group II. The males of T. accraensis, T. l. capensis, T. blanchardi and T. dentipes remain unknown, but the inner spine on the male P1 basis is not modified in the males of T. gracilicaudatus, T. gracilis or T. lutincola, but T. bouligandi, T. drachi and T. longifurcatus share a potentially synapomorphic modified elongate inner spine on the P1 basis. The number of inner accessory spines (modified spinules?) on the male P1 basis is highly variable within this group. Inner accessory spines on the male $\mathrm{P} 1$ basis are absent in T. bouligandi. Typhlamphiascus lutincola and T. drachi possess three inner accessory spines, $T$. gracilicaudatus displays from three to five inner accessory spines and T. gracilis possesses from seven to eight inner accessory spines. The armature formulae of P1-P4 is constant throughout the entire group, but $T$. dentipes is unique and differs from $T$. blanchardi - with which it shares the modified inner spine on the male P1 basis - and from the rest of the species of group I in the number of inner elements on the P4 EXP3 (with three setae in T. dentipes, but with two setae in T. blanchardi and in the rest of the species of group I). The armature complement of the male and female P5 endopodal lobe is fairly constant within group I (five setae in the females except for the female of T. gracilicaudatus with four setae; two setae in the males), but the number of setae on the male and female EXP varies from four (as in the males of T. gracilicaudatus and T. bouligandi, and in the female and male of $T$. longifurcatus), to five (as in the females of $T$. gracilicaudatus and T. dentipes, and in the males and females of $T$. gracilis and T. drachi), and six (as in the females of T. accraensis, T. l. capensis and T. bouligandi, and in the male and female of T. lutincola). The supranumerary armature complements of the female P5 EXP of T. blanchardi (eight elements), as reported by Scott \& Scott (1895), is most probably erroneous. Also, the shape of the female P5 EXP is rather constant within group I and within the genus, but $T$. blanchardi and T. dentipes share having the tip of the female P5 EXP modified into a hook-like process, as well as a marked tendency towards the reduction of the apical setae of the female P5 endopodal lobe. These two characters could constitute potential synapomorphies for these two species.

Por's group II is currently composed of T. higginsi, T. brevicornis, T. c. confusus, T. c. erythraeicus, T. c. gullmaricus, T. l. lamellifer, T. latifurca, T. ovale, T. pectinifer, T. tuerkayi, T. typhloides, T. typhlops, T. unisetosus and T. medici sp. nov. Kunz (1975) described a new subspecies of T. l. lamellifer, T. l. capensis from South Africa, without any justification for attributing the latter to this species. Typhlamphiascus l. lamellifer possesses one seta only on the P4 ENP3 (Por's group II), but two setae are present on the same segment in T. l. capensis (Por's group I). The armature complement of the 
P4 ENP3 has been consistently used to separate Por's groups I and II. In our opinion, the differences between these two taxa are beyond the differences that could be expected between a nominotypical species and its subspecies, and T. l. capensis probably represents a different species. Thus, we propose to consider T. l. lamellifer and T. l. capensis as distinct species and to give the latter full species rank as T. capensis Kunz, 1975 comb. nov. The inner spine on the male P1 basis is not modified in all the species and subspecies of this group; the males of T. unisetosus and T. brevicornis remain unknown, but the number of inner accessory spines on the male P1 basis is highly variable. Typhlamphiascus lamellifer possesses two inner accessory spines; T. higginsi, T. latifurca, T. pectinifer and T. medici sp. nov. possess three inner accessory spines; from three to five inner accessory spines can be found in T. c. confusus; T. c. erythraeicus possesses four inner accessory spines; T. c. gullmaricus possesses from five to seven inner accessory spines; $T$. ovale and $T$. tuerkayi possess eight inner accessory spines. The number of inner accessory spines seems to be highly variable in T. typhlops. Sars (1906b) described four inner accessory spines on the male P1 basis of this species, but Por (1963) and Chislenko (1967) reported from seven to eight inner accessory spines. The armature complements of P1-P4 are fairly constant in the species of group II, and only three species - T. higginsi, T. unisetosus, and T. typhlops - deviate from the most common armature formulae of P1-P4 EXP/ENP (P1: 0-0-0,2,3 / 1-1-1,1,1; P2: 1-1-1,2,3/1-2-1,2,1; P3: 1-1-1,2,3/1-1-2,2,1; P4: 1-1-2,2,3/1-1-1,2,1). Typhlamphiascus typhlops seems to occupy an isolated position given the lack of inner armature on P4 ENP2 (armature formula 1-0-1,2,1). Interestingly, Por (1963) had the opportunity to inspect two samples of T. typhlops in Lang's collection and observed the presence of an inner seta on P4 ENP2. Por considered this as the true condition for the P4 ENP2 of T. typhlops. Kunz (1975) described the P4 ENP2 of T. capensis comb. nov. without inner seta, but he suggested that this seta might have become detached from the supporting segment as indicated by the interrupted cuticle in the place where the inner seta might once have been, and suggested that the lack of this seta might be of little importance. Typhlamphiascus higginsi and T. unisetosus share the reduced inner armature complement of P3 ENP3 from two to one seta. Additionally, T. higginsi is unique within the genus by its lack of inner armature on the P2-P3 EXP3. The armature complements of the female P5 EXP and endopodal lobe (six and five setae, respectively) are constant in group II, and only one species, T. tuerkayi, possesses four setae on the endopodal lobe. The armature complement of the male P5 endopodal lobe is constant throughout the genus (with two bifurcate setae); not so the armature complements of the P5 EXP, which varies from four setae in T. tuerkayi, to five elements as in T. latifurca, and six as in T. higginsi, T. c. confusus, T. lamellifer, T. ovale, T. medici sp. nov. and T. pectinifer (males of T. unisetosus and T. brevicornis unknown). Noteworthy, T. lutincola of Por's group I, and T. pectinifer and T. medici sp. nov. of group II are unique within the genus in that they share a bifurcated innermost seta on the male P5 EXP. The bifurcated innermost seta on the male P5 EXP in T. pectinifer - known from Monterrey Bay (California, USA) (Lang 1965) and Tierra del Fuego (Argentina) (Pallares 1975) - and in T. medici sp. nov., but also in T. lutincola, known from the French Mediterranean (Soyer 1963a), could constitute a potential synapomorphy for these three species.

Twenty-three nominotypical species and two subspecies - T. confusus erythraeicus and T. c. gullmaricus - are here recognised in Typhlamphiascus. Of these, six species - Stenhelia hirsuta, Typhlamphiascus accraensis, $T$. drachi, T. longifurcatus, T. lutincola and T. typhloides - are considered as incertae sedis (Lang 1948; Wells 2007). Soyer (1971) described T. bouligandi from the French Catalan coast. He described his newly found species with antennular basis, the armature of the antennal exopod as 1-1$0 ; 3 ; 0$ - second exopodal segment with one seta - and the mandibular exopod as one-segmented with one lateral and two apical setae. Similar observational mistakes appear in the original descriptions of Typhlamphiascus accraensis and T. brevicornis (with one seta on the second exopodal segment of the antenna; T. brevicornis also with one-segmented mandibular exopod with three setae). Additionally, the record of three species and subspecies - T. typhlops sensu Por (1963), T. aff. confusus confusus sensu Moore (1976), T. confusus confusus sensu Marinov \& Apostolov (1985) - and five morphospecies Typhlamphiascus sp. (Vilela 1965), Typhlamphiascus sp. ? (Bodin 1964), Typhlamphiascus sp. ? (Bodin 
1964), Typhlamphiascus sp. I (?confusus) (Marinov 1977) and Typhlamphiascus sp. II (Marinov 1977) - have been relegated to species inquirendae and have naturally been omitted from recent keys to the species of Typhlamphiascus (e.g., Wells 2007; Chullasorn 2009; Ma \& Li 2017). Only one out of the six species incertae sedis, $S$. hirsuta, has been systematically excluded from most recent keys and species lists (e.g., Wells 2007; Chullasorn 2009; Ma \& Li 2017). The exclusion of this species is obvious given the dubious and controversial original description by Thompson (1893: 194-195, pl. 31, figs 1-13) (see also Lang 1948: 712).

To the best of our knowledge, the last diagnosis of the genus Typhlamphiascus was presented by Lang (1948: 705). The genus has been defined subjectively on a combination of features and no apomorphies have been detected for the genus, nor have any synapomorphy been found to unite all its species objectively, and the relationships between the species of Typhlamphiascus have been based on morphological similarities only.

Chullasorn (2009: 506) gave a list of autapomorphies for T. higginsi. These are: (i) male P1 basis with three inner accessory spines, (ii) reduced number of setae/spines on P3 ENP3 from five to four, (iii) reduced number of setae/spines on P4 ENP3 from five to four, (iv) P1 EXP1 reaching tip of ENP2, (v) caudal rami two times as long as wide, (vi) seven minute spinules on each side of the female genital somite, (v) fourth and fifth female urosomites with posterior spinular row ventrally and (vi) caudal rami twice as long as wide, with two small spinules at the base of caudal seta VII. In our opinion, these are not true autapomorphies for T. higginsi, since all of them are shared by one or more species within the genus. For example, the presence of three inner accessory spines on the male P1 basis is shared by a larger set of species (T. gracilicaudatus, T. lutincola, T. drachi, T. c. confusus, T. latifurca, T. pectinifer and T. medici sp. nov.), the reduced number of setae/spines on P3 ENP3 from five to four is also present in T. unisetosus and the reduced number of setae/spines on P4 ENP3 from five to four is present in all the species of Por's group II. The only potential (aut)apomorphy that we could detect for T. higginsi is the loss of the inner armature on P2-P3 EXP3. In her description of the maxilliped of T. higginsi, Chullasorn (2009) confused the basis with the syncoxa, a first endopodal segment with the basis, and a second endopodal segment with the one-segmented endopod. She also reversed P1 and P2, as well as P3 and P4 in her figures (Chullasorn 2009: 498, fig.3 and 499, fig. 4, respectively). Also, her figures of the ventral and dorsal views of the urosome of T. higginsi (Chullasorn 2009: 500, fig. 5a-b) are reversed, and so are the male maxilliped and maxilla (Chullasorn 2009: 502, fig. 7).

In their description of Typhlamphiascus tuerkayi, $\mathrm{Ma} \& \mathrm{Li}$ (2017) suggested a close relationship between their species and both $T$. ovale and T. higginsi based on (i) the presence of ventral hyaline frills on the posterior edge of the posterior half of the genital double-somite, and fourth and fifth urosomites, (ii) presence of one inner seta on P1-P4 EXP2, (iii) presence of an inner seta on P2-P4 EXP1, (iv) presence of one inner seta on P1-P4 ENP1, (v) P1 ENP3 with three setae, (vi) female P2 ENP2 with two inner setae, (vii) female P5 EXP with six setae and (viii) endopodal lobe of the male P5 with two bifid elements. However, all these features are common to the whole genus and are not indicative of a close relationship between T. tuerkayi on one hand and T. ovale and T. higginsi on the other. Also, Ma \& Li (2017) described the mandibular endopod as two-segmented - first segment with one, second segment with two setae - but on their figure (Ma \& Li 2017: 994, fig. 2d) the mandibular exopod appears as one-segmented with two setae.

Briefly, given the complex taxonomy of the genus and the lack of potential (syn)apomorphies, any hypothesis on the phylogenetic relationships of the species of Typhlamphiascus is at this moment futile and an in-depth revision of the genus is needed. At this point it seems that (i) Por's criterion (Por 1963) to subdivide the genus into two species groups on the armature complement of the P4 ENP3 is probably useful for identification purposes only, (ii) that some species seem to be related by the shape 
of the female P5 EXP and shape of the apical elements on the female P5 endopodal lobe (T. blanchardi and $T$. dentipes), the sexually dimorphic inner spine of the male P1 basis (T. bouligandi, $T$. drachi and T. longifurcatus), the presence of a bifurcated inner element on the male P5 EXP (T. lutincola, T. pectinifer and T. medici sp. nov.) and the reduced armature of the P3 ENP3 from five to four (T. higginsi and T. unisetosus) and (iii) that the only species with a potential (aut)apomorphy (without inner armature on P2 EXP3) is T. higginsi (see Tables 1-2).

Typhlamphiascus medici sp. nov. belongs to Por's group II. The new species proposed herein share the armature complements of the female P1-P5 with all species of group II except for T. typhlops (without inner seta on P4 ENP2; but see above), T. unisetosus (with only one inner seta on P3 ENP3), T higginsi (with only one inner seta on P3 ENP3 and without inner armature on P2-P3 EXP3) and T. tuerkayi (with only four setae on the P5 endopodal lobe). The males of T. unisetosus and T. brevicornis remain unknown and the males of some other species have been described incompletely. The male antennules of the species for which these appendages have been described have been shown to be nine-segmented, and only $T$ higginsi and $T$. medici sp. nov. were described with eight- and ten-segmented male antennules, respectively. The nine-segmented condition of the male antennule in $T$. ovale, T. pectinifer and T. tuerkayi is most probably the result of a failure to detect the separate third and fourth segments which are common in podogennontan harpacticoids (Willen 2000). Similarly, the eight-segmented condition of the male antennule of $T$. higginsi is most probably the result of a failure to detect the separated third and fourth segments, but also the sixth segment. The latter seems to be incorporated into the fifth segment in Chullasorn (2009: 502, fig. 7a) and requires confirmation. In our opinion it is highly probable that all species of Typhlamphiascus possess ten-segmented male antennules, as shown for T. medici sp. nov. The setation pattern of the male P5 endopodal lobe with two bifurcate setae is constant throughout the genus and group II; not so the armature complements of the exopod which varies in group II from four (T. tuerkayi) to five (T. latifurca) and six setae (T. higginsi, T. confusus, T. lamellifer, T. ovale, T, pectinifer, T. medici sp. nov. and T. typhlops). As noted above, T. pectinifer, T. medici sp. nov. and T. lutincola share the bifurcated innermost seta of the male P5 EXP. The number of inner accessory spines on the male $\mathrm{P} 1$ basis is variable in T. c. confusus (from three to five), T. c. gullmaricus (from five to seven) and T. typhlops (four inner accessory spines were observed by Sars 1906a, but from seven to eight by Por 1963 and Chislenko 1967). Four inner accessory spines have been reported in T. c. erythraeicus, and only two were observed in T. lamellifer. Typhlamphiascus medici sp. nov., T. higginsi, T. latifurca and T. pectinifer share the presence of three inner accessory spines on the male P1 basis. Typhlamphiascus medici sp. nov. is more similar to and probably bears a close relationship with $T$. pectinifer and T. lutincola, as suggested by the bifurcated condition of the inner distal bifurcate seta on the male P5 EXP. Besides the armature complement of P1-P5, the male armature complements of the male P5 and the bifurcate inner seta on the P5 male EXP, T. pectinifer and T. medici sp. nov. are unique also in the combination of having three inner accessory spines on the male P1 basis and six setae on the male P5 EXP. The Mexican material could be attributed to a new subspecies of T. pectinifer. Besides the features shared by these two species, this reasoning might find support also in their distribution. Typhlamphiascus pectinifer was described from Monterey Bay, central California, USA, about 2000 $\mathrm{km}$ from the type locality of T. medici sp. nov. in the mouth of the Gulf of California. Typhlamphiascus pectinifer was also reported from Tierra del Fuego, Argentina (Pallares 1975). Pallares' material fits Lang's description (Lang 1965), including the ventral spinular ornamentation of the last urosomites, but a more detailed examination of the South American population would be necessary to confirm its identity. A scenario where the original population from the Central Eastern Pacific split and gave birth to two different species through vicariance is feasible. The latter view is grounded in some differences to support the presence of two related species. These are: (i) subdistal inner ornamentation of caudal rami (with a row of spinules forming a comb in T. pectinifer, but with very few spinules in the Mexican species), (ii) dorsolateral spinular ornamentation of both halves of the genital double-somite, and fourth urosomite in the female, and of the genital, third and fourth urosomites in the male (without dorsolateral 
spinular ornamentation in T. pectinifer, but with some spinules in T. medici sp. nov.), (iii) relative length of the caudal setae (comparatively shorter in T. pectinifer), (iv) relative length of the two innermost setae of the female P6 (visibly longer in the Mexican material), (v) number of midventral spinules on the female fourth urosomite (with five spinules in Lang's species, but with 13 spinules in T. medici sp. nov.), (vi) number of midventral spinules on the female and male fifth urosomite (a continuous row of spinules in $T$. pectinifer, but with only six spinules in $T$. medici sp. nov.), (vii) relative length of the outer proximal seta of the female P5 EXP (relatively longer in the new species), (viii) relative length of the inner setae on the female P2 ENP2 (short and subequal in length in T. pectinifer, but subdistal seta visibly longer than proximal element in the Mexican species), (ix) relative length of the inner setae on the male P2 ENP2 (visibly shorter in T. pectinifer) and (x) probably the shape of the innermost element of the male P6 (seemingly setiform in T. pectinifer, but spiniform in the new species). The two large tube pores observed in the first and second antennulary segments in females and males of the new species have not been observed before. The presence of this pair of tube pores is deemed to be a potential apomorphy for the species, but its absence in other species still needs confirmation.

Our analyses showed Typhlamphiascus as the first offshoot of the Typhlamphiascus-Spinodiosaccus gen. nov. monophylum, before the acquisition of characters 24 and 26 (P2 and P3 EXP3 with short distal seta on the inner margin) which support the monophylum Monardius-Spinodiosaccus gen. nov.

\section{Phylogenetic position of Dinetia gen. nov., Pallarica gen. nov., Spinopedia gen. nov., Spinodiosaccus gen. nov. and Bulbamphiascus}

The complete clarification of the phylogenetic affinities within the Diosaccinae is far beyond the scope of this study. A more exhaustive analysis of a more complete data set including more characters (i.e., structure and setation of mouth parts, armature number and shape of swimming legs, homology of the inner armature of the male P1 basis and of the male P2 ENP) and as many species as possible would be necessary. Instead, our main objective was to test the monophyletic status of the genus Bulbamphiascus as defined by Mu \& Gee (2000). To accomplish this, and considering the high level of character convergence within the Diosaccinae (which probably fostered the establishment of nonmonophyletic genera based solely on the setal formulae of P1-P5), we included species of all genera, but restricted our analyses to the type species of the non-monophyletic genera. Our results on the phylogeny within the Diosaccinae are preliminary - its phylogeny is not fully resolved - but they reflect the phylogenetic relationships between Bulbamphiascus and the newly proposed genera. Given the preliminary nature of our results, the characters considered will not be discussed in detail. Instead, we will focus on the characters that contribute to the monophyletic status of i) a clade composed of Dinetia gen. nov., Pseudamphiascopsis and Rhyncholagena and ii) a clade composed of Pallarica gen. nov., Spinopedia gen. nov., Bulbamphiascus and Spinodiosaccus gen. nov.

The genus Bulbamphiascus was originally proposed by Lang (1944) and was defined as different from Amphiascus and other diosaccin genera primarily on the structure of the PI endopod, the setal formula of P2-P5, and the usually bulbous shape of the distal outer seta on the P5 EXP (Mu \& Gee 2000). They (Mu \& Gee 2000) gave a brief historical account of the genus and offered an amended diagnosis, in which they included some characters that we consider important synapomorphies for a more inclusive group of genera related to Bulbamphiascus, i.e., distal inner seta of P2-P4 EXP3 weakly developed (characters 24, 26, 28 in the present study; Table 3, Fig. 19), and P5 with medial and distal outer spines - sometimes - swollen at its base (or short and blunt) (characters 38 and 39 in the present study; Table 3, Fig. 19). Character 28 is a unique synapomorphy for a monophyletic clade represented by Robertsonia, Amphiascus, Pararobertsonia, Sinamphiascus, Pallarica gen. nov., Spinopedia gen. nov., Bulbamphiascus and Spinodiosaccus gen. nov. Characters 24 and 26 (see Table 3, Fig. 19) place Monardius and Tydemanella as the sister group of a clade supported by character 28 which seems to have appeared convergently also in Sarsamphiascus, the latter with an uncertain phylogenetic affinity 
with other groups. The original description of the type of Sarsamphiascus, S. minutus (Claus, 1863), is too incomplete, and Sars (1906a) omitted the P3. The male P2 ENP2 of S. minutus as illustrated by Sars (1906a: pl. 96) resembles that of Pallarica gen. nov. and Spinopedia gen. nov. in that the inner subdistal spine is blunt and only slightly sigmoid, and the outer subdistal spine is blunt and tapers slightly distally.

The diagnosis of Bulbamphiascus by $\mathrm{Mu} \&$ Gee (2000) and our own results indicate that the medial and subdistal outer elements of the female and male P5 EXP being reduced to short and basally bulbous elements is the only potential autapomorphy for the genus. This assumption lead to an alternative scenario where the new species attributed here to Spinodiosaccus gen. nov. would actually be a derived form of Bulbamphiascus, and the loss of the inner seta of P1 EXP2 and the inner seta of P2-P4 EXP1 should be interpreted as a secondary loss. However, in light of current research and upon re-diagnosis of Bulbamphiascus, the morphological homogeneity within this genus points towards a scenario in which Spinodiosaccus gen. nov. appears as an early offshoot of the Bulbamphiascus-Spinodiosaccus lineage. On the other hand, given the poor and sketchy descriptions of most species, it is difficult to detect any autapomorphy for Bulbamphiascus. Although we have not coded any character for the male P2 ENP2, the combination of the outer subdistal tapering spine and the inner subdistal sigmoid element in the male P2 ENP2 in Bulbamphiascus is regarded here as a potential apomorphy for that genus. Following this line of reasoning, Spinodiosaccus gen. nov. is defined by the presence of six autapomorphic character states: i) male antennule 11-segmented (character 2 in Table 3 , Fig. 19), a unique reversion within the Diosaccinae, ii) loss of the inner seta of P1 EXP2 (character 6 in Table 3, Fig. 19), iii) loss of the inner seta of P2 EXP1 (character 14 in Table 3, Fig. 19), iv) loss of the inner seta of P3 EXP1 (character 15 in Table 2, Fig. 19), v) loss of the inner seta of P4 EXP1 (character 16 in Table 3, Fig. 19) and vi) absence of an anterior tube pore on the male P3 EXP3 (character 31 in Table 3, Fig.19). Also, character 28 (presence of a short distal inner seta on P4 EXP3) is a potential synapomorphy for, at least, Amphiascus, Pararobertsonia, Sinamphiascus, Pallarica gen. nov., Spinopedia gen. nov., Bulbamphiascus and Spinodiosaccus gen nov. Characters 14-16 appeared convergently within the monophyletic clade Amonardia-Psammotopa (see Fig. 19). Similarly, character 6 appeared convergently in the sub-clade Pholenota-Psammotpoa and in the clade Antiboreodiosaccus-Pseudodiosaccus. The anterior tube pore on the male P3 EXP3 occurs convergently in many different genera within Diosaccinae, namely Amphiascus, Amphiascoides, Bulbamphiascus (Mu \& Gee 2000), Haloschizopera (Gee \& Fleeger 1990), Paramphiascella, Robertgurneya, Rhyncholagena, Sinamphiascus (Nam \& Lee 2012), Spinopedia gen. nov. and Typhlamphiascus. The condition within Robertsonia, Pararobertsonia and Pallarica gen. nov. must be re-investigated, since such structures as tube pores were frequently neglected in older descriptions.

Interestingly, the largest monophylum in which Bulbamphiascus and allied genera are included is supported only in the total consensus cladogram by the reversion of character 12 (see Table 3) - P1 ENP1 shorter or slightly longer than EXP. The plesiomorphic condition where the P1 EXP is considerably shorter than ENP1 is shared in all remaining genera of Diosaccinae. In the total consensus cladogram, the reversion of character 12 also appears as an independent evolution in the clade AntiboreodiosaccusPseudodiosaccus, which is also characterised by the reversion of characters 41 and 43, which also supports the monophyletic status of the clade Amonardia-Psammotopa. This clearly separates these monophyletic clades from the large monophylum containing Typhlamphiascus-Spinodiosaccus gen. nov. However, Antiboreodiosaccus-Pseudodiosaccus does not appear as closely related to AmonardiaPsammotopa in any of the 12 most parsimonious trees (see Supplementary File 1). This renders the synapomorphic condition of character 12 but also of characters 41 and 43 unclear, and the topology and optimization in Fig. 19 would be an artefact of the total consensus algorithm.

Bulbamphiascus cibimae is unique within the Diosaccinae by the male P5 EXP having seven setae (character 35 in Table 3 ). The medial and subdistal outer elements of the male P5 EXP of B. cibimae 
display some degree of reduction in size but are not spine-like blunt and are not swollen basally as in other species of the genus. This justifies the exclusion of B. cibimae from Bulbamphiascus and its reallocation in a new genus, Pallarica gen. nov. as $P$. cibimae comb. nov., also characterized by the apomorphic reduction in length of the medial and subdistal seta of the male P5 EXP. On the other hand, the reduced medial and subdistal outer spines of the male P5 EXP is regarded here as synapomorphic for Pallarica gen. nov., Spinopedia gen. nov., Bulbamphiascus and Spinodiosaccus gen. nov. These four genera also share the same morphology of the armature of the A2 EXP3, i.e., with one distal seta, one spine and a longer spiniform element (character 3 in Table 3 ). Character 3 is also shared with Sinamphiascus and indicates that this genus should be included in this clade as the most basal taxon. The male P2 ENP2 is very similar in Pallarica gen. nov. and Spinopedia gen. nov.

The establishment of Spinopedia gen. nov. is clearly supported by the spinular ornamentation on the male P2 ENP1 and ENP2. In addition, the second inner seta from inner to outer margin of the female P5 EXP does not arise from a setophore but inserts directly on the inner edge of the ramus. Spinopedia gen. nov. bears a sister-group relationship with Bulbamphiascus and Spinodiosaccus gen. nov., as indicated by the reduction of the subdistal outer element of the male P5 EXP into a short, bare spine-like element, but Spinodiosaccus gen. nov. differs from Bulbamphiascus and Spinopedia gen. nov. in the well-developed subdistal outer seta of the female P5 EXP.

Among all the genera proposed here, Dinetia gen. nov. is the only one that does not belong to the same larger monophyletic clade Pallarica-Spinodiosaccus. Dinetia gen. nov. cannot be included within any of the remaining clades either. In fact, it seems closely related to Pseudamphiascopsis and Rhyncholagena, with uncertain phylogenetic affinities with the remaining monophyla. The male of Dinetia gen. nov. remains unknown and the supposed apomorphic status of character 43 (see Table 3 ) for this genus - which was coded as '?' - is rather the result of the program's algorithm used in this study for the phylogenetic analysis. The same happens for the supposed synapomorphic status of character 34 - male P5 EXP with five spines - for Dinetia gen. nov., Pseudamphiascopsis and Rhyncholagena, and character 11 - P1 ENP3 elongate, at least 1.5 times as long as ENP2 - is the only synapomorphy for this group of genera. However, it is not clear whether the Dinetia-Rhyncholagena clade is a true monophyletic clade or if these genera are clumped together by convergent characters. Bulbamphiascus minutus, the type species of Dinetia gen. nov., does not share important diagnostic characters with Bulbamphiascus, e.g., presence of a short inner distal seta on P2-P4 EXP3, and cannot be included in the latter. Dinet (1971) expressed some doubts about the membership of B. minutus in that genus and suggested some affinities with Typhlamphiascus. He placed his newly described species in Bulbamphiascus based on superficial similarities of the P5 and relative length of the caudal rami, and the general shape of the antennule, antenna and maxilliped. However, as recognized by Dinet (1971), B. minutus lacks the bulbous setae on the female P5 EXP. Also, the general shape of the female antennule is common to the Diosaccinae, Dinet's descriptions of the mouth parts are too sketchy to allow further comparisons (see Dinet 1971), and the caudal rami of B. minutus are longer than in other species of Bulbamphiascus except for B. chappuisi, which is relegated here as species incertae sedis, and taper distally.

Our results show that most genera are arranged into three large monophyletic groups-AntiboreodiosaccusPseudodiosaccus, Typhlamphiascus-Spinodiosaccus and Amonardia-Psammotopa - the remaining groups being less speciose and of unclear phylogenetic affinities. The Amonardia-Psammotopa clade can easily be identified by the male P5 EXP having four or five setae (but three in Psammotopa). The remaining characters showed reversal along the topology in an almost haphazard manner. The TyphlamphiascusSpinodiosaccus clade can easily be characterized by having the P1 ENP1 at most slightly longer than EXP (character 12); this character seems to have evolved convergently in the AntiboreodiosaccusPseudodiosaccus clade as well as in Balucopsylla-Helmutkunzia, Protopsammotopa, but also in Psammotopa. The Typhlamphiascus-Spinodiosaccus clade is also characterized by the presence of a 
Table 5. Mean density values (ind. $10 \mathrm{~cm}^{-2}$ ) of $T$. medici sp. nov. and $S$. primus gen. et sp. nov. at the sampling stations along the Urías system recorded on 18 Jan. 2019. See also Gómez (2020a: 43, fig. 1).

\begin{tabular}{lllllllllll}
\hline & Stn 1 & Stn 2 & Stn 3 & Stn 4 & Stn 5 & Stn 6 & Stn 7 & Stn 8 & Stn 9 & Stn 10 \\
\hline T. medici sp. nov. & 0 & 5.96 & 0 & 0.68 & 1.36 & 1.21 & 0 & 0 & 0 & 0.68 \\
S. primus gen. et sp. nov. & 0 & 5.15 & 0 & 0.67 & 3.66 & 1.36 & 0 & 0 & 1.49 & 0.27 \\
\hline
\end{tabular}

middle inner seta of the female P5 EXP issuing from a setophore (character 42 in Table 3 ); this character evolved independently in Paramphiascella, Robertgurneya, Schizoperoides, Pseudamphiascopsis and Rhyncholagena. Interestingly, the clade Monardius-Spinodiosaccus is unique in the - synapomorphicpresence of a short distal inner seta on the P2-P3 EXP3.

Although not recovered in our analyses, the Antiboreodiosaccus-Pseudodiosaccus clade could be basal to the Amonardia-Psammotopa clade. These two clades share character 43 (the middle - or the third seta from inner to outer margin - of the female P5 EXP not issuing from a setophore and arising directly from the ramus; a character reversion within the Diosaccinae). The loss of the inner armature of the P1 EXP2 (character 6 in Table 3) in the Antiboreodiosaccus-Pseudodiosaccus clade and at the base of the Amonardia-Psammotopa clade (in Pholenota-Psammotopa) is a potential piece of evidence for merging them.

Briefly, our preliminary data support the split of Bulbamphiascus into different genera, clearly showing that Dinetia gen. nov. does not belong to the Typhlamphiascus-Spinodiosaccus monophyletic clade. Our data also show that the Diosaccinae are divided into at least two large monophyletic units, but more work is needed to prove the monophyly of several genera and their phylogenetic relationships.
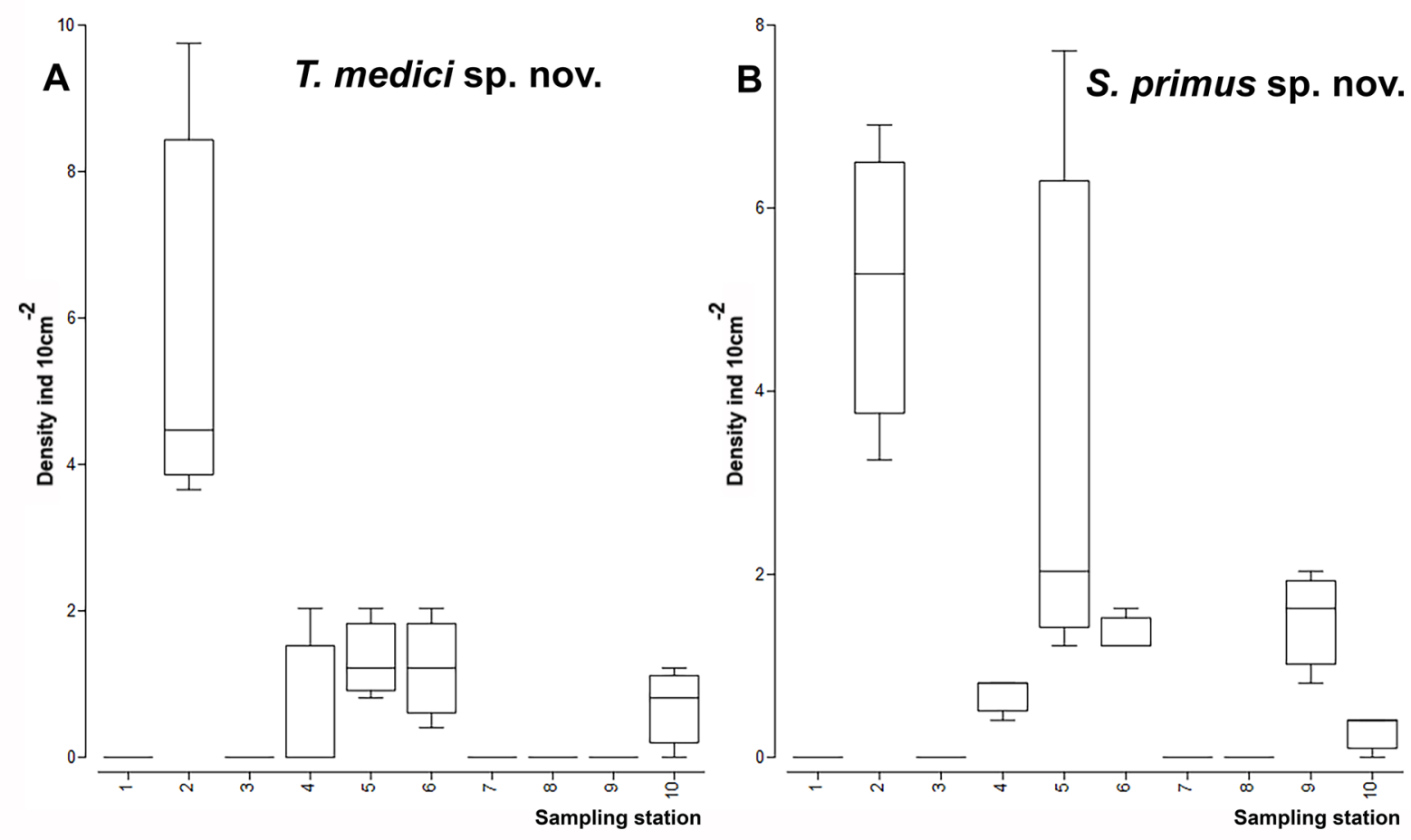

Fig. 20. Mean density values (ind. $10 \mathrm{~cm}^{-2}$ ) of $T$. medici sp. nov. and $S$. primus gen. et sp. nov. recorded on 18 Jan. 2019 at the sampling stations along the Urías system. See also Gómez (2020a: 43, fig. 1). A. T. medici sp. nov. B. S. primus gen. et sp. nov. 
GÓMEZ S. et al., On new genera and species of Harpacticoida

Table 6. Environmental variables at each sampling station along the Urías system recorded on 18 Jan. 2019. See also Gómez (2020a: 43, fig. 1).

\begin{tabular}{ccccccccc}
\hline Station & $\begin{array}{c}\text { Depth } \\
(\mathrm{m})\end{array}$ & $\begin{array}{c}\text { Salinity } \\
(\mathrm{ups})\end{array}$ & $\begin{array}{c}\text { Temperature } \\
\left({ }^{\circ} \mathrm{C}\right)\end{array}$ & $\begin{array}{c}\text { Dissolved oxygen } \\
\left(\mathrm{mg} \mathrm{L}^{-1}\right)\end{array}$ & $\begin{array}{c}\text { Organic matter } \\
(\%)\end{array}$ & $\begin{array}{c}\text { Sand } \\
(\%)\end{array}$ & Silt (\%) & Clay $(\%)$ \\
\hline 1 & 1.5 & 38.9 & 22.9 & 4.18 & 6.43 & 25.31 & 38.94 & 35.75 \\
2 & 1.8 & 38.6 & 23.2 & 4.48 & 6.86 & 80.42 & 11.28 & 8.29 \\
3 & 2.2 & 37.4 & 23.9 & 3.52 & 5.69 & 60.66 & 25.91 & 13.42 \\
4 & 0.7 & 37.4 & 24.2 & 4.7 & 1.94 & 82.44 & 9.29 & 8.27 \\
5 & 0.6 & 37.5 & 26.8 & 5.44 & 1.71 & 78.61 & 14.67 & 6.72 \\
6 & 1.4 & 36.8 & 25 & 3.78 & 2.84 & 61.44 & 23.99 & 14.57 \\
7 & 3.7 & 36.2 & 24.8 & 2.21 & 9.62 & 10.78 & 51.68 & 37.54 \\
8 & 4 & 36.2 & 24.7 & 2.43 & 8.05 & 7.04 & 64.18 & 28.78 \\
9 & 5.4 & 35.9 & 24.4 & 3.1 & 2.43 & 64.81 & 27.11 & 8.09 \\
10 & 6 & 35.9 & 24.1 & 2.82 & 2.07 & 69.12 & 22.97 & 7.91 \\
\hline
\end{tabular}

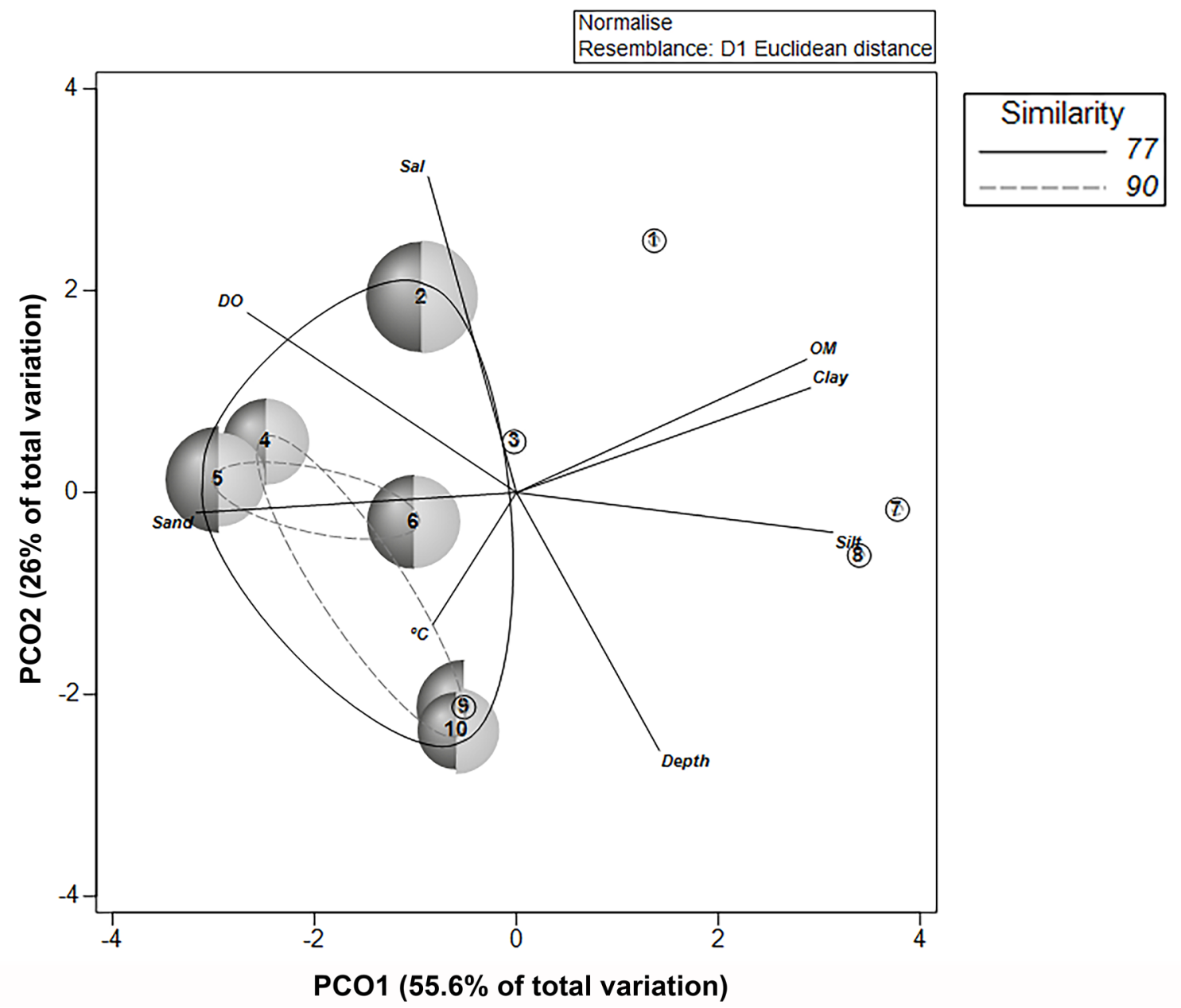

Fig. 21. Principal coordinates analysis between environmental variables $(\mathrm{DO}=$ dissolved oxygen; $\mathrm{Sal}=$ salinity; $\mathrm{OM}=$ organic matter content; temperature in ${ }^{\circ} \mathrm{C}$; depth in $\mathrm{m}$; grain size: sand, silt, clay), and mean density of $T$. medici sp. nov. (light grey semicircles) and $S$. primus gen. et sp. nov. (dark grey semicircles) at the sampling stations (Arabic numerals) along the Urías system. 
Table 7. Spearman's correlation coefficient between density of Typhlamphiascus medici sp. nov. and environmental variables. $\mathrm{Sal}=$ salinity $;{ }^{\circ} \mathrm{C}=$ temperature; $\mathrm{DO}=$ dissolved oxygen; $\mathrm{OM}=$ organic matter content.

\begin{tabular}{ccccccccc}
\hline & Density & Depth & Sal & ${ }^{\circ} \mathrm{C}$ & DO & OM & Sand & Silt \\
\hline Depth & -0.513 & & & & & & & \\
Sal & 0.347 & -0.752 & & & & & & \\
${ }^{\circ} \mathrm{C}$ & 0.169 & -0.212 & -0.367 & & & & & \\
DO & 0.655 & -0.842 & 0.752 & -0.091 & & & & \\
OM & -0.428 & 0.358 & 0.018 & -0.212 & -0.588 & & & \\
Sand & 0.753 & -0.394 & 0.226 & -0.091 & 0.721 & -0.709 & & \\
Silt & -0.817 & 0.503 & -0.330 & 0.091 & -0.758 & 0.673 & -0.964 & \\
Clay & -0.525 & 0.067 & 0.135 & -0.127 & -0.455 & 0.855 & -0.770 & 0.685 \\
\hline
\end{tabular}

\section{Ecology}

Typhlamphiascus medici sp. nov. and S. primus gen. et sp. nov. were present at sampling stations 2, 4, 5, 7 and 10, and S. primus gen. et sp. nov. was also recorded at station 9 (Table 5, Fig. 20). Spearman's correlation coefficient $(\mathrm{p} \leq 0.05)$ revealed a strong positive correlation between the density of both T. medici sp. nov. and S. primus gen. et sp. nov., and sand and dissolved oxygen (see also Table 6 for environmental variables). Similarly, Spearman's correlation coefficient showed a strong negative correlation between the density of these two species and silt and clay contents (Tables 7-8).

The non-parametric analysis of variance revealed statistical differences $(F=5.09, p<0.05)$ in the density values of $T$. medici sp. nov. and $S$. primus gen. et sp. nov. between stations along the Urías system.

The PCoA (Fig. 21) showed that principal component 1 (PCO1) accounts for $55.6 \%$ of total variation and principal component 2 (PCO2) explains $26 \%$ of total variation. Stations 1,7 and 8 with silty sediments and station 3 with comparatively coarser sediments are considered as atypical due to the absence of both T. medici sp. nov. and S. primus gen. et sp. nov. Stations 2, 4, 5, 6 and 10 are $77 \%$ similar in terms of mean density of both species, and station 9 is excluded from this group due to the absence of T. medici sp. nov. Stations 5 and 6 are $90 \%$ similar, as are stations 4 and 10 in terms of mean density of both species. Station 2 seems to be different from all the other stations where T. medici $i$ sp. nov. and S. primus gen. et sp. nov. were found. On the other hand, higher mean density values of $T$. medici sp. nov. and S. primus gen. et sp. nov. were recorded at stations characterized by well-oxygenated sandy sediments at the shallower upper and middle-upper region of the Urías system with comparatively higher salinity values (stations 2, 5, 4 and 6). Comparatively lower mean density values of these two species were recorded at the comparatively deeper station 10 with sandy sediments, where a comparatively lower salinity and dissolved oxygen values were also observed. Typhlamphiascus medici sp. nov. was not found at station 9 , where only S. primus gen. et sp. nov. was present. See Gómez (2020a: 43, fig. 1) for a map with the location of the sampling stations.

Briefly, grain size and dissolved oxygen content are the main proxies for the distribution of T. medici sp. nov. and $S$. primus gen. et sp. nov. in the Urías system. High levels of organic matter content and low levels of dissolved oxygen are commonly associated with muddy sediments and are likely important factors for the distribution of these two species. Morales-Serna et al. (2006) showed similar results in their study on the spatial and temporal variation of species richness of benthic copepods from the same area. The analysis of the distribution of these two species and of the rest of the harpacticoids collected 
GÓMEZ S. et al., On new genera and species of Harpacticoida

Table 8. Spearman's correlation coefficient between density of Spinodiosaccus primus gen. et sp. nov. and environmental variables. $\mathrm{Sal}=$ salinity; ${ }^{\circ} \mathrm{C}=$ temperature; $\mathrm{DO}=$ dissolved oxygen; $\mathrm{OM}=$ organic matter content.

\begin{tabular}{ccccccccc}
\hline & Density & Depth & Sal & ${ }^{\circ} \mathrm{C}$ & DO & OM & Sand & Silt \\
\hline Depth & -0.325 & & & & & & & \\
Sal & 0.148 & -0.752 & & & & & & \\
${ }^{\circ} \mathrm{C}$ & 0.200 & -0.212 & -0.367 & & & & & \\
DO & 0.600 & -0.842 & 0.752 & -0.091 & & & & \\
OM & -0.494 & 0.358 & 0.018 & -0.212 & -0.588 & & & \\
Sand & 0.782 & -0.394 & 0.226 & -0.091 & 0.721 & -0.709 & & \\
Silt & -0.700 & 0.503 & -0.330 & 0.091 & -0.758 & 0.673 & -0.964 & \\
Clay & -0.700 & 0.503 & -0.330 & 0.091 & -0.758 & 0.673 & -0.964 & 1.000 \\
\hline
\end{tabular}

during four sampling campaigns in the year 2019 is still pending, but a similar trend is expected at least for other genera of the family Miraciidae.

\section{Acknowledgements}

We are deeply indebted to Abraham Guerrero Ruíz (Centro de Investigación en Alimentación y Desarrollo, Unidad Mazatlán) and to Sergio Rendón Rodríguez (Instituto de Ciencias del Mar y Limnología, Unidad Académica Mazatlán) for their help during the sampling campaigns. We also thank Nataly Ortíz Gálvez and Ángel A. Valenzuela Cruz for their help during the sampling campaigns and for processing the sediment samples. This is a contribution to project IN202019, Biodiversidad de la meiofauna en un ecosistema costero contaminado del sur de Sinaloa: un enfoque integrativo de técnicas taxonómicas clásicas y moleculares, financed by the Programa de Apoyo a Proyectos de Investigación e Innovación Tecnológica (DGAPA-PAPIIT) of the Universidad Nacional Autónoma de México.

\section{References}

Ax P. 1984. Das Phylogenetische System. Systematisierung der lebenden Natur aufgrund ihrer Phylogenese. Gustav Fischer Verlag, Stuttgart.

Bodin P. 1964. Recherches sur la systématique et la distribution des Copépodes Harpacticoïdes des substrats meubles des environs de Marseille. Recueil des Travaux de la Station Marine d'Endoume 51 (35): 107-183.

Bodin P. 1968. Copépodes Harpacticoïdes des étages bathyal et abyssal du Golfe de Gascogne. Mémoires du Muséum national d'Histoire naturelle 55 (1): 1-107.

Brady G.S. 1905. On Copepoda and other Crustacea taken off Northumberland and Durham in July, 1904. Natural History Transactions of Northumberland, New Series 1: 210-223.

Burgess R. 2001. An improved protocol for separating meiofauna from sediments using colloidal silica sols. Marine Ecology Progress Series 214: 161-165. https://doi.org/10.3354/meps214161

Chislenko L.L. 1967. Garpaktitsidy (Copepoda Harpacticoida) Karelskogo poberezh'ya Belogo Morya. [Copepoda Harpacticoida of the Karelian coast of the White Sea.] In: Gidrobiologicheskaya Issledovaniya na Karel'skom Poberezh'e Belogo Morya. [Hydrobiological Research of the Karelian Coast of the White Sea.] Issledovaniya Fauny Morei [Explorations of the Fauna of the Seas] 7 (15): 48-196. Academy of Sciences of the USSR, Leningrad. 
Chullasorn S. 2009. A review of Typhlamphiascus Lang, 1944 (Copepoda: Harpacticoida: Miraciidae) with a new species Typhlamphiascus higginsi from Phuket Island, Thailand. Zoological Studies 48 (4): 493-507.

Clarke K. \& Gorley R. 2015. PRIMER version 7: User manual/tutorial. PRIMER-E Ltd, Plymouth.

Dinet A. 1971. Copépodes harpacticoïdes d'un sable fin organogène des environs de Marseille. Tethys 2 (3): 747-762.

Gee J.M. \& Fleeger J.W. 1990. Haloschizopera apprisea, a new species of harpacticoid copepod from Alaska, and some observations of sexual dimorphism in the family Diosaccidae. Transactions of the American Microscopical Society 109 (3): 282-299.

Goloboff P.A. 1999. Nona: a tree searching program. Program and documentation. Version 2.0.

Gómez S. 2020a. On some new species of Stenheliinae Brady, 1880 (Copepoda: Harpacticoida: Miraciidae) from north-western Mexico, with the proposal of Lonchoeidestenhelia gen. nov. ZooKeys 987: 41-79. https://doi.org/10.3897/zookeys.987.52906

Gómez S. 2020b. A new species of Robertgurneya Apostolov \& Marinov, 1988, with an illustrated record of $R$. rostrata (Gurney, 1927), an amended genus diagnosis and comments on $R$. soyeri (Apostolov, 1974) and R. spinulosa (Sars, 1911) (Harpacticoida: Miraciidae). Zootaxa 4861 (4): 451-485. https://doi.org/10.11646/zootaxa.4861.4.1

Hennig W. 1966. Phylogenetic Systematics. University of Illinois Press, Urbana, IL.

Huys R. \& Boxshall G.A. 1991. Copepod Evolution. The Ray Society, London.

Klie W. 1941. Marine Harpacticoiden von Island. Kieler Meeresforschungen 5 (1): 1-44.

Kunz H. 1975. Copepoda Harpacticoidea aus dem Litoral des südlichen Afrika. I. Teil. Kieler Meeresforschungen, Sonderheft 31: 179-212.

Lang K. 1944. Monographie der Harpacticiden (vorläufige Mitteilung). Almqvist \& Wiksells Boktryckeri AB, Uppsala, Sweden.

Lang K. 1948. Monographie der Harpacticiden, Volumes I and II. Nordiska Bokhandeln, Stockholm.

Lang K. 1965. Copepoda Harpacticoidea from the Californian Pacific coast. Kungliga Svenska Vetenskapsakademiens Handlingar, Series 410 (2): 1-560.

Ma L. \& Li X. 2017. A new species of the genus Typhlamphiascus (Copepoda, Harpacticoida, Miraciidae) from the South China Sea. Crustaceana 90 (7-10): 989-1004.

https://doi.org/10.1163/15685403-00003679

Marinov T. 1977. Harpacticoida from the Eastern Central Atlantic Coast. Izvestiya na Instituta Okeanografiya i Ribno Stopanstvo, Varna 15: 83-98.

Marinov T. \& Apostolov A. 1985. Copépodes harpacticoïdes de l'Océan Atlantique. 1. Espèces des cotes du Sahara espagnol. Cahiers de Biologie marine 26: 165-180.

Moore C.G. 1976. The harpacticoid families Ectinosomatidae and Diosaccidae (Crustacea, Copepoda) from the Isle of Man. Journal of Natural History 10 (2): 131-155.

https://doi.org/10.1080/00222933.1976.tNAH0131

Morales-Serna F.N., Gómez S. \& Bustos-Hernández I.M. 2006. Spatial and temporal variation of taxonomic composition and species richness of benthic copepods (Cyclopoida and Harpacticoida) along a polluted coastal system from north-western Mexico during two contrasting months. Contributions to the Study of East Pacfic Crustaceans 4 (1): 41-59. 
GÓMEZ S. et al., On new genera and species of Harpacticoida

Mu F. \& Gee J.M. 2000. Two new species of Bulbamphiascus (Copepoda: Harpacticoida: Diosaccidae) and a related new genus, from the Bohai Sea, China. Cahiers de Biologie Marine 41: 103-135.

Nam E. \& Lee W. 2012. First record of the genus Sinamphiascus (Copepoda: Harpacticoida) from Korean waters. Journal of Species Research 1 (1): 44-55. https://doi.org/10.12651/jsr.2012.1.1.044

Nixon K.C. 2002. WinClada ver. 1.00.08.

Available from http://www.softpedia.com/get/Science-CAD/NONA.shtml [accessed 15 Jun. 2021].

Pallares R.E. 1975. Copépodos harpacticoides marinos de Tierra del Fuego (Argentina). 1. Isla de los Estados. Contribuciones Científicas del Centro de Investigacion de Biología Marina (CIBIMA), Buenos Aires 122: 1-34.

Por F.D. 1963. A comparative study in the genus Typhlamphiascus Lang (Copepoda, Harpacticoida). Arkiv för Zoologi, New Series 16 (11): 189-206.

Por F.D. 1967. Level bottom Harpacticoida (Crustacea, Copepoda) from Elat (Red Sea), Part I. Israel Journal of Zoology 16 (3): 101-165.

Por F.D. 1968. Copepods of some land-locked basins on the islands of Entedebir and Nocra (Dahlak Archipelago, Red Sea). Sea Fishery Research Station in Haifa Bulletin 49: 37-41.

Rohal M., Thistle D. \& Easton E.E. 2016. Extraction of metazoan meiofauna from muddy deep-sea samples: operator and taxon effects on efficiency. Journal of Experimental Marine Biology and Ecology 502: 105-110. https://doi.org/10.1016/j.jembe.2017.01.006

Rouch R. 1962. Harpacticoïdes (Crustacés Copépodes) d'Amérique du Sud. In: Delamare D. \& Rapoport E. (eds) Biologie de l'Amérique Australe. Vol. 1, Études sur la Faune du Sol: 237-280. Éditions du Centre national de la Recherche scientifique, Paris.

Sars G.O. 1906a. Copepoda Harpacticoida. Parts XI \& XII. Thalestridae (concluded), Diosaccidae (part). An Account of the Crustacea of Norway with Short Descriptions and Figures of all the Species 5: 133-156.

Sars G.O. 1906b. Copepoda Harpacticoida. Parts XIII \& XIV. Diosaccidae (continued). An Account of the Crustacea of Norway with Short Descriptions and Figures of all the Species 5: 157-172.

Sars G.O. 1911. Copepoda Harpacticoida. Parts XXXI \& XXXII. Supplement (continued). An Account of the Crustacea of Norway with Short Descriptions and Figures of all the Species 5: 369-396.

Scott T. 1894. Report on Entomostraca from the Gulf of Guinea, collected by John Rattray, B.Sc. Transactions of the Linnean Society of London, Series 2, Zoology 6 (1): 1-161.

https://doi.org/10.1111/j.1096-3642.1894.tb00660.x

Scott T. 1902. Notes on gatherings of Crustacea collected by the fishery steamer 'Garland', and the steam trawlers 'Star of Peace' and 'Star of Hope', of Aberdeen, during the year 1901. Annual Report of the Fishery Board for Scotland 20 (3): 447-484.

Scott T. \& Scott A. 1895. On some new and rare British Copepoda. Annals and Magazine of Natural History 16 (6): 353-362. https://doi.org/10.1080/00222939508680286

Soyer J. 1963a. Copépodes harpacticoïdes de Banyuls-sur-Mer. II. Typhlamphiascus lutincola sp. n. Vie et Milieu 14 (2): 233-244.

Soyer J. 1963b. Copépodes harpacticoïdes de l'étage bathyal de la région de Banyuls-sur-Mer. II. Le genre Typhlamphiascus Lang. Vie et Milieu 14: 819-832. 
Soyer J. 1971. Contribution à l'étude des copépodes harpacticoïdes de Méditerranée Occidentale. 5. Stenhelia (Delavalia) coineauae n. sp., Stenhelia (D.) bocqueti n. sp. et Typhlamphiascus bouligandi n. sp. (Diosaccidae, Sars). Vie et Milieu (A) 22 (2): 263-280.

Thompson I.C. 1893. Revised report on the Copepoda of Liverpool Bay. Proceedings and Transactions of the Liverpool Biological Society 7: 175-230.

Thompson I.C. \& Scott A. 1903. Report on the Copepoda collected by Professor Herdman, at Ceylon, in 1902. In: Herdman W.A. (ed.) Report to the Government of Ceylon on the Pearl Oyster Fisheries of the Gulf of Manaar 1: 227-307. The Royal Society, London.

Vilela M.H. 1965. Copépodes da Ria de Faro-Olhão. Notas e Estudos do Instituto de Biologia Maritima, Lisboa 31: 1-38.

Wells J.B.J. 2007. An annotated checklist and keys to the species of Copepoda Harpacticoida (Crustacea). Zootaxa 1568 (1): 1-872. https://doi.org/10.11646/zootaxa.1568.1.1

Willen E. 2000. Phylogeny of the Thalestridimorpha Lang, 1944 (Crustacea, Copepoda). Cuvillier Verlag, Göttingen, Germany.

WoRMS Editorial Board (2020). World Register of Marine Species. Available from http://www.marinespecies.org [accessed 29 May 2020]. https://doi.org/10.14284/170

Manuscript received: 15 January 2021

Manuscript accepted: 15 March 2021

Published on: 13 July 2021

Topic editor: Rudy Jocqué

Desk editors: Natahca Beau and Danny Eibye-Jacobsen

Printed versions of all papers are also deposited in the libraries of the institutes that are members of the EJT consortium: Muséum national d'histoire naturelle, Paris, France; Meise Botanic Garden, Belgium; Royal Museum for Central Africa, Tervuren, Belgium; Royal Belgian Institute of Natural Sciences, Brussels, Belgium; Natural History Museum of Denmark, Copenhagen, Denmark; Naturalis Biodiversity Center, Leiden, the Netherlands; Museo Nacional de Ciencias Naturales-CSIC, Madrid, Spain; Real Jardín Botánico de Madrid CSIC, Spain; Zoological Research Museum Alexander Koenig, Bonn, Germany; National Museum, Prague, Czech Republic.

Supplementary File 1. Twelve most parsimonious cladograms of the possible generic relationships within the Diosaccinae Sars, 1906. 126 steps, CI of 42 and RI of 77. Empty circle = homoplasy; dark circle $=$ apomorphy. https://doi.org/10.5852/ejt.2021.759.1433.4671 